\title{
7 Die rentenversicherungsrechtliche Seite des NS-Besatzungsregimes
}

Die Schwierigkeiten und Probleme bei der regionalen Ausweitung des Angestelltenversicherungsgesetzes potenzierten sich noch durch die Einführung der Angestelltenversicherung bzw. zumindest von Teilen derselben in den im Laufe des Krieges eroberten Gebieten. Die rentenversicherungsrechtliche Expansion folgte dabei keiner stringenten Strategie; vielmehr spiegelten sich die komplexen Strukturen der Besatzungsherrschaft des NS-Regimes auch in der Angestelltenversicherung wider. Die annektierten Gebiete wurden teilweise ins Deutsche Reich eingegliedert, teilweise aber auch nur den Gauleitern der benachbarten Reichsgaue unterstellt, die in der Folge als „Chefs der Zivilverwaltung“ (CdZ) agierten und in dieser Funktion direkte Akteure - und zum Teil sogar Weisungsgeber der RfA - in den rentenversicherungsrechtlichen Angelegenheiten der jeweiligen Gebiete wurden. In den Westgebieten behielt das besetzte Frankreich seine bisherige Rentenversicherung ebenso wie die Niederlande und auch Norwegen und Dänemark; in Belgien wurde nur das kleine Gebiet um Eupen-Malmedy ganz dem deutschen Versicherungsrecht unterworfen, dagegen kamen Elsass-Lothringen und auch Luxemburg insgesamt in den Geltungsbereich der AV des Deutschen Reichs und wurden versicherungsrechtlich in das Altreich integriert. Unter vielfach anderen Vorzeichen, aber ebenfalls keineswegs konsistent, verlief die Einführung von Verordnungen und Maßnahmen der Angestelltenversicherung in den eingegliederten und besetzten Ostgebieten, mit deutlichen Abstufungen der Versicherungsrechte und Leistungsansprüche zwischen Volksdeutschen bzw. Angehörigen deutscher Volkszugehörigkeit und Polen oder Staatenlosen. Die RfA verstrickte sich dabei nicht nur weiter in das NS-Unrecht, sondern verhedderte sich auch in den vielen Ungereimtheiten der vom Regime vorgegebenen rentenversicherungsrechtlichen Exklusion.

Die Sozialversicherung in den ehemals polnischen Gebieten und im belgischen Eupen-Malmedy sowie Moresnet war nicht bloß auf diese Regionen beschränkt gewesen, sondern hatte sich jeweils auf das gesamte Staatsgebiet Polens bzw. Belgiens erstreckt. Infolgedessen musste dort, wie auch schon im Sudetenland, der jeweilige Versichertenbestand geteilt und aus den bestehenden Rechtsverhältnissen ausgegliedert werden. Einer solchen Bestimmung bedurfte es jedoch, wie schon in Österreich, nicht für Luxemburg, Lothringen und das Elsass, da in diesen Gebieten eine besondere Sozialversicherung bestand und deshalb alle zu der Versicherung dieser Gebiete gehörenden Versicherten geschlossen in den Gültigkeitsbereich des Reichsrechts übergingen und damit unter die RVO fielen, ohne Rücksicht darauf, wo sie am Stichtag wohnten oder beschäftigt waren. Wenn man so will, dann betrieb die RfA im Bereich der Angestelltenversicherung nur die komplizierte Rückabwicklung der nach dem Ersten Weltkrieg vom Völkerbundrat und den Siegermächten geforderten nicht minder komplexen versicherungsrechtlichen Abtrennung der damals abgetretenen 
Gebiete. ${ }^{1}$ Allerdings waren die versicherungsrechtlichen Maßnahmen nun zusätzlich NS-ideologisch aufgeladen und von deutlichen rassisch begründeten Diskriminierungsmaßnahmen begleitet. Zur Durchführung der komplizierten Überleitungsmaßnahmen erfolgte seinerseits eine Fülle von Gesetzgebungsmaßnahmen mit vielen vorläufigen Regelungen, die, kaum eingeführt, infolge der sich ändernden Kriegslage bald wieder obsolet werden sollten.

\section{1 „Amtsstelle Straßburg“: Die RfA und die besetzten Westgebiete}

Am 12. September 1940 richtete das Reichsarbeitsministerium einen Schnellbrief an die jeweiligen Reichskommissare, Wirtschaftsbeauftragten sowie die Chefs der Zivilverwaltungen bzw. der Militärverwaltungen in den Niederlanden, Norwegen, Dänemark, Frankreich, Belgien und Luxemburg, der auch an die RfA adressiert war. Darin wurden eine Reihe von Richtlinien aufgestellt, nach denen künftig zu verfahren war, „um eine einheitliche Durchführung der Sozialversicherung in den besetzten Gebieten sicherzustellen“.2 Die in diesen Gebieten beschäftigten Reichsdeutschen unterlagen demnach sämtlich der Reichsversicherung und mussten sich die jeweiligen Beitragsmarken beschaffen und entsprechend einkleben. Die einheimischen Arbeitskräfte jedoch blieben bei ihren ursprünglichen Versicherungsträgern, auch dann, wenn sie etwa in einer deutschen Behörde oder bei deutschen Firmen beschäftigt waren. Diese mussten die jeweiligen Beiträge an den heimischen Versicherungsträger abführen. Die in den besetzten Gebieten beschäftigten ausländischen Arbeitskräfte, z. B. holländische oder polnische Arbeiter in Belgien, unterlagen ebenfalls nicht der Reichsversicherung, sondern mussten nach dem Recht des jeweiligen Gebietes, in dem sie jetzt wohnten und arbeiteten, versichert werden. Entsprechend galt für die in

1 Vgl. dazu die 1930 erstellte Übersicht der Beziehungen der RfA zu ausländischen Versicherungsträgern und darin die detaillierte Darlegung der Auswirkungen des Vertrags von Versailles auf die Angestelltenversicherung, in: RfA-Archiv Nr. 182 o. Das Deutsche Reich trat damit rund 67.000 Versicherte ab und zahlte dafür an die jeweiligen Versicherungsträger im Mai 1922 insgesamt 18,4 Mio. Papiermark für Elsass-Lothringen und im November 1922 noch einmal 12,5 Mio. Papiermark für PosenWestpreußen. Für Oberschlesien war eine Abfindung von 26 Mio. Goldmark festgesetzt worden. Durch den Übergang der Angestelltenversicherung ergab sich, dass die Versicherten in den abgetretenen Gebieten im Allgemeinen keinen Anspruch mehr gegenüber der RfA weder auf Leistungen noch auf freiwillige Weiterversicherung hatten. Mit Rücksicht auf die Verschiedenartigkeit und teilweise Unvollkommenheit der für die Sozialversicherung in den abgetretenen Gebieten getroffenen Entscheidungen und Abkommen und in dem Bestreben, die Rechte der ehemaligen Versicherten zu schützen, hat das damalige Direktorium der RfA jedoch eine Reihe von Beschlüssen und Verwaltungsgrundsätzen aufgestellt, nach denen unter anderem die früheren Konten wieder hergestellt wurden, wenn der ehemalige Versicherte aus dem abgetretenen Gebiet nach Deutschland zurückwanderte.

2 Das Schreiben vom 12.9.1940, in: RfA-Archiv Fach 18, Nr. 3. Vgl. dazu auch die entsprechende Verordnung, in: Mitteilungen der RfA Nr. 10, 1940, S. 37-38. 
Nordfrankreich eingesetzten Arbeitskräfte aus Belgien das französische Sozialversicherungsrecht, auch wenn sie dort auf Veranlassung deutscher Dienststellen beschäftigt waren. Versicherungsrechtlich gab es mithin grundsätzlich zwei Seiten der militärischen Expansion und des Aufbaus des Besatzungsregimes in den eroberten Ländern. Denn neben der Frage nach Art und Umfang der Übernahme der dort lebenden Versicherten und Rentenempfänger galt es zuallererst auch den versicherungsrechtlichen Status der zahlreichen deutschen Angestellten zu klären, die nun in den zivilen wie militärischen Einrichtungen der besetzten Gebiete tätig waren.

Die Art und Weise der Beziehungen zwischen der RfA und den ausländischen Versicherungsträgern war dabei von Land $\mathrm{zu}$ Land verschieden. Zwischen den holländischen und deutschen Trägern der Rentenversicherung, insbesondere der grenznahen Landesversicherungsanstalten und dem Raad van Arbeid (RvA) in Nymwegen, hatte schon seit längerer Zeit eine Verwaltungshilfe bestanden, die im Dezember 1939 auch auf die RfA ausgedehnt wurde. ${ }^{3}$ Ein offizielles Gegenseitigkeitsabkommen bestand jedoch nicht, allerdings gab es im Sommer 1939 nur 192 RfARenten, die in Holland zur Auszahlung kamen. ${ }^{4}$ Im Dezember 1940 übersandte das RAM an den inzwischen in Den Haag amtierenden Reichskommissar für die besetzten niederländischen Gebiete und die involvierten deutschen Versicherungsträger eine vorläufige Regelung der Beziehungen zwischen der deutschen und der niederländischen Rentenversicherung. ${ }^{5}$ Hintergrund war der inzwischen angelaufene großangelegte Einsatz von niederländischen Zwangsarbeitskräften im Deutschen Reich. Ziel der Verordnung war es, die Rechte der niederländischen Arbeitskräfte gegenüber der heimischen Invaliditäts- und Alterssicherung durch die Beschäftigung in Deutschland zu erhalten, auch wenn während der Beschäftigungszeit keine Beiträge an den niederländischen Versicherungsträger bezahlt wurden. Umgekehrt aber ging es auch darum, die deutschen Rückwanderer aus den Niederlanden, die während ihrer Beschäftigung Anwartschaften auf Leistungen der niederländischen Rentenversicherung erworben hatten, davor zu schützen, dass ihre Ansprüche durch die Rückkehr in das Reich und die damit verbundene Einstellung der Beitragszahlungen gemindert wurden. Wie groß die Zahl der Betroffenen auf beiden Seiten war, für die die RfA zuständig war, geht aus den Akten nicht hervor. RfA-Direktor Koch monierte jedoch im Januar 1941 in einem Brief die fehlenden Anrechnungsmöglichkeiten bei Beitragsleistungen und Wartezeit für die deutschen Rückkehrer, was für diese deutliche Nachteile mit sich brachte. ${ }^{6}$ Im Februar bzw. April 1941 wurde der entsprechende Erlass dann durch das RAM in Kraft gesetzt.

3 Vgl. Abteilungsverfügung vom 1.12.1939, in: RfA-Archiv Nr. 24.

4 Vgl. dazu auch den Bericht über eine Besprechung des RVA mit dem Reichsverband Deutscher Rentenversicherungsträger im Mai 1939, an der auch RfA-Direktor Koch teilgenommen hatte, in: RfAArchiv Nr. 60 a.

5 Vgl. das Schreiben vom 23.12.1940, in: RfA-Archiv Fach 116, Nr. 11.

6 Vgl. Schreiben Kochs an das RAM vom 10.1.1941, in: ebd. 
In der Folgezeit war die RfA dann aber vor allem mit Anfragen von deutschen Angestellten befasst, die im Zuge der Besatzungsverwaltung, etwa als Angestellte in der deutschen Handelskammer für die Niederlande in Amsterdam, vom Reich in die Niederlande übersiedelten. Für sie galten generell die Vorschriften der Reichsversicherungsordnung, d.h. sie mussten Beiträge zur AV zahlen. Ausgabestellen für Versicherungskarten sowie auch Verkaufsstellen der Beitragsmarken waren die in den besetzten Gebieten inzwischen errichteten Zweigstellen deutscher Krankenkassen. ${ }^{7}$ Allerdings war der versicherungsrechtliche Status ausgerechnet der 25 deutschen Angestellten der Deutschen Handelskammer auch im Sommer 1942 noch immer nicht geklärt, da fraglich war, ob die Kammer, die ein eingetragener Verein nach niederländischem Recht war, als deutsches Unternehmen bezeichnet werden konnte, wogegen der zuständige Reichskommissar in Den Haag Bedenken erhob. ${ }^{8}$ Das Problem lag wieder einmal in einer unklaren Formulierung in dem RAM-Erlass. Darin war die Anwendung der Reichsversicherungsvorschriften für diejenigen ausgenommen worden, die schon vor der Besetzung in dem jeweiligen Gebiet gewohnt hatten, es sei denn, dass sie bei einem deutschen Unternehmen beschäftigt waren. Eine bei der deutschen Wehrmacht in Den Haag beschäftigte deutsche Zivilangestellte wandte sich daher im Frühjahr 1942 hilfesuchend an die RfA, da die zuständige Wehrmachtstelle die Entrichtung von anteiligen AV-Beiträgen für diese mit der Begründung ablehnte, „dass es absolut noch nicht feststeht, die Wehrmacht in besetzten Gebieten als Unternehmer im Sinne der Verordnung vom 4. 8.1941 zu bezeichnen“. ${ }^{9}$ Kompliziert wurde das Ganze auch noch dadurch, dass nach allgemeinen staatsrechtlichen Grundsätzen die Versicherungspflicht nach dem Territorialitätsprinzip grundsätzlich nur Beschäftigungen im Inland, also innerhalb der Grenzen des Deutschen Reichs betraf. Die Rechtsprechung hatte inzwischen aber die sogenannte Ausstrahlungstheorie ausgebildet. Danach erstreckte sich die Versicherungspflicht auch auf eine nur gelegentliche oder geringfügige Ausdehnung der inländischen Betriebstätigkeit ins Ausland, die sich als Teil, Zubehör oder Fortsetzung des inländischen Betriebs darstellte. Nicht anwendbar war die Ausstrahlungstheorie jedoch auf Filialen im Ausland - auch wenn sie keine Rechtspersönlichkeit nach ausländischem Recht waren -, da sie Dauercharakter hatten. ${ }^{10}$ Damit waren die Angestellten in den ausländischen Tochterunternehmen nicht versicherungspflichtig und für sie bestand nur die Möglichkeit zur freiwilligen Selbstversicherung in der deutschen AV. Allerdings gingen viele Betroffene im Mai 1942 noch davon aus, dass auch in Holland in Bälde eine Reichsversicherung nach deutschem Muster eingeführt werden würde, und warteten daher erst einmal die weitere Entwicklung ab.

7 Vgl. das Antwortschreiben der RfA auf eine entsprechende Anfrage vom 4.10.1941 hin, in: RfA-Archiv Fach 18, Nr. 2.

8 Vgl. das Schreiben des Reichskommissars an das RVA vom 13.10.1942, in: ebd.

9 Vgl. Schreiben der RfA an den Reichskommissar in Den Haag vom 29.5.1942, in: ebd.

10 Vgl. das Schreiben der RfA an eine Remscheider Werkzeugfabrik mit Zweigniederlassung in Amsterdam vom 24.4.1942, in: ebd. 
Der rentenversicherungsrechtliche Status vieler in den besetzten Gebieten beschäftigten und eingesetzten bzw. dorthin auch abgeordneten deutschen Angestellten war mithin lange Zeit unsicher und prekär. Das galt offenbar auch für die Angestellten im deutschen Unterdrückungs- und Besatzungsapparat, denn sowohl die DAF-Außenstelle im holländischen Tilburg als auch der Befehlshaber der Sicherheitspolizei und des SD für die besetzten niederländischen Gebiete wandten sich im März bzw. Mai 1942 mit entsprechenden Anfragen an die RfA. ${ }^{11}$ Und auch der Reichskommissar selbst richtete direkt an die RfA die Bitte, zur Beratung und Unterrichtung der verhältnismäßig großen Zahl angestelltenversicherungspflichtiger Gefolgschaftsmitglieder seiner Behörde für einige Tage einen Beamten nach Den Haag zu schicken - was dann tatsächlich auch Ende Juni 1942 geschah. ${ }^{12}$ Im Januar 1942 war es zudem zu einer versicherungstechnischen Durchführungsverordnung zur bis dahin immer noch vorläufigen Regelung der Beziehungen zwischen der deutschen und der niederländischen Rentenversicherung gekommen, nach der die durch Berücksichtigung deutscher Versicherungszeiten bei der Feststellung der niederländischen Renten eintretende Erhöhung der Sonderzuschläge nicht etwa von den deutschen Versicherungsträgern übernommen werden musste, sondern auf die niederländischen Träger abgewälzt wurde. Die RfA musste der niederländischen Reichsversicherungsbank lediglich einen Teil des Grundbetrags und der Steigerungsbeträge erstatten. ${ }^{13}$ Die Frage des Versicherungsstatus insbesondere von Reichsdeutschen, die schon vor der Besetzung in den Niederlanden gewohnt hatten und nun beim zuständigen Wehrmachtbefehlshaber beschäftigt waren, blieb jedoch auch Anfang 1943 unklar und strittig, ehe in einer eigenen Verordnung vom Februar 1943 der Reichskommissar die Versicherungspflicht bestimmte, was seitens der Wehrmachtstelle erhebliche Beitragsnachzahlungen an die RfA erforderlich machte. ${ }^{14}$

In Dänemark und Norwegen war die versicherungsrechtliche Lage der deutschen „Besatzungsangestellten“ nicht minder kompliziert. In Dänemark standen allerdings die devisenrechtlichen Probleme bei der Auszahlung an die 305 im April 1941 dort lebenden RfA-Rentner und vor allem auch die Berechnung der Umrechnungskurse lange Zeit im Mittelpunkt. ${ }^{15}$ In Norwegen dagegen musste sich die RfA wie schon in Holland vor allem mit der Frage der Versicherungspflicht dort tätiger deutscher Angestellter, unter anderem der Schriftleiter der „Deutschen Zeitung in Norwegen“ sowie

11 Vgl. die Schreiben vom 12.3.1942 sowie vom 23.5.1942, in: RfA-Archiv Fach 18, Nr. 4.

12 Vgl. das Schreiben vom 19.5.1942, in: RfA-Archiv Fach 20, Nr. 3 sowie das Schreiben der RfA an das RAM betr. Genehmigung der Dienstreise vom 8.6.1942, in: ebd.

13 Vgl. Rundschreiben vom 30.1.1942, in: RfA-Archiv Nr. 197 a.

14 Vgl. Schreiben des Reichskommissars an das RVA vom 30.6.1943, in: RfA-Archiv Fach 18, Nr. 5. 15 Vgl. zum Zahlungsprocedere, das über die Kreissparkasse Flensburg abgewickelt wurde, das Schreiben der BfA an die Landeszentralbank Schleswig-Holstein vom 3.4.1950, in: RfA-Archiv Nr. 182. Mit Kriegsausbruch wurde das Verfahren der gegenseitigen Überweisungen jedoch zugunsten eines Verrechnungsverfahrens aufgegeben. Vgl. auch das Schreiben der RfA an das RVA vom 2.4.1941, in: BArch R 89/3414. 
der deutschen Handelskammer in Oslo herumschlagen. ${ }^{16}$ Klar war hingegen der Status der dänischen Arbeitskräfte, die für deutsche Stellen, sei es Behörden, NSDienststellen, insbesondere die Organisation Todt, oder Unternehmen in Norwegen arbeiteten. Sie mussten in vollem Umfang zur deutschen Sozialversicherung angemeldet werden. ${ }^{17}$ Das betraf auch die in Norwegen eingesetzten niederländischen Zwangsbeschäftigten; eine Ausnahme galt explizit nur für einheimische, polnische und russische Arbeitskräfte. Strittig und unklar war allerdings der Geltungszeitpunkt dieser Bestimmung, der offenbar immer wieder geändert wurde. ${ }^{18}$ Für erhebliche Verwirrung bei allen Beteiligten sorgte dann aber die „Verordnung zur Durchführung und Ergänzung der Verordnung über die Sozialversicherung in den besetzten Gebieten vom 10. Februar 1942“. Demnach waren aufgrund einer an sich versicherungspflichtigen Beschäftigung in den besetzten Gebieten für die Zeit der Besetzung des Landes bis einschließlich 31. August 1941 weder Beiträge zur Reichsversicherung noch zum Reichsstock für Arbeitseinsatz abzuführen. Bereits entrichtete Beiträge wurden auf Antrag erstattet, der allerdings spätestens bis 1. Juli 1943 gestellt werden musste. ${ }^{19}$ Warum diese Verordnung erging, geht aus den Akten nicht hervor. Sie traf bei der RfA auf wenig Verständnis, da sie nicht nur erheblichen Verwaltungsaufwand bedeutete, sondern vor allem aus Sicht der Behörde nicht den Interessen der Versicherten entsprach. Diesen würden die Beiträge später bei der Festsetzung der Rentenleistungen und der Erfüllung der Wartezeit fehlen, was den Verlust des Rentenanspruchs insgesamt bedeuten konnte. In der Folgezeit wurde die RfA jedoch von entsprechenden Rückerstattungsanträgen deutscher Angestellter vor allem aus Norwegen geradezu überflutet - seien es Angestellte deutscher Baufirmen und Flugmotorenhersteller, Hilfssachbearbeiterinnen der Reichsrundfunk GmbH oder Zivilangestellte bei Behörden wie der Auslandsbriefprüfstelle sowie verschiedenen Wehrmachtstellen wie dem Luftgaukommando Norwegen. ${ }^{20}$ Auch sämtliche Angestellte des Sicherheitsapparats SS/SD beim Reichskommissar für Norwegen beantragten die Rückerstattung, was pro Person wenigstens 100 und in einigen Fällen bis zu 400 RM ausmachte. Nur wenige zogen nach entsprechender Aufklärung durch die RfA ihre Anträge wieder zurück. Der Großteil, vor allem weibliche Angestellte, beharrte auf der Rückerstattung. Doch wie so oft gab es auch bei dieser Verordnung einen Haken. Nicht nur, dass aufgrund der knappen Antragsfrist viele Betroffene ihre Ansprüche zu spät anmeldeten, die Verordnung galt zudem - was man bei der RfA selbst erst im Oktober 1943 realisierte nicht für Gefolgschaftsmitglieder, die aus dem Reichsgebiet in die besetzten Gebiete

16 Vgl. dazu den Schriftwechsel vom Juli 1941 und vom Januar bis März 1942, in: RfA-Archiv Fach 18, Nr. 4.

17 Vgl. Schreiben des RAM vom 16.3.1942, in: RfA-Archiv Fach 18, Nr. 3.

18 Vgl. Schreiben des Leiters der AOK Berlin an die RfA vom 16.6.1943, in: RfA-Archiv Fach 18, Nr. 5. 19 Vgl. dazu das entsprechende Rundschreiben des Reichskommissars für die besetzten norwegischen Gebiete vom 7.4.1943, in: RfA-Archiv Fach 9, Nr. 6.

20 Vgl. dazu die diversen Rückerstattungsanträge vom Juli 1943, in: RfA-Archiv Fach 18, Nr. 3 sowie Nr. 43 b und vor allem auch RfA-Archiv Fach 9, Nr. 1-8. 
abgeordnet worden waren. Insofern kam letztlich kaum eine Handvoll von „Auslandsangestellten“ in den Genuss der Regelung. ${ }^{21}$

Eine besondere Situation ergab sich in den ins Reich wieder eingegliederten Gebieten Belgiens. Die Landesteile um Eupen, Melmedy und Moresnet wurden durch Erlass Hitlers vom 18. Mai 1940 wieder Bestandteile des Deutschen Reichs und verwaltungsmäßig der Rheinprovinz zugeteilt. Ab 1. September 1940 galt dort das Reichsrecht und durch Verordnung vom 11. November 1940 wurde dann das Angestelltenversicherungsrecht mit Wirkung zum 1. Januar 1941 in Kraft gesetzt. ${ }^{22}$ Obwohl vom finanziellen Umfang wie von der Zahl der Versicherten (850) und Rentner (114) her unbedeutend, zog sich die Ausgliederung der Versichertenkonten und die endgültige auch vermögensrechtliche Trennung von dem belgischen Versicherungsträger bis Mai 1941 hin. Der verwaltungsorganisatorische Aufwand für die RfA war erheblich. Im Reichsarbeitsministerium gab es zahlreiche Besprechungen, um das Vorgehen im Einzelnen zwischen RfA und der zuständigen LVA Rheinprovinz abzustimmen und vor allem auch das „äußerst verwickelte belgische Recht“ möglichst rasch abzuschaffen. ${ }^{23}$ Anfang September 1940 machte ein RfA-Beamter eigens eine Dienstreise nach Malmedy, um vor Ort die dortige Sozialversicherungsanstalt und ihre Unterlagen in Augenschein zu nehmen und einen Überblick über die laufenden Renten zu erhalten. ${ }^{24}$ Ende September meldete RfA-Präsident Grießmeyer dann an das RAM, dass ,in Eupen-Malmedy verschiedene Versicherungszweige und Versicherungsträger [bestehen], die der deutschen Angestellten- und Invalidenversicherung und deren Trägern entsprechen und von diesen ohne größere Schwierigkeiten übernommen werden können“. ${ }^{25}$ Doch dann verzögerten unter anderem Unstimmigkeiten und auch Kompetenzkonflikte zwischen der RfA und der offiziell mit der Durchführung der Sozialversicherung in Eupen-Malmedy beauftragten und federführenden LVA Rheinprovinz die Umsetzung. ${ }^{26}$ Im September 1941 sorgte ein Schreiben der DAF an das Reichsarbeitsministerium für Unruhe, in dem über erhebliche Schwierigkeiten und soziale Härten bei der Übernahme der Sozial- und Unfallrentner im ehemaligen belgischen Gebiet geklagt wurde. ${ }^{27}$ Allerdings bezog sich der Bericht vor allem auf die niedrigen Unfall- und Invalidenrenten; insofern sah man sich in der Ruhrstraße davon nicht betroffen. Tatsächlich waren von der RfA erhebliche Rentensteigerungen für die Betroffenen in dem Gebiet mit überwiegend ländlichem und kleinstädtischem Charakter gewährt wurden, die mit 61,70 RM fast das Dreifache der bisher umgerechnet ge-

21 Vgl. Schreiben der RfA vom 5.10.1943, in: RfA-Archiv Fach 9, Nr. 6.

22 Vgl. Grießmeyer, Großdeutschland, S. II 260.

23 Vgl. dazu den Bericht über die Besprechung im RAM vom 23.7.1940, in: RfA-Archiv Nr. 129.

24 Vgl. Bericht über die Dienstreise nach Malmedy vom 5.9.1940, in: ebd.

25 Schreiben vom 28.9.1940, in: RfA-Archiv Nr. 129.

26 Vgl. unter anderem Bericht über die Besprechung bei Ministerialrat Heller vom RAM am 2.11.1940, in: ebd.

27 Vgl. das Schreiben vom 25.9.1941, in: RfA-Archiv Nr. 129 a, auch als Abschrift in: BArch R 89/3211. 
zahlten belgischen Renten betrugen. ${ }^{28}$ Dennoch machte die RfA hier erstmals bei der Übernahme von Versicherten einen „Gewinn“: Nach einem später nachträglich erstellten Rechnungsabschluss für die Zeit zwischen dem 10. Mai 1940 und dem 31. Juli 1944 verbuchte die Behörde ein Vermögen aus Beitragseinnahmen und aufgelösten Konten sowie Vermögenswerten der Pensionskasse für Privatangestellte von 1,8 Mio. RM, denen ausgezahlte Renten in Höhe von insgesamt 360.000 RM gegenüberstanden. ${ }^{29}$

Von erheblich größerer Bedeutung war die Einführung der deutschen Angestelltenversicherung in Luxemburg. Das frühere Großherzogtum wurde formal nicht dem Reichsgebiet eingegliedert, doch versicherungsrechtlich konnte es ab 1. Oktober 1940 praktisch als Inland gelten. Bereits im Januar 1940 hatten zwischen der großherzoglichen Regierung, dem luxemburgischen Präsidenten des Sozialversicherungsamtes, dem Präsidenten der Pensionskasse für Privatangestellte und den Reichsbehörden Verhandlungen über den Abschluss eines Gegenseitigkeitsvertrages über die Sozialversicherung stattgefunden, die zwar zu einem Vertragsentwurf führten, aber dann aufgrund der im Mai 1940 erfolgten Besatzung durch die deutschen Truppen nicht mehr weitergeführt wurden. ${ }^{30}$ Die Regierungsgewalt lag nach der Besetzung in den Händen eines Chefs der Zivilverwaltung (CdZ), des Gauleiters Gustav Simon, der dann festlegte, dass in Luxemburg ab Oktober die RVO und auch das AV-Gesetz gelten sollten. ${ }^{31}$ Mit einem gleichzeitig vom Reichsarbeitsministerium verfügten Erlass wurde die RfA zur Mitwirkung an der Durchführung der Sozialversicherung in Luxemburg bestellt und der Behörde die alleinige Zuständigkeit für die praktische verwaltungsmäßige Realisierung der Angestelltenrentenversicherung übertragen. Seit 1. Juni 1931 hatte in dem Land eine eigene Angestelltenversicherung bestanden, so dass sich die RfA bei der Erfüllung ihrer Aufgabe des bisherigen luxemburgischen Versicherungsträgers, der Pensionskasse für Privatangestellte, bedienen konnte. Noch im Oktober 1940 reisten zwei hochrangige RfA-Beamte nach Luxemburg, um die Durchführung der Rentenversicherung in Gang zu bringen. Von Seiten des CdZ und Gauleiters gab es dafür eindeutige Anweisungen: Erstens sollte möglichst schnell mit den luxemburgischen Versicherungsträgern Fühlung aufgenommen werden. Zweitens „soll aus politischen Gründen vorläufig möglichst wenig geändert und ,tres doucement‘ vorgegangen werden“, drittens sollten die Gehälter der Beamten und Angestellten möglichst schnell den entsprechenden reichsdeutschen Gehaltsgruppen angeglichen und

28 Vgl. dazu der interne Vermerk vom 14.11.1941, in: ebd.

29 Vgl. den Rechnungsabschluss vom Oktober 1946 sowie die Niederschrift einer Besprechung mit einem britischen Beamten der Reparationsabteilung der Britischen Besatzungsbehörde vom 27.9.1946, in: RfA-Archiv Fach 99, Nr. 44.

30 Vgl. Schreiben des RAM an die RfA vom 19.1.1940, in: RfA-Archiv Nr. 138.

31 Vgl. dazu auch Grießmeyer, Großdeutschland, S. II 259. 
schließlich viertens alle Maßnahmen nur im Einvernehmen mit dem CdZ getroffen werden. ${ }^{32}$

Eine der ersten Maßnahmen war es denn, die Pensionskasse für Privatangestellte formell durch die RfA zu übernehmen; die Geschäftsstelle firmierte nun als eigene „Amtsstelle der Reichsversicherungsanstalt für Angestellte“ in Luxemburg, d.h. sämtliche zehn Angestellte standen dort nun formell im Dienste der RfA. Der bisherige Präsident Dr. Nikolaus Kuffer blieb zwar formell im Amt, jedoch konnte er in Zukunft Anordnungen und Verfügungen nur gemeinsam mit dem RfA-Beauftragten treffen. ${ }^{33}$ Die Verwaltungsorganisation wie die Aktenführung der Luxemburger Behörde waren, wie man sich schnell vergewissert hatte, in gutem Zustand, der Kreis der Versicherten betrug ca. 7000, eine Jahresarbeitsverdienstgrenze gab es nicht und zehn Prozent des Arbeitsverdienstes wurden je hälftig vom Versicherten und vom Arbeitgeber als Beiträge abgeführt. Für ungefähr 2200 Versicherte des Industriekonzerns Arbed, aus dessen Werkskassen die Luxemburgische Angestelltenversicherung entstanden war, wurden 16 Prozent Beiträge gezahlt mit entsprechend höherem Leistungsanspruch. ${ }^{34}$ Die RfA-Beamten sorgten in der Folgezeit dafür, dass umgehend das Markensystem des Angestelltenversicherungsgesetzes eingeführt wurde, und an die ca. 1100 Arbeitgeber wurden die neuen grünen Versicherungskarten ausgegeben. Die Gesamtzahl der laufenden und damit von der RfA zu übernehmenden Renten betrug ungefähr 700, und ihre Durchschnittshöhe entsprach in etwa der des Deutschen Reichs, wobei allerdings die gesunkene Kaufkraft der RM bei einem Kurs von 1:10 nicht berücksichtigt war. Zudem galt es zu überprüfen, „ob und inwieweit eine Einschränkung der Anwendung des Reichsrechts angebracht ist, soweit es ungünstiger als das bisherige Recht ist, z. B. bei der Bezugsdauer der Kinderzuschüssen und Waisenrenten““. ${ }^{35}$ Die Luxemburger Pensionskasse gewährte ähnlich wie die RfA den Versicherten auch Heilverfahren als freiwillige Leistungen zur Wiederherstellung der Berufsfähigkeit. All dies war auch deshalb für die RfA weiterhin aufrechtzuerhalten, da die Vermögensverhältnisse der Luxemburger, wie die Beamten aus Berlin erleichtert feststellten, günstig waren. Die Anwartschaftsdeckung der Pensionskasse betrug infolge großer Reserven ein Vielfaches der Anwartschaftsdeckung der Renten nach dem AVG, und deshalb solle man, wie der Präsident der Pensionskasse forderte, die Luxemburger Versicherten eigentlich auch besser stellen, als das Reichsrecht es vorsehe. ${ }^{36} 1939$ wies die Bilanz der Kasse Einnahmen von 17,4 Mio. Fr. aus Beiträgen, 2,3 Mio. Fr. an Staatszuschüssen, 6,6 Mio. Fr. Zinsen und ein Vermögen von 158,3 Mio. Fr. auf; alles in allem mithin umgerechnet knapp 18,5 Mio. RM, denen jährliche Leistungszahlungen

32 Bericht des ORR Hartmann über seine Dienstreise mit Regierungsamtmann Perlin zur Durchführung der AV in Luxemburg (vom 8.10. bis 17.10.1940), in: RfA-Archiv Nr. 138.

33 Vgl. dazu auch die Präsidialverfügung Grießmeyers vom 22.1.1941, in: RfA-Archiv Nr. 138 a.

34 Vgl. ebd., S. 3.

35 Ebd., S. 4.

36 Vgl. ebd., S. 5. 
von ca. 550.000 RM gegenüberstanden. ${ }^{37}$ Anders als in Österreich und dem Sudetenland blieb aber eine Vermögensauseinandersetzung aus; eine Übernahme der Rücklagen und verfügbaren Gelder nach Berlin kam entgegen den ursprünglichen Erwartungen der RfA nicht zustande, nicht zuletzt auch aufgrund der Weigerung des CdZ, „da alle Bestände im Lande bleiben sollen“ “. ${ }^{38}$ Innerhalb nur weniger Tage hatten die RfA-Beamten mithin die verwaltungsorganisatorische wie praktische Überführung der Luxemburger Angestelltenversicherung unter deutsches Recht und deutsche Hoheit erfolgreich bewältigt. Nach zehn Tagen intensiver Recherchen und Besprechungen reiste der eine RfA-Beamte nach Berlin zurück, während der andere als offizieller Beauftragter der Reichsversicherungsanstalt vor Ort blieb. Allerdings war nur eine Übergangszeit von zwei bis drei Wochen vorgesehen, bis die Pensionskasse, so die Planungen, alleine weiterarbeiten konnte und nur noch gelegentliche Kontrollbesuche aus Berlin erfolgen sollten.

Zurück in Berlin erstattete der RfA-Beamte umgehend im RAM Bericht und musste sich sofort Kritik wegen der - auch vom CdZ aus politischen Gründen gewünschten - verfügten Weiterzahlung der Kinderzuschüsse und Waisenrenten anhören, da dies den reichsrechtlichen Bestimmungen nicht entspreche. Dabei ging es jedoch nur um 23 Renten. ${ }^{39}$ Auch in der Folgezeit blieb die Luxemburger Rentenversicherung politisch prekär, und die RfA versuchte sich zwischen den beiden unterschiedlichen Entscheidungsträgern $\mathrm{CdZ}$ in Luxemburg und RAM in Berlin durchzulavieren, denen sie jeweils untergeordnet war. Bei der Neufestsetzung der Renten etwa favorisierte man bei der RfA statt der Gewährung einer vorläufigen Leistung in Höhe der nach luxemburgischen Recht zustehenden Renten die Zahlung eines Vorschusses, da eine eventuelle spätere Herabsetzung „misslich“ wäre und unter allen Umständen vermieden werden sollte. ${ }^{40}$ Alle zweifelhaften Fragen mussten umgehend in die Ruhrstraße gemeldet werden, wo dort dann nach eingehenden Erwägungen die entsprechenden Entscheidungen gefällt wurden. Mit erheblichem Aufwand und entsprechenden Rücksichtnahmen wurde denn auch von den RfA-Beamten in Berlin und Luxemburg gemeinsam an einem Entwurf einer Durchführungsverordnung über die Angestelltenversicherung in Luxemburg gearbeitet. ${ }^{41}$ Faktisch wurde darin eine Erhöhung der Renten um 20 Prozent in Aussicht genommen, da mit der allgemeinen Anpassung des Preisniveaus an die Sätze im Deutschen Reich andernfalls ein großer Teil der übernommenen Rentner der öffentlichen Fürsorge zur Last gefallen wäre. ${ }^{42}$ Die damit verbundenen Mehrausgaben von knapp 550.000 RM im Jahr waren aus den Vermögensrücklagen ohne Probleme

37 Vgl. ebd., S. 6.

38 Ebd., S. 6 RS.

39 Vgl. Bericht von ORR Hartmann an RA Perlin vom 19.10.1940, in: RfA-Archiv Nr. 138.

40 Vermerk Hartmanns vom 21.10.1940, in: ebd.

41 Vgl. dazu das Schreiben der RfA Luxemburg an die RfA Berlin vom 4.12.1940 und die allein 28 Seiten umfassende detaillierte Begründung der Verordnung, in: ebd.

42 Vgl. ebd. 
zu bestreiten. Voraussetzung war allerdings, dass dieses Vermögen tatsächlich nur den Angestelltenversicherten zugutekäme und nicht, wie von der RfA befürchtet, für anderweitige Zwecke, insbesondere die Finanzierung der Invalidenversicherung in Luxemburg, missbraucht würde. Eine möglichst großzügige Neuberechnung der Renten erschien auch deshalb notwendig, da es eine Reihe von Leistungen gab, die nach Einführung des Reichsrechts wegfielen, wie die Witwenrente für die schuldlos geschiedene Ehefrau, Kinderzuschuss und Waisenrente über das 18. Lebensjahr hinaus, Abfindung an Witwe und Kinder, wenn beim Tod des Versicherten die Wartezeit nicht erfüllt war, Rückerstattung der halben Beiträge für weibliche Versicherte ohne Bedingungen und ein Begräbnisgeld. Die RfA-Beamten lehnten auch einen vor allem vom RAM immer wieder vorgebrachte Vergleich der Rentenniveaus mit dem Altreich ab. Die luxemburgische Angestelltenversicherung war von Anfang an auf das Anwartschaftsdeckungsverfahren ausgerichtet gewesen, was auch den hohen Deckungsgrad je Versicherten Ende 1938 mit umgerechnet rund 1505 RM erklärte, während dieser im Deutschen Reich zur gleichen Zeit gerade einmal 189 RM betrug. ${ }^{43}$ Es sei daher nur billig, so die RfA-Beamten, den luxemburgischen Rentnern auch 1940 noch nachträglich diverse Sonderzuschüsse zu gewähren. Und das Reichsarbeitsministerium segnete diese Vorschläge der RfA zunächst tatsächlich ab. ${ }^{44}$

Es sollte dennoch bis Ende Mai 1941 dauern, bis die entsprechende Durchführungsverordnung vom CdZ erlassen wurde. Der Grund waren inzwischen doch noch vorgebrachte Bedenken des RAM gegen die faktisch vorgesehene Erhöhung der Angestelltenrenten, während nach den Plänen der LVA die Invalidenrenten nicht nur nicht erhöht, sondern nach der Neuberechnung praktisch niedriger ausfallen würden als bisher. ${ }^{45}$ Eine solche Diskrepanz zwischen Angestellten- und Arbeiterrenten erschien politisch höchst riskant. Nur wenig später erfolgte über eine dritte Durchführungsverordnung Anfang August 1941 die Einführung des Leistungsverbesserungsgesetzes auch in Luxemburg, womit erneut Rentenerhöhungen verbunden waren. Doch es gab unerwartete Probleme. Da das Reich die Kosten der Rentenerhöhungen aus dem Leistungsverbesserungsgesetz übernahm, wurde der RfA-Beauftrage in Luxemburg im Oktober 1941 dementsprechend beim CdZ vorstellig, um jedoch lapidar mitgeteilt zu bekommen, dass hierfür keine Mittel zur Verfügung stünden. ${ }^{46}$ Wie das Finanzierungsproblem behoben wurde, geht aus den Akten nicht hervor. Vermutlich musste doch die RfA selbst einspringen, obwohl die Amtsstelle Luxemburg tatsächlich nicht über den großen RfA-Haushalt lief, sondern gesondert bilanzierte. Der Voranschlag für das Kalenderjahr 1942 wies etwa 1,5 Mio. RM an Beitragseinnahmen auf,

43 Vgl. S. 24 der Verordnungsbegründung, in: ebd.

44 Vgl. Vermerk vom 8.1.1941, in: ebd.

45 Vgl. Vermerk vom Juli 1941 über eine Besprechung im RAM vom 21.3.1941, in: RfA-Archiv Nr. 138 a. Vgl. auch den Bericht über die Berechnung der Renten der Angestelltenversicherung nach der zweiten Verordnung über die Durchführung der Sozialversicherung in Luxemburg vom 26.5.1941, in: ebd.

46 Vgl. Schreiben der RfA Luxemburg an die RfA Berlin vom 17.10.1941, in: ebd. 
denen einmalige und regelmäßige Leistungsausgaben von knapp 700.000 RM gegenüberstanden. ${ }^{47}$ Dennoch gab es zunehmende finanzielle Verflechtungen zwischen der Luxemburger Stelle und Berlin. Im Januar 1943 etwa wurde zwischen CdZ und RAM einvernehmlich verfügt, dass die inzwischen auch in Luxemburg von den Krankenkassen eingezogenen Beiträge zur AV an die RfA nach Berlin abgeführt, von dort jedoch wieder zurück an die Amtsstelle Luxemburg überwiesen würden, die dann die Auszahlungen vornähme. Und für die überschüssigen Mittel würden durch Vermittlung der Reichsbank in Luxemburg Reichsschatzanweisungen gekauft werden. ${ }^{48}$

Aus dem vorübergehend geplanten Aufenthalt des RfA-Beauftragten in Luxemburg wurde letztlich ein bis Sommer 1944 dauernder Einsatz. Völlig überraschend für die Beamten sowohl in Berlin wie in Luxemburg wurde diesem auf einer Besprechung beim CdZ eröffnet, dass rückwirkend zum 31. März 1944 die Unfallversicherung und die Rentenversicherung der Arbeiter wie der Angestellten vereinheitlicht und in einem neuen Versicherungsträger mit dem Namen Sozialversicherungsanstalt Moselland zusammengeführt würden. Die Initiative dazu kam bemerkenswerterweise nicht vom CdZ in Luxemburg, sondern war „von obersten Reichsstellen und der Parteikanzlei gewünscht worden, weil die Sozialversicherung sich künftig vielleicht in dieser Richtung weiterentwicklen könnte“, wie es in einem Vermerk des RfA-Beamten heißt. ${ }^{49}$ Zum 31. Juli 1944 wurde damit die Amtsstelle Luxemburg der RfA aufgelöst, wenig später musste die neue Sozialversicherungsanstalt jedoch aufgrund der Kriegsereignisse ihren Sitz verlegen und in Koblenz eine Auffangstelle errichten, die sich vor allem um die gleichzeitig rund 12.500 ebenfalls aus Luxemburg geflüchteten Volksdeutschen bzw. Reichsdeutschen kümmerte. ${ }^{50}$ Seit September 1944 flossen auch keine Rentenzahlungen mehr nach Luxemburg.

Komplex waren schließlich auch die verwaltungsorganisatorischen Entwicklungen der Angestelltenversicherung in Frankreich. Schon die regionale bzw. territoriale Zersplitterung machte die Lage kompliziert. Neben den beiden abgetrennten und in das Deutsche Reich reintegrierten Regionen Elsass und Lothringen gab es die von der Deutschen Wehrmacht besetzte und verwaltete Zone vor allem in Nordfrankreich sowie die vom - vom Deutschen Reich abhängigen - Vichy-Regime geführten übrigen Regionen Frankreichs. Prinzipiell galt in beiden letzteren Gebieten für alle deutschen Staatsbürger, die dorthin vorübergehend als Angestellte in einem Beschäftigungsverhältnis bei Unternehmen oder Wehrmachtstellen abgeordnet waren, der Erlass des RAM vom 12. September 1940, ergänzt später durch eine Verordnung über die Sozialversicherung in den besetzten Gebieten vom 4. August 1941. Sie unterlagen also den Bestimmungen der Reichsversicherung, waren mithin angestelltenversicherungspflichtig und mussten Beiträge an die RfA abführen. Das Beitragsverfahren hatte bis

47 Vgl. den Voranschlag, in: ebd.

48 Vgl. Schreiben der RfA Berlin an das RAM vom 6.1.1943, in: BArch R 89/9265.

49 Bericht des Regierungsdirektors Hartmann über seine Dienstreise nach Luxemburg vom 20.6.1944, in: RfA-Archiv Nr. 138 a.

50 Vgl. Schreiben vom 24.10.1944, in: ebd. 
dahin vor allem in Frankreich erhebliche Schwierigkeiten bereitet, da es keine Verkaufsstellen für Marken gab und diese nur über die in den besetzten Gebieten errichteten Zweigstellen Deutscher Krankenkassen bezogen werden konnten. ${ }^{51}$

Nach Einführung des Lohnabzugsverfahrens funktionierte das Beitragsverfahren für die Betroffenen in den besetzten Gebieten nur leidlich, da, wie etwa die Deutsche Krankenkasse in Paris im Oktober 1942 an die RfA schrieb, diese lediglich eine Verbindungsstelle der deutschen Krankenversicherung für die besetzten französischen Gebiete sei und deshalb auch keine Beiträge zur Angestelltenversicherung einziehe. ${ }^{52}$ Vor allem aus Paris erreichten daher schon seit Frühjahr 1941 die RfA dutzende Schreiben besorgter oder verunsicherter deutscher Angestellter, die vor allem bei französischen Niederlassungen deutscher Baufirmen, Verlagen oder wie in einem anderen Fall, dem Filmkonzern UfA, beschäftigt waren. Die französischen Tochterfirmen waren nicht zur Beitragsleistung an die RfA verpflichtet bzw. verweigerte sie, obwohl die Verordnung gegenüber dem ausländischen Recht vorrangig war und auch ausländische Unternehmen, die Reichsdeutsche beschäftigten, der AV-Pflicht unterlagen. ${ }^{53}$ Mit einigen Firmen, unter anderem der französischen Zweigniederlassung des Logistikkonzerns Schenker, der in Paris als Société Anonyme Francaise firmierte, war es darüber $\mathrm{zu}$ einem regelrechten Disput mit entsprechendem Schriftwechsel gekommen. ${ }^{54}$ Schenker legte im Mai 1941 die Frage schließlich dem Militärbefehlshaber in Frankreich zur Entscheidung vor, die jedoch auf sich warten ließ, so dass sich die französische Tochterfirma auch im November 1941 nach wie vor beharrlich weigerte, für seine deutschen Angestellten in Paris Versicherungsbeiträge zu leisten. Eine Möglichkeit der RfA, die rückständigen Beiträge zwangsweise einzutreiben, bestand jedoch nicht. Im Laufe des Jahres 1942 relativierte die RfA ihre Haltung zur Versicherungspflicht jedoch dahingehend, dass man zugab, dass die Frage, ob ein französischer Unternehmer verpflichtet wäre, für einen deutschen Staatsangehörigen Beiträge zur Reichsversicherung zu leisten, dem Reichsarbeitsminister zwar schon länger zur Entscheidung vorliege, aber bislang noch keine getroffen worden sei. ${ }^{55}$ Erst im März 1943, nach mehr als zwei Jahren Hin und Her wurde seitens des RAM dahingehend entschieden, dass angestellte Reichsdeutsche bei einem ausländischen Unternehmen von der AV-Pflicht befreit und daher auch die jeweiligen Firmen nicht zur Beitragsleistung verpflichtet seien. ${ }^{56}$ Noch im September 1943 erhielt die RfA jedoch von der Pariser Außenstelle der Deutschen Umsiedlungs-Treuhand-Gesellschaft - einer Dienststelle des Reichsführers SS und Reichskommissars für die Fes-

51 Vgl. dazu auch das Schreiben Grießmeyers an das RAM vom 1.5.1942, in. BArch R 89/3172.

52 Vgl. dazu den Bericht der RfA an das RAM vom 3.11.1942, in: RfA-Archiv Fach 18, Nr. 3.

53 Vgl. dazu die Anfrage an die RfA vom 28.9.1941 sowie weitere Schreiben an die RfA, in: RfA-Archiv Fach 18, Nr. 2.

54 Vgl. etwa das Schreiben von Schenker Paris an die RfA vom 29.4.1941, in: ebd.

55 Schreiben der RfA an eine Versicherte vom 12.2.1943, in: ebd.

56 Vgl. Schreiben der RfA vom 6.2.1943 unter anderem auch auf eine Anfrage der Verbindungsstelle Frankreich der Organisation der Deutschen Wirtschaft hin, in: ebd. 
tigung des deutschen Volkstums - eine Anfrage, inwieweit die in Frankreich beschäftigten Gefolgschaftsmitglieder weiterhin der RfA und der Angestelltenversicherungspflicht unterlägen. ${ }^{57}$ Bislang waren keinerlei Versicherungsbeiträge einbehalten bzw. abgeführt worden, und allgemein bestand bei den Betroffenen die Annahme, dass während der Dauer der Auslandstätigkeit die Beitragszahlung ruhe, jedoch Anwartschaften bzw. Wartezeiten aufrechterhalten blieben - was, da es sich bei der Treuhand-Gesellschaft um ein deutsches Unternehmen handelte, jedoch falsch war. ${ }^{58}$

Für Frankreich galt im Übrigen auch hinsichtlich der Überweisung von Renten aus Deutschland insofern eine Ausnahme, als es nicht als feindliches Ausland zählte und Rentenzahlungen nach erfolgter Devisengenehmigung durch die RfA auch im Krieg vorgenommen wurden. ${ }^{59}$ Zunächst galt diese Regelung seit November 1940 nur für den besetzten Teil Frankreichs, mit Erlass des RAM vom 19. April 1941 wurden die Rentenzahlungen jedoch auch in die unbesetzten Gebiete erlaubt. ${ }^{60}$ Es gab jedoch eine Einschränkung: Rentenzahlungen an Berechtigte früherer polnischer Staatsangehörigkeit und auch in Frankreich lebende Juden waren davon ausgeschlossen. Das hatte zu der bereits erwähnten merkwürdigen Aktion der RfA geführt, zur Feststellung der „Rasse“ bzw. Nationalität Fragebogen an die Betroffenen zu schicken. Da auch im Fall der in Frankreich lebenden „,nationalpolnischen“ Ruhegeldempfänger eine Überprüfung der Identität praktisch undurchführbar war, gestattete das RVA letztendlich dann aber auch die Rentenzahlung an diese Betroffenen. ${ }^{61}$ Weder das RVA noch die RfA wussten, wieviele polnische oder jüdische Ruhegeldempfänger in Frankreich wirklich davon betroffen waren; mehr als einige wenige Einzelfälle dürften es nicht gewesen sein, aber bei dem letztlich doch erheblichen Verwaltungsaufwand, den sich RfA, RVA und RAM in dieser Detailfrage machten, ging es auch gar nicht um konkrete Fälle, sondern um prinzipielle rassisch-ideologische Symbolpolitik im Sinne des NS-Regimes. ${ }^{62}$

57 Vgl. das Schreiben vom 17.9.1943, in: RfA-Archiv Fach 18, Nr. 5.

58 Vgl. den Bescheid der RfA vom 6.12.1943, in: ebd.

59 Vgl. dazu die umfangreichen Richtlinien für die Bearbeitung von Devisensachen vom 15. 8.1942, in: RfA-Archiv Nr. 210.

60 Vgl. den Erlass vom 19.4.1941, in: Mitteilungen der RfA vom Juni 1941, S. 26 sowie auch in: BArch R 89/3414. Die Rentenzahlungen an die verbündeten Staaten wie Kroatien, Ungarn und Italien waren schon früher wieder aufgenommen worden, auch jene in neutrale Länder wie Schweden und die Schweiz, seit Februar 1943 galten jedoch für die Auszahlungen in die Schweiz erhebliche Restriktionen. Vgl. dazu das Rundschreiben des RVA vom 5.2.1943 und vom 27.2.1943, in: BArch R 89/3414. Zu Schweden vgl. RfA-Archiv Nr. 127 a.

61 Vgl. Schreiben des RVA an die RfA vom 22.2.1941, in: ebd.

62 Ein einziger Fall ist in den RfA-Akten überliefert, in dem der Sachbearbeiter der Devisenstelle Berlin die RfA zur Feststellung der Arier- oder Judeneigenschaft aufforderte, und bis zur Vorlage des entsprechenden Nachweises die Zahlungsgenehmigung verweigerte bzw. den entsprechenden Antrag liegen ließ. Vgl. Vermerk vom 20.6.1941, in: RfA-Archiv Nr. 132 a. Im Übrigen musste sich die RfA in der Frage der letztlich monatelang ausgesetzten Rentenzahlungen in den unbesetzten Teilen Frankreichs mit einem dubiosen Schweizer Anwalt aus Lausanne auseinandersetzen, der sich für eine Reihe Versicherter bzw. Rentenempfänger in den unbesetzten Teilen Frankreichs einsetzte und eine möglichst 
Mitte Oktober 1941 war es dann zu einer deutsch-französischen Vereinbarung über die Sozialversicherung gekommen, die aber erst am 22. Februar 1943 in eine faktische Bestimmung zur weiteren Handhabung der gegenseitigen Zahlung von Sozialversicherungsrenten mündete. Demnach wurden nun auch die infolge des Krieges eingestellten französischen Rentenzahlungen an Berechtigte im Deutschen Reich rückwirkend wieder aufgenommen. Gleichzeitig wurde bestimmt, dass unbeschadet einer späteren endgültigen Regelung die deutschen Versicherungsträger verpflichteten seien, bei der Feststellung und Zahlung von Renten an französische Staatsangehörige die besonderen Vorschriften, die das deutsche Sozialversicherungsrecht für Ausländer vorsah, mit Wirkung vom 1. November 1941 nicht mehr anzuwenden. ${ }^{63} \mathrm{Im}$ Juli 1943 kam es dann noch zu einer Durchführungsvorschrift über die deutsche Sozialversicherung in Nordfrankreich, die die rechtliche Situation mehr verkomplizierte als klärte, denn darin war nun zum einen wieder von der Versicherungspflicht nach französischem Recht für deutsche Staatsangehörige in französischen Betrieben die Rede, zum anderen aber von der Versicherungspflicht nach deutschem Recht für diejenigen Reichsdeutschen, die in französischen Betrieben beschäftigt, jedoch von den Stellen im Reich nach Nordfrankreich abgeordnet worden waren. ${ }^{64}$ Die Verordnung enthielt auch diverse Regelungen zur Art und Weise der Versicherungspflicht der verschiedenen ausländischen Zwangsarbeiter etwa aus Holland, die in Frankreich eingesetzt wurden. Einen nennenswerten Schriftwechsel oder dokumentierte Verwaltungsaktivitäten generierte diese Verordnung bei der RfA jedoch nicht.

Der Hauptaufwand der RfA zur Rentenversicherung in Frankreich betraf jedoch die Integration der elsass-lothringischen Gebiete in die Angestelltenversicherung. Mit knapp 60.000 Versicherten und fast 7000 Empfängern laufender Renten stellten diese ehemaligen französischen Regionen nach Österreich und dem Sudetenland den drittgrößten Anteil unter den im Zuge des Krieges zum Altreich hinzukommenden Bevölkerungsgruppen, die unter die Bestimmungen des AVG fielen.

Tab. 20: Übersicht über die regionale Verteilung der seit 1938 zum Bestand des Altreichs der RfA hinzugekommenen aktiv Versicherten sowie Rentenempfänger in den Westgebieten (Stand Ende 1941)

\begin{tabular}{lll}
\hline Gebiet & Versicherte & Rentenempfänger \\
\hline Saargebiet & 28.000 & 2364 \\
\hline Österreich & 280.000 & 49.500 \\
\hline
\end{tabular}

rasche Wiederaufnahme der Rentenzahlungen zu erreichen suchte. Vgl. dazu den zwischen Juni 1941 und September 1942 laufenden Schriftwechsel, in den sogar die Deutsche Botschaft in Paris sowie die Deutsche Gesandtschaft in Bern und letztlich die Gestapo eingeschaltet wurden, um mehr über die Identität des Anwalts zu erfahren, in: RfA-Archiv Nr. 127.

63 Vgl. Abschrift des Erlasses des RAM vom 28.4.1943 sowie vom 22.2.1943, in: RfA-Archiv Nr. 210. 64 Vgl. Schreiben des RAM vom 16.10.1943 an die Träger der Reichsversicherung, in: ebd. 
Tab. 20: Übersicht über die regionale Verteilung der seit 1938 zum Bestand des Altreichs der RfA hinzugekommenen aktiv Versicherten sowie Rentenempfänger in den Westgebieten (Stand Ende 1941) (Fortsetzung)

\begin{tabular}{lll}
\hline Gebiet & Versicherte & Rentenempfänger \\
\hline Sudetenland & 120.000 & 29.500 \\
\hline Luxemburg & 7000 & 710 \\
\hline Eupen-Malmedy (Belgien) & 850 & 114 \\
\hline Elsass-Lothringen & 59.000 & 6800 \\
\hline Insgesamt & 494.850 & 88.988 \\
\hline
\end{tabular}

Quelle: Vermerk vom 24.12.1941, in: RfA-Archiv Nr. 79. Vgl. auch Grießmeyer, Die AV im werdenden Großdeutschland, S. 261.

Nach der Kapitulation Frankreichs im Juni 1940 waren beide Gebiete verwaltungsmäßig getrennt und wie in Luxemburg je einem Chef der Zivilverwaltung mit Sitz in Straßburg bzw. Saarbrücken unterstellt worden. Zum Chef der Zivilverwaltung in Lothringen mit Sitz in Saarbrücken wurde der Reichskommissar für die Saarpfalz und Gauleiter der NSDAP Josef Bürckel, ernannt. In Straßburg dagegen residierte als zuständiger CdZ für das Elsass Robert Wagner, Gauleiter und Reichsstatthalter in Baden. ${ }^{65}$ Obwohl in der Folgezeit vielfach gleichzeitige und auch gleichlautende Verordnungen der CdZ im Elsass und in Lothringen zur Neuordnung der Sozialversicherung erfolgten, befand sich die RfA auch hier in einem komplexen Geflecht unterschiedlicher Akteure, verbunden mit einem erheblichen Koordinierungsaufwand. Im Oktober 1940 hatte sich zunächst der CdZ in Lothringen direkt an RfAPräsident Grießmeyer gewandt und die Einführung der Reichsversicherung zum 1. Januar 1941 angekündigt. Gleiches war für das Elsass vorgesehen, und die beiden $\mathrm{CdZ}$ verbanden die Ankündigung der damit auf die RfA zukommenden neuen Aufgabe der praktischen Durchführung der Angestelltenversicherung mit einer ganzen Liste von konkreten Vorgaben und Vorschlägen bei der Umsetzung. ${ }^{66}$ Zum einen galten die in der Angestelltenversicherung Elsass-Lothringens zurückgelegten Versicherungszeiten als Versicherungszeiten nach der Reichsversicherung, d.h. sie sollten den Zeiten nach der RVO grundsätzlich gleichgestellt werden. Auch die elsasslothringischen 13 Pflichtbeitragsklassen sollten den reichsdeutschen Beitragsklassen gleichgestellt werden, was eine erhebliche Leistungssteigerung für die jeweiligen

65 Vgl. Ludger Syré, „Der Führer vom Oberrhein. Robert Wagner, Gauleiter, Reichsstatthalter in Baden und Chef der Zivilverwaltung im Elsass“, in: Michael Kißener und Joachim Scholtyseck (Hrsg.), Die Führer der Provinz. NS-Biographien aus Baden und Württemberg, Konstanz 1997, S. 733-779 sowie Lothar Wettstein, Josef Bürckel: Gauleiter - Reichsstatthalter - Krisenmanager Adolf Hitlers, Norderstedt 2009, S. $458 \mathrm{ff}$.

66 Vgl. Schreiben vom 18.10.1940, in: RfA-Archiv Nr. 133. 
Berechtigten bedeutete, denn die untersten elsass-lothringischen Breitragsklassen lagen noch deutlich unter den niedrigsten reichsdeutschen.

Die notwendigen Anpassungen galten jedoch nicht nur für die zukünftig festzustellenden Leistungen der Rentenversicherung, sondern auch für die laufenden Leistungen, die entsprechend den reichsdeutschen Bestimmungen umgerechnet werden mussten. Angesichts von fast 8000 laufenden Renten, von denen der CdZ damals noch ausging, konnte das nicht sofort passieren. Insofern sollte den Berechtigten „auf die zukünftig neu festzustellende Rente ein angemessener Vorschuss [gezahlt werden]““ ${ }^{67}$ Die durchschnittliche als Ruhegeld gezahlte Rente betrug - nach der bereits am 28. August 1940 erlassenen Bekanntmachung - umgerechnet 64,80 RM, die Witwenrente 32,40 RM und die Waisenrente 10,80 RM im Monat; sie entsprachen damit in etwa dem Niveau im Altreich, allerdings ohne Berücksichtigung der Steigerungsbeträge. Dazu kamen aber noch Vergünstigungen, die im AVG nicht vorgesehen waren, wie etwa die Gewährung der Altersrente bereits vom 60. Lebensjahr an sowie eine sogenannte vorzeitige Altersrente bereits vor dem 60. Lebensjahr. Ob und inwieweit in diesen Fällen eine Minderung der Rente eintreten sollte, um eine Besserstellung gegenüber den Rentenempfängern im Reich zu vermeiden, sollte ebenso Gegenstand der Erörterungen zwischen der RfA und den beiden Chefs der Zivilverwaltung sein wie die Klärung der technischen Durchführung der Weiterzahlung der Renten. Zu diesem Zweck bat man Grießmeyer um die Entsendung „einer Ihrer Herren Sachbearbeiter" nach Saarbrücken und Straßburg.

Daraufhin reiste RfA-Direktor Koch Ende Oktober selbst nach Elsass-Lothringen. Allerdings konnte er zu dem zentralen Grundgedanken der Vorschläge der CdZ, dass wie auch in Luxemburg die Versicherten bezüglich der Kaufkraft der Renten auf keinen Fall schlechter gestellt werden durften als bisher, keine Stellung nehmen, da er die Finanzlage der 1918 gegründeten und in Straßburg residierenden und bis dahin zuständigen „Versicherungsanstalt für Angestellte“ nicht kannte. ${ }^{68}$ Da Elsass-Lothringen staatsrechtlich nicht Reichsgebiet war, sollte, so der ausdrückliche Wunsch der beiden CdZ, die Versicherungsanstalt auch weiterbestehen. Die Behörde mit ihren 45 Beamten und Angestellten war in Vielem ähnlich organisiert wie die RfA, es gab mit dem Rentenausschuss in Straßburg eine Spruchbehörde erster Instanz und regelmäßige Rechnungsabschlüsse. Diese wiesen für Ende 1939 jährliche Beitragsleistungen von 38 Mio. französischer Franc (FF), Rentenausgaben von rund 15 Mio. FF und ein Vermögen von ca. 422,4 Mio. FF auf; bei einem Umrechnungskurs von $1 \mathrm{FF}=0,05 \mathrm{RM}$ ergaben sich mithin 1,9 Mio. RM Beitragseinnahmen, 750.000 RM an Leistungsausgaben und ein Vermögen von 21,1 Mio. RM. Die Versicherungsanstalt besaß zudem vier eigene Heilstätten in den Vogesen. Dazu gab es eine Ersatzkasse des lothringischen Konzerns De Dietrich. Allerdings war das Beitragsverfahren völlig verschieden, die Beiträge wurden per Barzahlung entrichtet und nach dem alten Kontensystem ver-

67 Ebd., S. 3.

68 Vgl. Bericht Kochs über die Dienstreise vom 28.10. bis 3.11.1940, in: RfA-Archiv Nr. 133. 
bucht. Anders als in der späteren Statistik vermerkt, kam Koch bei seinen Ermittlungen sowohl bei der Zahl der Versicherten wie der Rentenempfänger mit etwa 80.000 bzw. knapp 8400 zu erheblich höheren Zahlen. ${ }^{69}$ Gegen eine grundsätzliche Rentenerhöhung zur Anpassung an die reichsdeutschen Renten und die gestiegenen Lebenshaltungskosten sprach in den Augen Kochs nichts, allerdings gab er in seinem Bericht $\mathrm{zu}$ bedenken, dass die Verhältnisse im restlichen Frankreich wesentlich anders lagen:

Wenn die Rente in gleicher Weise auch für rentenberechtigte erhöht wird, die in Frankreich oder im sonstigen Ausland wohnen, so erhalten diese eine durch die Wirtschaftslage nicht begründete Aufwertung ihrer Renten, die so hoch sein werden, dass in vielen Fällen die Rente das Einkommen aktiver Angestellter der dortigen Gegend übersteigt. Eine Sonderbehandlung der Renten im Ausland wird deshalb nötig sein. ${ }^{70}$

Mitte November 1940 schickte Grießmeyer auf der Basis des Berichts von Direktor Koch einen Brief an die beiden $\mathrm{CdZ}$, in dem er ausführlich zu den geplanten Einführungs- und Überleitungsmaßnahmen des Angestelltenversicherungsgesetzes in Elsass-Lothringen Stellung nahm. An erster Stelle thematisierte er dabei die Finanzierbarkeit der künftigen Rentenzahlungen. ${ }^{71}$ Die Belastung für die Rentenausgaben bei Zugrundelegung der von den CdZ beabsichtigten Regelung würde jährlich etwa 4,5 Mio. RM betragen, zu deren vollständiger Deckung ein Kapital von rund 52 Mio. RM erforderlich wäre. Angesichts der tatsächlich vorhandenen 21 Mio. RM bestand eine Deckungslücke von über 50 Prozent. „Trotzdem können wir uns“, so der RfA-Präsident, „der Notwendigkeit nicht verschließen, dass die Renten in Elsass und in Lothringen den gesteigerten Lebenshaltungskosten angepasst und den reichsdeutschen Renten angeglichen werden müssen [...]“; etwaige Bedenken müssten mithin zurückgestellt werden. ${ }^{72}$ Überdies war im Zuge der Wirtschaftsbelebung eine Erhöhung der laufenden Beitragseinnahmen zu erwarten, so dass Grießmeyer nicht davon ausging, dass die Gesamtbilanz der Reichsversicherungsanstalt durch die Belastung aus den elsass-lothringischen Renten „wesentlich beeinflusst wird““ ${ }^{73}$ In der Folge präsentierte Grießmeyer dann eine geradezu maßgeschneiderte Regelung der künftigen Beitrags- und Rentenberechnung, die akribisch auf die Besonderheiten der elsass-lothringischen Versicherten und ihre erworbenen Ansprüche einging. Das begann mit der Berücksichtigung der Tatsache, dass es dort anders als in Deutschland in den 1920er Jahren zu keiner Inflation gekommen war und damit auch die Beiträge zwischen 1921 und 1923 anzuerkennen waren, und endete mit der komplizierten Anrechnung der Kriegsdienstzeiten. Für französische Kriegsdienstzeiten im Ersten Weltkrieg sollten keine Steigerungsbeträge gewährt werden, dagegen aber für solche,

69 Vgl. ebd., S. $3 \mathrm{f}$.

70 Ebd., S. 5.

71 Vgl. Schreiben Grießmeyers an den CdZ in Saarbrücken vom 12.11.1940, in: RfA-Archiv Nr. 132 a.

72 Ebd.

73 Ebd. 
die im gegenwärtigen Krieg im französischen Heer geleistet worden waren, da sich die Versicherten als französische Staatsbürger diesem nicht hätten entziehen können. Außerdem gab es Bestimmungen für die komplizierte Regelung der Wanderversicherung, d.h. dem Zusammentreffen von Pflichtbeiträgen mit Beiträgen zur innerfranzösischen Invalidenversicherung.

Und schließlich äußerte sich Grießmeyer auch zu der Sonderstellung der Altersruhegeldbezieher vor Vollendung des 65. Lebensjahres, die er mit Hinweis auf die bereits erworbenen Ansprüche ablehnte. Man könne sich einzig überlegen, ob nicht in diesen Fällen wie bei den österreichischen und sudetendeutschen Rentnern bei Aufnahme einer Beschäftigung das Ruhen der Rente anzuordnen wäre. „Nach den Erfahrungen mit den österreichischen und sudetendeutschen Rentnern möchten wir dies nicht vorschlagen, umso weniger als jetzt besonderer Wert darauf gelegt wird, die Rentner durch Weitergewährung der Rente zur Aufnahme einer Beschäftigung anzu-

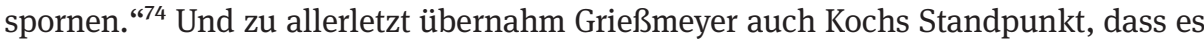
nicht gerechtfertigt sei, „französischen Staatsangehörigen oder Juden, die in Frankreich oder im sonstigen Ausland leben, die Renten in gleicher Weise zu erhöhen wie den im Elsass oder in Lothringen lebenden Rentnern““. ${ }^{75}$ Wie von der RfA vorgeschlagen, wurden die Bestimmungen dann tatsächlich in der ersten Durchführungsverordnung Anfang Dezember übernommen, die zum 1. Januar 1941 in Kraft trat. ${ }^{76}$ Die entscheidenden Weichen für die Einführung der deutschen Angestelltenversicherung in Elsass-Lothringen waren damit in direkten Verhandlungen zwischen der RfA und den beiden CdZ gestellt worden, ohne dass das Reichsarbeitsministerium dabei erkennbar involviert war. Dieses wurde erst im Dezember 1940 aktiv, als es wie in Luxemburg per Erlass die RfA auch formell zur Durchführung des AVG bestellte und dabei auch die Unterstellung der bestehenden Versicherungsanstalt für Angestellte in Straßburg unter die RfA bzw. ihre Umfirmierung zur „Reichsversicherungsanstalt für Angestellte, Amtsstelle in Straßburg“ bestimmte. ${ }^{77}$ Der bereits vorher amtierende Leiter blieb wie in Luxemburg im Amt, ohne dass ihm ein Beauftragter aus Berlin an die Seite gestellt wurde. Dennoch wurde die Straßburger Amtsstelle von Berlin aus an der kurzen Leine geführt und war an die Weisungen der RfA gebunden.

Trotz aller akribischer Vorbereitung und weitestgehender Einbeziehung der RfA in den Gesetzgebungsprozess kam es in der Folgezeit zu Problemen. Eine „nicht geringe Menge von Zweifels- und Auslegungsfragen“ musste geklärt und die Grundsätze für die Umrechnung der laufenden Renten mussten festgelegt werden. ${ }^{78}$ Anfang Februar kündigte Grießmeyer beim CdZ im Elsass selbst seinen Besuch zur Aussprache über

74 Ebd., S. 3 RS.

75 Ebd., S. 4.

76 Vgl. Rundschreiben des CdZ vom 5.12.1940, in: RfA-Archiv Fach 119, Nr. 4 sowie „Sozialversicherung wird angeglichen“, in: Metzer Zeitung vom 16.12.1940, in: ebd.

77 Vgl. dazu auch die Präsidialverfügung Grießmeyers vom 26. 2.1941, in: RfA-Archiv Nr. 132 und auch Grießmeyer, Großdeutschland, S. II 260.

78 Ebd. 
die zur Durchführung der Anordnung erforderlichen Maßnahmen an und fragte dabei auch „nach besonderen Wünschen“ für die Umsetzung. ${ }^{79}$ Die gab es nicht. Dennoch beschwerte sich der zuständige Beamte des Sachgebiets Sozialversicherung beim CdZ in Saarbrücken darüber, dass die Versicherungsanstalt für Angestellte in ElsassLothringen „,immer noch unter der alten Firma weiterarbeitet“, obwohl laut Erlass des RAM die Aufgaben doch auf die RfA übergegangen seien. „Das ist sowohl für uns wie für die Versicherungsträger peinlich, weil wir das Bestreben haben, die früheren elsass-lothringischen Versicherungsträger möglichst rasch auch nach außen hin verschwinden zu lassen. "80 Tatsächlich verwandte die Versicherungsanstalt bei ihrem nun einsetzenden regen Schriftverkehr mit der RfA bis Frühjahr 1941 den alten Briefkopf und übernahm erst dann die neue Amststellenbezeichnung. ${ }^{81}$

\section{Reidsversiderungsanstalt für Angestellte}

AMTSSTELLE IN STRASSBURG

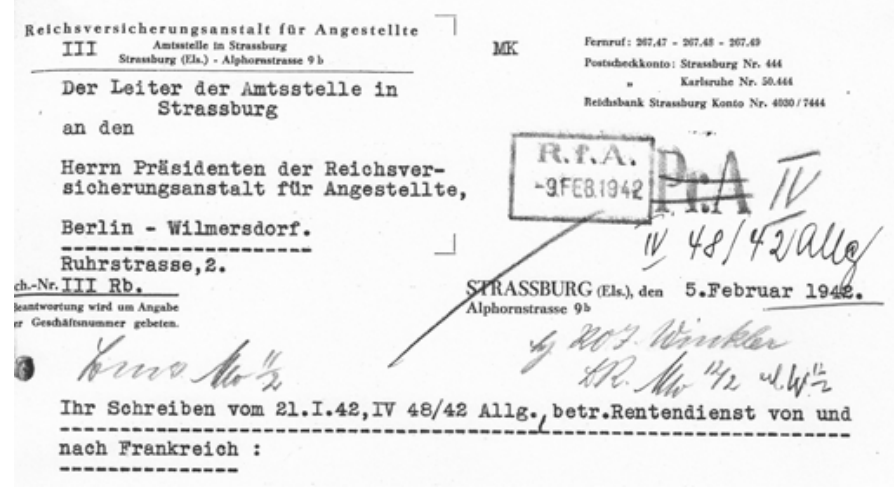

Abb. 54: Briefkopf der RfA, Amtsstelle Strassburg

RfA-Direktor Koch, der Grießmeyer auf der Reise begleitete, hielt später die Ergebnisse der zwischen dem 21. und 25. Februar 1941 abgehaltenen Besprechungen in Saarbrücken und Straßburg fest. ${ }^{82}$ Zunächst wurden jegliche devisenrechtlichen Beschränkungen bei der Zahlung von Leistungen aufgehoben und festgelegt, dass bei der Auslegung des Gesetzes, namentlich auch des Übergangsrechts, wohlwollend verfahren und möglichst zugunsten des Berechtigten entschieden werden sollte, so-

79 Vgl. Schreiben vom 8. 2.1941, in: RfA-Archiv Nr. 132 sowie auch den Dienstreiseantrag an das RAM vom 19.2.1941, in: BArch R 3901/103525, Teil 1, Bd. 3.

80 Schreiben an Grießmeyer vom 15.2.1941, in: ebd.

81 Vgl. dazu etwa das Schreiben vom 18.2.1941 mit einer langen Aufstellung erster Fragen zur Klärung der augenblicklichen Rechtslage, in: ebd.

82 Vgl. Ergebnis der Besprechungen, den Vermerk von RfA-Direktor Koch vom 1.3.1941 sowie den „Bericht über meine Dienstreise“ vom 1.3.1941, in: ebd. 
weit unterschiedliche Auslegungen möglich waren. Bei der Anrechnung bzw. Anerkennung der Anwartschaften allerdings sollten politische Kriterien ausschlaggebend sein, denn dem Vorschlag Grießmeyers und Kochs - die Bestimmungen zur Halbdeckung, die an einen Stichtag geknüpft waren, aus verwaltungstechnischen Gründen zu streichen - „wurde erwidert, dass die Beschränkung auf die Zeit nach dem Stichtag aus politischen Gründen notwendig sei, um das Wiederaufleben erloschener Anwartschaften bei den nicht deutsch gewordenen Versicherten nicht zu erleichtern““. ${ }^{83}$ Eine längere Diskussion ergab sich zudem über die Art und Weise der Anwendung der verschiedenen inzwischen erlassenen Gesetze, wie etwa das „Gesetz über weitere Maßnahmen in der Reichsversicherung aus Anlass des Krieges vom 15. Januar 1941“, auch in Elsass-Lothringen. Schließlich ging es aber vor allem um verwaltungsorganisatorische Fragen. Die bis dahin bestehenden Vertrauensmänner und Ortsausschüsse wurden zum 31. März 1941 abgeschafft und ,sind nicht weiter in Anspruch zu nehmen“. Die Straßburger Anstalt hatte keine eigenen Überwachungsbeamten, sondern ließ die Überwachungstätigkeit von der Landesversicherungsanstalt miterledigen, was einstweilen beibehalten wurde. Bis April 1941 sollten auch alle Voraussetzungen dafür geschaffen werden, dass das deutsche Markenbeitragsverfahren eingeführt werden könnte. Die aktuell festgestellte Zahl der Versicherten stellte sich nun mit 58.944, davon 6100 freiwillig Versicherten, deutlich niedriger heraus als erwartet, allerdings war infolge der wesentlich höheren Versicherungsgrenze der reichsdeutschen Rentenversicherung mit einer erheblichen Steigerung dieser Zahl zu rechnen. ${ }^{84}$ Die Ergebnisse der Besprechungen mündeten schließlich in die von Koch entworfenen zehnseitigen „Vorläufige[n] Richtlinien für die Durchführung der Angestelltenversicherung im Elsass und in Lothringen““ ${ }^{85}$ Dennoch blieben auch jetzt noch viele Detailfragen ungeklärt, so dass Anfang März erneut ein RfA-Beamter für mehrere Tage nach Straßburg reiste, um vor allem die Arbeitsweise der Amtsstelle zu koordinieren und auch die Umstellung des Auszahlungsverfahrens von der bisherigen Auszahlung durch die Postämter zum damals im Reich noch gültigen Postscheckverfahren zu organisieren - was sich jedoch, wie sich schnell zeigte, schon aufgrund des Personalmangels hinsichtlich der dafür notwendigen Herstellung der Adremaplatten und Lochkarten als unmöglich herausstellte. ${ }^{86}$

Im April wurde schließlich eine gemischte Kommission aus Vertretern der RfAAmtsstelle Straßburg und der gleichfalls in Straßburg residierenden gemeinsamen LVA-Außenstellen Baden und Saarpfalz eingerichtet, um das komplizierte Problem der Umrechnung und Neuberechnung der Renten für Wanderversicherte in Angriff zu nehmen. Kurz zuvor hatte der CdZ in Straßburg in einem explizit als vertraulich bezeichneten und nicht veröffentlichten Erlass zudem bestimmt, dass für die Berech-

83 Ebd., S. 1 RS.

84 Vgl. ebd., S. 2 sowie die statistische Übersicht im dortigen Anhang.

85 Vgl. die Richtlinien vom 6.3.1941, in: ebd.

86 Vgl. Bericht über die Dienstreise nach Straßburg vom 9. bis 18. März 1941, in: RfA-Archiv Nr. 130 b sowie Schreiben der RfA an den Reichspostminister vom 10.3.1941, in: RfA-Archiv Nr. 132. 
nung der Beitragserstattungen der Franken zum Kurs von $1 \mathrm{zu}$ 0,1645 RM und damit deutlich günstiger als die offiziellen Kurse umzurechnen sei. ${ }^{87}$ In intensivem Schriftwechsel zwischen RfA und den beiden CdZ entstanden in kurzer Folge weitere Durchführungsbestimmungen. ${ }^{88}$ Für Irritationen auf Seiten der RfA hatte dabei allerdings Ende April gesorgt, dass man von dem Entwurf einer neuen, zweiten Durchführungsverordnung der CdZ nur auf inoffiziellem Wege erfahren hatte. ${ }^{89}$ Vor allem ließ dieser Entwurf die meisten der von der RfA in früheren Schreiben aufgeworfenen Fragen unberücksichtigt, „obwohl deren Regelung dringend erwünscht wäre, um die Erledigung der vorliegenden Leistungsanträge zu ermöglichen“.$^{90}$ Es gab offensichtlich Kommunikationsprobleme zwischen der Ruhrstraße und den CdZ in Straßburg und Saarbrücken, denn im Juni etwa äußerte die RfA in einem von Koch verfassten Brief ihre Überraschung darüber, dass diverse offene Fragen inzwischen offensichtlich entschieden worden seien und die zweite Durchführungsverordnung für Lothringen bereits ergangen sei bzw. für den Elsass demnächst ergehen würde. ${ }^{91}$ Dennoch setzten beide $\mathrm{CdZ}$ weiterhin durchaus auf den Rat und die Kompetenz der RfA. ${ }^{92}$ Anfang Juli 1941 sah sich RfA-Direktor Koch zu einer erneuten Dienstreise nach Straßburg gezwungen, um dort nach wie vor auftauchende versicherungsrechtliche Detailfragen zu klären.

Es gab vor allem drei Probleme: Erstens hatte sich durch die Einführung des Reichsrechts in Elsass-Lothringen die Höchstgrenze für die Versicherungspflicht gegenüber dem bisherigen Recht erhöht. Dadurch waren zahlreiche bisher versicherungsfrei gewesene Versicherte versicherungspflichtig geworden. Viele dieser Versicherten hatten jedoch bereits Lebensversicherungsverträge abgeschlossen und konnten nur dann von der zusätzlichen Beitragsleistung befreit werden, wenn der Vertrag bereits mindestens drei Jahre bestanden hatte. Es galt mithin nach Lösungen zu suchen, die dadurch entstandenen Härten zu vermeiden oder abzumildern. Zudem waren, wie sich zeigte, die Fälle ziemlich zahlreich, in denen Versicherungsansprüche nur durch Zusammenrechnung von AV-Beiträgen und von solchen Beiträgen bestanden, die zur innerfranzösischen Sozialversicherung entrichtet worden waren. Auch hier galt es nach flexiblen Verwaltungspraktiken zu suchen, um soziale Härten zu vermeiden. ${ }^{93}$ Zweitens machte die Anwendung des reichsdeutschen Leistungsverbesserungsgesetzes vom Juni 1941 erhebliches Kopfzerbrechen. Und drittens sah sich

87 Vgl. der Erlass vom 14.4.1941, in: BArch R 89/3114.

88 Vgl. dazu etwa das Schreiben des CdZ in Saarbrücken an die RfA vom 19.3.1941, in: ebd.

89 Vgl. Schreiben der RfA Straßburg an Grießmeyer vom 25.4.1941, in: RfA-Archiv Nr. 132.

90 Ebd. Vgl. dazu auch den Vermerk Kochs vom 9.5.1941, in: ebd. Der Vorwurf der Nichtberücksichtigung wurde allerdings vom CdZ Ende Mai heftig bestritten.

91 Schreiben vom 12.6.1941, in: ebd.

92 Vgl. dazu den Schriftwechsel vom Mai 1941, in: ebd.

93 Vgl. Vermerk Kochs vom 18.7.1941 sowie das Protokoll des Leiters der RfA-Amtsstelle Straßburg über die Besprechungen am 8.7.1941 sowie das Protokoll über die gemeinsam mit den Vertretern der LVA abgehaltene Arbeitstagung vom 9.7.1941, in: RfA-Archiv Nr. 132 a. 
die RfA plötzlich mit der Forderung der CdZ konfrontiert, dass sie auch die Versicherten und Rentner der Angestellten der Mühlhausener und der Straßburger Straßenbahn übernehmen sollte, die jeweils in einer eigenen Ersatzkasse versicherten waren, deren Vermögenslage allerdings jeweils völlig unklar war. ${ }^{94}$ Auch die Versicherten und Rentner der Pensionskasse des lothringischen Unternehmens De Dietrich sollte die RfA übernehmen, ausreichende Deckungsmittel waren allerdings auch hier nicht vorhanden. ${ }^{95}$ Besonders dieser letzte Punkt sorgte in der Ruhrstraße für erhebliche Missstimmung und in einem internen Vermerk wurde zu dieser grundsätzlichen Frage offen die Anweisungskompetenz der CdZ gegenüber der RfA angezweifelt. Zudem sah man seitens der RfA weder eine rechtliche noch eine moralische Verpflichtung, jene Versichertenbestände zu übernehmen, da es sich formal nicht um Ersatzkassen handelte. Das Ansinnen der CdZ, das diese auch in einer eigenen Besprechung Ende Juni 1941 gegenüber der RfA-Amtsstelle Straßburg geradezu ultimativ deutlich gemacht hatten, bedeutete nichts anderes, als dass gewährte Versicherungsleistungen von den Schultern privater Unternehmen und Dienstgeber auf die Schultern der RfA gelegt werden würden, mit unabsehbaren Folgen. ${ }^{96}$ Demgegenüber erschien es fast zweitrangig, dass auch im Sommer 1941 noch immer nicht alle rechtlichen Details über Art und Umfang der Auslegung bzw. überhaupt der Frage, welches Recht wann und wie anzuwenden sei, geklärt waren, um endlich mit den Umrechnungs- und Neuberechnungsarbeiten der laufenden Renten beginnen zu können. In der RfA suchte man gegenüber den Forderungen der CdZ Zeit zu gewinnen und das Ganze, unter anderem auch durch Einschaltung des Reichsarbeitsministeriums, zu verzögern. Aber Ende Februar 1942 sollte das Problem infolge einer Verordnung der CdZ über die Versicherungs- und Beitragspflicht der elsässischen Straßenbahner erneut auf den Tisch kommen. Nach wie vor stand jedoch in der Verordnung kein Wort darüber, ob und wie der neue Versicherungsträger RfA dafür entschädigt werden würde, dass er nun Leistungen aus Zeiten zu übernehmen hatte, während der überhaupt keine Beiträge an ihn entrichtet worden waren. ${ }^{97}$

Erst im September 1941 liefen die Umrechnungsarbeiten in der Amtsstelle Straßburg an, allerdings nur bei den einfachen Angestelltenrenten, da die LVA bzw. Invalidenversicherung ihrerseits noch nicht so weit war und zudem auch ein Auslegungsstreit mit der LVA Baden die Inangriffnahme der Umrechnungsarbeiten bei den Wanderversicherten blockierte. ${ }^{98}$ Mitte Oktober 1941 reiste daher RfA-Direktor Koch

94 Wie sich bald herausstellte, stand ein Deckungsvermögen von gerade einmal 575.000 RM laufenden Leistungsaufwendungen von über 1,6 Mio. RM gegenüber.

95 Vermerk Kochs vom 18.7.1941, in: ebd.

96 Vgl. Aktenvermerk des CdZ in Saarbrücken vom 30.6.1941 sowie Vermerk Kochs vom 24.7.1941 und ein weiterer Vermerk des RfA-Versicherungsmathematikers vom 13.8.1941, in: ebd.

97 Vgl. Schreiben des CdZ an die RfA Straßburg und die RfA Berlin vom 25. 2.1942 sowie das Schreiben der RfA Straßburg dazu vom 7.3.1942, in: RfA-Archiv Nr. 132 a.

98 Vgl. Bericht der RfA Straßburg nach Berlin vom 18.9.1941 sowie das Schreiben Kochs an die RfA Straßburg vom 9.10.1941, in: ebd. 
abermals zur Erörterung rechtlicher und verfahrenstechnischer Fragen nach Straßburg. ${ }^{99}$ Bis Mitte Dezember 1941 waren immerhin 2725 Renten neu- bzw. umgerechnet worden, was allerdings noch immer nicht einmal die Hälfte aller laufenden Renten ausmachte. ${ }^{100}$ Dann tauchte allerdings ein neues Problem auf. Mitte Dezember 1941 hatten die beiden CdZ im Elsass und in Lothringen mit dem französischen Arbeitsministerium unter Vermittlung des Militärbefehlshabers in Frankreich ein Abkommen über die Wiederaufnahme des gegenseitigen Rentendienstes geschlossen. ${ }^{101}$ Bei der Ausführung dieses Pariser Abkommens ergaben sich allerdings bald Zweifel, unter anderem darüber, ob es zulässig wäre, dass in Frankreich lebende Rentenberechtigte der elsass-lothringischen Versicherung bestimmen konnten, dass der deutsche Versicherungsträger die Rente an Familienangehörige im Elsass zahlte. ${ }^{102}$ Anfang Februar 1942 kam es daher zu einer Besprechung in Straßburg, die unter anderem das bemerkenswerte Ergebnis hatte, dass die kurz zuvor erlassene Abteilungsverfügung der RfA über die Einstellung der Rentenzahlung an im Ausland wohnende Juden keine Anwendung zu finden hatte, soweit es sich um Berechtigte aus diesem Pariser Abkommen handelte, die in Frankreich wohnten, „da das Abkommen internationalen Charakter hat". ${ }^{103}$

Gleichzeitig sorgte eine Entscheidung des Revisionssenats des RVA für Verunsicherung. Obwohl es um die Verhandlung einer strittigen Invalidenrentensache ging, war das Urteil auch für die Angestelltenversicherung von Bedeutung, da es um die grundsätzliche Aufrechterhaltung der Anwartschaft bei der Rentenversicherung im Elsass und in Lothringen ging. Die Rechtsauffassung des RVA wiedersprach, so zumindest das Urteil des Leiters der Straßburger Amtsstelle, dem Willen der CdZ, die mit ihren Anordnungen ganz allgemein den Erhalt der Anwartschaften aus allen irgendwann in Elsass-Lothringen zur Rentenversicherung gezahlten Beiträgen ohne Ausnahme forderten. Die neue Auffassung des Revisionssenats

lässt nun wieder vielfach Unsicherheit aufkommen in der Frage der Anwartschaftserhaltung, von der wir angenommen hatten, dass sie im Elsass und in Lothringen den Absichten der Chefs der Zivilverwaltung gemäß in sozial-großzügiger, klarer, eindeutiger und für die Versicherten verständlicher Weise gelöst wäre,

beklagte sich daraufhin die Straßburger RfA-Stelle gegenüber Berlin. ${ }^{104}$ Erst im September 1942 konnte daher die Umstellung und Neuberechnung der letzten Ange-

99 Vgl. Bericht über die Dienstreise vom 13. und 14.10.1941, in: RfA-Archiv Nr. 133 a.

100 Vgl. Bericht der RfA Straßburg nach Berlin vom 19.12.1941, in: RfA-Archiv Nr. 130 c.

101 Vgl. dazu das Schreiben des CdZ an die RfA vom 6.3.1942, in: RfA-Archiv Nr. 131.

102 Vgl. Bericht der RfA Straßburg nach Berlin vom 18.4.1942, in: RfA-Archiv Nr. 130 c.

103 Bericht der RfA Straßburg nach Berlin vom 5.2.1942, in: RfA-Archiv Nr. 131. Vgl. zur Anwendung des Pariser Abkommens auch das Schreiben des Reichsstatthalters in der Westmark und zugleich CdZ in Lothringen an die RfA vom 20.8.1942, in: RfA-Archiv Nr. 131.

104 Schreiben der RfA Straßburg nach Berlin vom 14.4.1942, in: RfA-Archiv Nr. 131. 
stelltenrenten in Elsass-Lothringen erfolgen. ${ }^{105}$ Inzwischen war von den beiden CdZ die siebente Ergänzungs- und Durchführungsverordnung zur Sozialversicherung im Elsass und in Lothringen ergangen, in der es unter anderem um die Anrechnung der bei französischen Versicherungsträgern zurückgelegten Versicherungszeiten ging. Auch die ersten Widersprüche gegen RfA-Bescheide beim zuständigen Oberversicherungsamt Speyer, unter anderem über die strittige Frage der Versicherungspflicht eines Lebensmittel-Filialleiters, waren eingegangen und verhandelt worden. ${ }^{106} \mathrm{Im}$ Januar 1943 musste man sich jedoch noch immer mit der Übernahme der Straßenbahner und der Rentenberechnung und Leistungsgewährung für diese Versichertengruppierung herumschlagen. ${ }^{107}$ Gleichzeitig landete ein Schreiben des CdZ in Lothringen auf dem Schreibtisch Grießmeyers, in dem vehement gegen die restriktive Auslegung des „Gesetzes über weitere Maßnahmen in der Rentenversicherung aus Anlass des Krieges“ durch das RVA protestiert wurde. Bekanntlich galten nach dem Gesetz für alle Versicherten, die infolge des Krieges gestorben oder invalide geworden waren, die Wartezeiten als erfüllt. Das RVA hatte nun aber bestimmt, dass dies nicht für Soldaten deutscher Volkszugehörigkeit gelten sollte, die auf feindlicher Seite hatten kämpfen müssen. Die Anwendung dieser Vorschrift auf Lothringer, die während des Krieges auf französischer Seite kämpfen mussten, widersprach nach Meinung des CdZ dem Grundgedanken jener von ihm erlassenen Vorschriften, wonach Lothringer französische Wehrdienstzeiten mit Wartezeit und Anwartschaft angerechnet bekämen und dafür auch Steigerungsbeträge erhielten. Er bestimmte daher kurzerhand, dass die oben genannte Verordnung zur vorzeitigen Erfüllung der Wartezeit auch für Lothringer Versicherte anwendbar sei, die bis zum Waffenstillstand als Soldaten auf französischer Seite gestorben oder berufsunfähig geworden seien. ${ }^{108}$ Eine gleichlautende Verordnung wurde wenig später auch vom CdZ im Hinblick auf die Elsässer Versicherten erlassen. ${ }^{109}$ Tatsächlich kämpften zwischen 1942 und 1944 auf Seiten der Deutschen ca.130.000 Elsässer und Lothringer, die als „Volksdeutsche“ in die Wehrmacht oder die Waffen-SS eingezogen worden waren und auf die die neuen Bestimmungen potenziell zutrafen.

Dass das Thema der Rentenversicherung in Elsass-Lothringen auch anderweitig anhaltende Aktualität besaß, zeigt die Einberufung einer Tagung der CdZ zusammen mit den Versicherungsträgern Mitte Februar 1943 in Saarbrücken. Dabei stand vor allem die bis dahin nicht einmal ansatzweise geklärte Vermögensauseinandersetzung mit den früheren Sozialversicherungsträgern im Elsass und in Lothringen auf der Tagesordnung sowie die Rückführung ihres in Frankreich befindlichen Vermögens ${ }^{110}$

105 Vgl. Bericht der RfA Straßburg nach Berlin vom 19.9.1942, in: ebd.

106 Der Fall vom Juni 1942, in: RfA-Archiv Fach 119, Nr. 4. Zur strittigen Auslegung der Verordnung vgl. das Schreiben der RfA Berlin an die RfA Straßburg vom 26.1.1943, in: RfA-Archiv Nr. 133.

107 Vgl. Schreiben der RfA an das RVA vom 6.1.1943, in: RfA-Archiv Nr. 133 a.

108 Vgl. Schreiben des CdZ an die RfA vom 28.1.1943, in: RfA-Archiv Nr. 133 a.

109 Vgl. Erlass vom 20.1.1943, in: RfA-Archiv Nr. 27.

110 Vgl. das Einladungsschreiben vom 1.2.1943, in: RfA-Archiv Nr. 131. 
Ob und wie eine Vermögensauseinandersetzung tatsächlich erfolgte, geht aus den Akten jedoch nicht hervor. Das letzte nachweisbare Schreiben der RfA-Amtsstelle Straßburg nach Berlin datiert vom Juli 1944, in dem die Zahl der Leistungsempfänger in Elsass-Lothringen angegeben wird. Demnach gab es 8333 Rentenberechtigte, davon 4545 Ruhegeldempfänger sowie 2876 Witwen- und 912 Waisenrentenempfänger. ${ }^{111}$ Kurz darauf begannen in der Region die Kämpfe im Zuge des Vormarsches der alliierten Truppen. Eine formelle Auflösung der RfA-Amtsstelle Straßburg erfolgte jedoch nicht mehr.

\section{2 „Polenstatut“ und andere Sonderrechte: Angestelltenversicherung in den eingegliederten und besetzten Ostgebieten}

Nicht minder kompliziert als in den okkupierten Westgebieten gestaltete sich die Einführung der Angestelltenversicherung deutschen Rechts in den eingegliederten und besetzten Ostgebieten. Zum 1. Mai 1939 war der als Memelgebiet unter Litauischer Hoheit stehende Teil Ostpreußens wieder in das Deutsche Reich eingegliedert und am 17. August 1939 per Erlass dort die Einführung der Angestelltenversicherung unter Verantwortung der RfA verfügt worden. Es ging um 2500 Versicherte und eine nicht bekannte Zahl von Rentenempfängern. ${ }^{112}$ Der nächste größere Zuwachs an Versicherten und Rentenberechtigten erfolgte kurz nach Kriegsbeginn mit der Einführung der Reichsversicherung in der bisherigen Freien Stadt Danzig zum 22. Januar 1940. Dort war nach dem Ersten Weltkrieg eine Landesversicherungsanstalt für Angestellte als Nachfolgerin der RfA und zuständiger Versicherungsträger errichtet worden. Die damalige Danziger Regierung hatte sich von Anfang an bemüht, die Grundlagen der AV möglichst in Übereinstimmung mit der reichsrechtlichen Entwicklung zu halten, so dass zum Zeitpunkt der Rückkehr Danzigs in das Deutsche Reich nur geringfügige Rechtsabweichungen auf dem Gebiet der Angestelltenversicherung bestanden. ${ }^{113}$ Die versicherungsmäßige Integration der 28.000 Versicherten und 2650 laufenden Renten verlief daher reibungslos und ohne größeren bürokratischen Aufwand. Als Grundsatz galt hier wie vorher im Memelgebiet, dass die betroffenen Angestellten und Rentner so gestellt werden sollten, als ob die tatsächliche Unterbrechung ihrer Zugehörigkeit zur RfA nicht stattgefunden hätte. Das Hauptproblem in Danzig war die Umrechnung vom Danziger Gulden in RM, die in der Weise erfolgte, dass zur bisherigen Rente ein

111 Vgl. Schreiben vom 3.7.1944, in: RfA-Archiv Nr. 131 a.

112 Vgl. dazu Grießmeyer, Großdeutschland, S. II 258.

113 Ebd. Zu Danzig vgl. auch den Schriftwechsel der RfA unter anderem mit dem Senat von Danzig 1935 bis 1937, in: RfA-Archiv Nr. 128. Vgl. auch das am 1.4.1939 geschlossene Abkommen zwischen der RfA und der Landesversicherungsanstalt der Freien Stadt Danzig über die Angestelltenversicherung, in: RfA-Archiv Ordner Danzig (ohne Sign.). 
pauschaler Zuschlag von zehn Prozent gewährt wurde. ${ }^{114}$ Bereits im Februar 1940 wurden die Danziger Renten von Berlin aus gezahlt, wobei nicht nur das Verhältnis zwischen aktiv Versicherten und Rentnern dem im Deutschen Reich ähnlich war, sondern auch die Vermögensverhältnisse der Danziger Angestelltenversicherung „nicht ungünstig“ waren. ${ }^{115}$ Die Übernahme des Deckungsvermögens, dessen genaue Höhe aus den Akten nicht hervorgeht, in die Verwaltung der RfA konnte daher aus Sicht der Behörde reibungslos und in kurzer Zeit erfolgen.

Im besetzten Polen jedoch wurde die Reichsversicherung nicht überall und auch nicht gleichzeitig eingeführt. Der Hauptteil Zentralpolens mit der Hauptstadt Warschau firmierte nun als Generalgouvernement mit eigener Zivilregierung in Krakau. Die Reichsversicherung galt hier nicht; Mitte Juni 1940 erfolgte nur eine „Verordnung über die Sozialversicherung der deutschen Staatsangehörigen im Generalgouvernement für die besetzten polnischen Gebiete“, die rückwirkend zum 1. Oktober 1939 den deutschen Volkszugehörigen anstelle der Ansprüche auf Leistungen aus der polnischen Sozialversicherung Unterstützungen (allerdings ohne Rechtsanspruch) in Höhe der früheren gesetzlichen Leistungen gewährte. ${ }^{116}$ Daneben bestanden zwei Gebiete (Reichsgau Wartheland und Reichsgau Danzig-Westpreußen) sowie einige kleinere in die Provinz Ostpreußen eingegliederte polnische Gebiete, in denen zunächst noch das ehemalige polnische Versicherungsrecht Geltung behielt. Und schließlich gab es das stark industrialisierte und mit einem hohen Anteil an Deutschen bewohnte Gebiet OstOberschlesiens um die Städte Kattowitz und Königshütte, die das Reich nach dem Ersten Weltkrieg ebenfalls hatte abtreten müssen und nun mit Oberschlesien bzw. dem Gau Schlesien wieder verschmolzen wurde. Mit 30.000 Versicherten und knapp 9000 laufenden Renten war es das eigentliche Kernland der rentenversicherungsrechtlichen Expansion der RfA in Osteuropa, in dem Mitte Januar 1940 die Reichsversicherung eingeführt wurde - mit der „Verordnung über die Einführung der Reichsversicherung in den der Provinz Schlesien eingegliederten ehemals polnischen Gebieten“. ${ }^{117}$

Tab. 21: Übersicht über die regionale Verteilung der seit 1938 zum Bestand des Altreichs der RfA hinzugekommenen aktiv Versicherten sowie Rentenempfänger in den Ostgebieten (Stand Ende 1941)

\begin{tabular}{lll}
\hline Gebiet & Versicherte & Rentenempfänger \\
\hline Memelgebiet & 2500 & - \\
\hline
\end{tabular}

114 Vgl. ebd.

115 Ebd.

116 Vgl. ebd.

117 Vgl. dazu auch Heinz-Georg Mischkowsky, Die eingegliederten Ostgebiete und das Generalgouvernement in ihrer Bedeutung für die Dienststelle I Allgemein, unter besonderer Berücksichtigung der Staatszugehörigkeitsverhältnisse in diesen Gebieten (nur für den Dienstgebrauch), Berlin 1951, in: Bibliothek der DRV-Bund. 
Tab. 21: Übersicht über die regionale Verteilung der seit 1938 zum Bestand des Altreichs der RfA hinzugekommenen aktiv Versicherten sowie Rentenempfänger in den Ostgebieten (Stand Ende 1941) (Fortsetzung)

\begin{tabular}{lll}
\hline Gebiet & Versicherte & Rentenempfänger \\
\hline Freistaat Danzig & 28.000 & 2650 \\
\hline Ostoberschlesien (Polen) & 30.000 & 8744 \\
\hline Übrige Ostgebiete (Gau Westpreußen und Wartheland) & - & 2120 \\
\hline Insgesamt & 60.500 & 13.514 \\
\hline
\end{tabular}

Quelle: Vermerk vom 24.12.1941, in: RfA-Archiv Nr. 79. Vgl. auch Grießmeyer, Die AV im werdenden Großdeutschland, S. 261.

Präsident Grießmeyer hat aus seiner Sicht auch diese Entwicklungen in seinem Aufsatz über „Die Angestelltenversicherung im werdenden Großedeutschland“ nüchtern und betont sachlich geschildert. Tatsächlich jedoch entpuppen sich die Vorgänge beim Blick in die überlieferten Generalakten der RfA als komplexe und auch dynamische Entwicklung der AV-Verwaltungspraxis, die zwischen großangelegter rassischvölkischer Exklusion und germanisierungspolitischer Inklusion oszillierte. Die Regelung der Rentenversicherungsfälle und die gegenseitigen Abgrenzungen und die Abrechnung der jeweiligen Ansprüche im Versicherungsfall zwischen der RfA und dem zuständigen polnischen Versicherungsträger - der Sozialversicherungsanstalt in Warschau bzw. deren fünf regionale Zweiganstalten (in Lemberg, Posen, Königshütte, Lodz und Krakau) - war schon vor Kriegsausbruch kompliziert gewesen, da damals auf polnischer Seite als Folge des Ersten Weltkriegs ein regional vielfach zersplittertes und heterogenes Sozialversicherungsrecht unterschiedlicher Rechtstraditionen geherrscht hatte. ${ }^{118} \mathrm{Am}$ 11. Juni 1931 war ein erster deutsch-polnischer Vertrag über die Sozialversicherung geschlossen worden, dem im März 1933 sowie Ende Januar 1934 ergänzende Verhandlungen bezüglich seiner Umsetzung gefolgt waren, bei denen es insbesondere um die Abwicklung und Regelung der jeweiligen deutsch-polnischen Renten ging. ${ }^{119}$

Doch vieles war strittig geblieben und die Umsetzung auf beiden Seiten konfliktbeladen. Im Februar 1937 etwa beschwerte sich Grießmeyer in einem Schreiben an

118 Vgl. ebd., S. 18-24 sowie dazu (mit allerdings NS-spezifischem polemischen Duktus) Werner Kahl, Die Sozialversicherung im ehemaligen Polen, in: NS-Sozialpolitik 7 (1940), S. 86 - 87 und S. $113-$ 115, insb. S. $115 \mathrm{zu}$ den Leistungen der polnischen Angestelltenversicherung, die unter anderem einen Anspruch auf Kapitalabfindung im Fall des Eintritts des Versicherungsfalls vor Erfüllung der Wartezeit kannte.

119 Vgl. dazu die diversen Protokolle der Verhandlungen, in: RfA-Archiv Nr. 166 a bis e. Im Mai 1935 hatte dazu die RfA ein Schreiben an das RAM über die nach wie vor bestehenden Zweifelsfragen bei der Durchführung und Auslegung des deutsch-polnischen Vertrags von 1931 geschickt. Vgl. RfA-Archiv Nr. 166. 
das RVA darüber, dass es von polnischer Seite immer wieder Verzögerungen bei den Zahlungsanweisungen gebe. ${ }^{120}$

Wir müssen uns ganz entschieden dagegen verwahren, dass die polnischen Behörden durch ihre Unpünktlichkeit und Lässigkeit bei der Ausführung des Zahlungsabkommens die rechtzeitige Zahlung der Renten durch uns unmöglich machen und dann noch dazu durch unrichtige Auskünfte bei den Rentenempfängern den Eindruck erwecken, dass durch unser Verschulden die Rente unpünktlich gezahlt werde. ${ }^{121}$

Überhaupt bestanden auf deutscher Seite viele Unklarheiten über Struktur und Anzahl der ehemals deutschen Versicherten auf polnischer Seite. Man ging zwar von rund 14.000 Versicherten der AV aus, die sich Mitte Juni 1922 in den abgetrennten Gebieten befunden hatten; aber es fehlten jegliche Unterlagen darüber, wieviele von ihnen noch in Polen lebten oder inzwischen ins Reich zurückgewandert waren. ${ }^{122} \mathrm{Im}$ September 1936 hatte der Gesamtverband Deutscher Angestelltengewerkschaften in Polnisch-Oberschlesien an die RfA eine „Denkschrift zur Frage der Aufrechterhaltung der Anwartschaften bei der polnischen Angestelltenversicherung im Falle eines Wohnungswechsels des Versicherten aus Polen nach Deutschland“ geschickt und auch andere Organisationen wie der Verband Deutscher Angestellten in Polen wandten sich mit ähnlichen Problemen an die RfA. ${ }^{123}$

Für die vielfach beklagte Schlechterstellung der deutschen Angestelltenrentner mit polnischen Renten waren allerdings - darauf wies die RfA gegenüber dem RVA explizit hin - keineswegs einseitig unbillige Kürzungen der polnischen Leistungen verantwortlich, sondern dies war Folge der Kürzungen bei den deutschen Steigerungsbeträgen. ${ }^{124}$ Dazu kamen nicht unerhebliche Kursverluste infolge der Umrechnung der polnischen Renten von Zloty in RM. ${ }^{125}$ Immer öfter sah sich die RfA daher mit Streitfällen und Widersprüchen Betroffener konfrontiert, in die sich verstärkt auch die Gaurechtsberatungsstelle Ausland der DAF einschaltete. ${ }^{126}$ Deshalb war die RfA im Sommer 1939 der allgemeinen Überzeugung, dass die Lage der in Polen wohnenden „volksdeutschen“ Versicherten und Rentenbezieher ungünstig und von sozialen Härten geprägt sei, umgekehrt aber auch die Rentenempfänger im Reich oder der Ostmark mit polnischen Teilrenten vergleichsweise schlecht dastünden. Angesicht der

120 Vgl. Schreiben vom 15.2.1937, in: RfA-Archiv Nr. 82.

121 Ebd., S. 2. Vgl. auch den Beschwerdebrief von Betroffenen aus Oberschlesien an die RfA vom 5.2. 1937 sowie den Schriftwechsel mit dem polnischen Versicherungsträger in Warschau vom 11.2.1937, in: ebd.

122 Vgl. Schreiben der RfA an das RVA vom 23.8.1937, in: RfA-Archiv Nr. 166.

123 Vgl. die Denkschrift, in: RfA-Archiv Nr. 166 d.

124 Vgl. Schreiben der RfA an das RVA vom 20.3.1939, in: ebd.

125 Vgl. dazu auch das Schreiben der RfA an die NSDAP-Auslandsorganisation vom 25.3.1938, in: ebd. 126 Vgl. dazu etwa das Schreiben der DAF-Rechtsberatungsstelle Ausland an die RfA vom 13.6.1939, in: RfA-Archiv Nr. 166 e sowie die Verhandlung eines Streitfalles am 7.2.1938 zunächst vor dem OVA Breslau sowie die Entscheidung desselben am 21.12.1938 durch den Revisionssenat der RVA, in: BArch R 89/23090. 
anhaltenden Probleme wurden zwischen den deutschen Stellen und der polnischen Regierung bis Kriegsbeginn praktisch permanent Verhandlungen zu Sozialversicherungsfragen geführt. ${ }^{127}$ Zeitweise waren auch RfA-Direktor Koch und weitere RfA-Beamte $\mathrm{zu}$ den Verhandlungen nach Polen gereist und hatten dort als Vertreter der Angestellten agiert. ${ }^{128}$ Doch wer gedacht hatte, dass all diese komplexen Regelungsprobleme der deutsch-polnischen Rentenversicherung mit der Besetzung und Zerschlagung Polens und der teilweisen Reintegration der Gebiete in das Deutsche Reich mit einem Schlag beseitigt sein würden, der sah sich getäuscht.

Eines der Grundprobleme vor dem Hintergrund der in der Sozialpolitik dominierenden rassisch-völkischen Denkweise des NS-Regimes war, dass über die genauen Volkstums- und Staatsangehörigkeitsverhältnisse in den eingegliederten und annektierten Ostgebieten vielfach Unklarheit herrschte. Schon für die Zeitgenossen waren die Begriffe und der jeweilige Rechtsstatus verwirrend. Neben den wiedervereinigten (Ost-)Gebieten wie Memelland und Danzig gab es die eingegliederten Ostgebiete (OstOberschlesien), daneben aber auch die besetzten Ostgebiete, allen voran das Generalgouvernement, aber auch der Bezirk Bialystok und das Reichskommissariat Ostland (das Gebiet der ehemaligen baltischen Staaten) bzw. das Reichskommissariat Ukraine. Im Zusammenhang mit den annektierten und eingegliederten Ostgebieten wurden zudem eine Reihe neuer, dem bisherigen Staatsangehörigkeitsrecht fremde Begriffe geprägt wie „deutsche Volkszugehörige“, „Volksdeutsche“, „Staatsangehörige auf Widerruf“ und „Schutzangehörige deutschen oder polnischen Volkstums“. All das erschwerte die Bemühungen der Sozialversicherungsträger zur Übernahme der Versicherten und Rentner in den besetzten Gebieten Polens und zur möglichst raschen Wiederaufnahme der durch den Krieg unterbrochenen Rentenzahlungen, die unmittelbar nach Beendigung der Kampfhandlungen einsetzten. Die Vertreter der LVA Schlesien, die die Invalidenversicherung übernahm, waren allerdings schneller vor Ort in Kattowitz und Königshütte, wo die Zweiganstalten der Sozialversicherungsanstalt in Warschau lagen. Das Aktenmaterial und die Rentenlisten auch für die Angestelltenversicherung seien vorhanden, so berichtete der Leiter der LVA Schlesien aus Breslau nach seiner Rückkehr aus den polnischen Gebieten an RfA-Direktor Koch. Allerdings seien die Renten für September noch nicht ausgezahlt worden und die Geldmittel von dem geflüchteten polnischen Personal mitgenommen worden. ${ }^{129}$

Alle Beteiligten vor Ort betonten „die Dringlichkeit der Rentenzahlungen im Interesse der Befriedung des eroberten Gebietes“. ${ }^{130}$ Wenige Tage später lag auch der umfangreiche Bericht des inzwischen eingesetzten Treuhänders der Zivilverwaltung Oberschlesien für den Betrieb der Sozialversicherungsanstalt Königshütte auf dem Schreibtisch Grießmeyers, der gleichfalls im Interesse der Aufrechterhaltung von Ruhe

127 Vgl. dazu etwa den RfA-internen Vermerk vom 7.2.1939 über die Vereinbarungen der deutschpolnischen Verhandlungen vom 9.8.1938, in: RfA-Archiv Nr. 166 e.

128 Vgl. etwa den Vermerk über die Verhandlungen vom 28.9.1937, in: ebd.

129 Vgl. Schreiben der LVA Schlesien an die RfA vom 12.9.1939, in: RfA-Archiv Nr. 163.

130 Ebd. 
und Ordnung auf die Wiederaufnahme der Rentenzahlungen drängte. Die Behörde in Königshütte hatte für den Bereich der Angestelltenversicherung monatlich 1,2 Mio. Zloty (umgerechnet ca. 600.000 RM) aufgewendet. ${ }^{131}$ Die deutschen Versicherungsträger waren jedoch nach Ansicht des Treuhänders weder in der Lage noch mangels gesetzlicher Bestimmungen berechtigt, die erforderlichen Mittel aufzubringen und der Versicherungsanstalt in Königshütte zur Verfügung zu stellen, so dass er hier die Zivilverwaltung Ostoberschlesien und den Reichsfinanzminister in der Pflicht sah. Die damaligen Schätzungen gingen von etwa 9800 Empfängern von Ruhegeld aus, deren baldige Auszahlung durch die RfA jedoch nicht ins Gewicht fiel - verglichen mit den ca. 80.000 Invalidenrentnern, für die die LVA zuständig war und deren Rentenanweisungen aufgrund der chaotischen Aktenlage zunächst einmal in den Sternen stand. Als Oberregierungsrat Hartmann für die RfA am 13. September 1939 nach Königshütte reiste, fand er tatsächlich bei seiner Ankunft in der Sozialversicherungsanstalt die Akten und Rentenunterlagen für die Angestellten, anders als die Kollegen der LVA, „fein säuberlich geführt“ im Dienstgebäude vor. Von den früher knapp 200 Angestellten waren etwa 60, die deutsch und polnisch sprachen, wieder zur Arbeit erschienen, so dass einer raschen Wideraufnahme der Rentenzahlungen eigentlich nichts im Wege stand. ${ }^{132}$ Allerdings führte der deutsche Treuhänder die Anstalt zunächst unter seiner Regie weiter, so dass eine Übernahme der Abteilung Angestelltenversicherung der Anstalt durch die RfA, ähnlich wie in Luxemburg und Straßburg, zunächst nicht in Frage kam. Dennoch übernahm ein zusätzlich von der RfA entsandter Oberinspektor die weitere kommissarische Leitung der AV-Abteilung. Als Zahl der Versicherten in der AV wurden 31.600 ermittelt, und immerhin waren, wie sich nun herausstellte, im September noch an ca. 20 Prozent der Rentenempfänger die entsprechenden Auszahlungen vorgenommen worden.

Doch bei der Wiederaufnahme der Rentenzahlungen wurde sofort eine deutliche Unterscheidung getroffen. Bei Besprechungen von Treuhänder und RfA im Reichsarbeitsministerium wurde beschlossen, dass die Zahlung der polnischen Renten der Anstalt Königshütte vorläufig nicht wieder aufgenommen werden sollte, da die polnische Verwaltung kein Bargeld hinterlassen hatte und es zweckmäßig erschien, erst die völlige Beruhigung des ostoberschlesischen Gebietes und die politischen Entscheidungen über dessen endgültiges Schicksal abzuwarten. „Diese Rentenempfänger sind daher an die Fürsorgeämter und auf etwaigen späteren Kriegsschadenersatz zu verweisen. “133 Die Weiterzahlung der deutschen Renten dagegen sollte im Rahmen des technisch Möglichen und aus Reichsmitteln erfolgen, allerdings war mit einer raschen Wiederaufnahme des Postbetriebs nicht zu rechnen, so dass man sich auch hier vor allem logistischen Problemen gegenübersah. Auf Drängen des Treuhänders nahm das

131 Der Bericht vom 15.9.1939, in: ebd.

132 Grießmeyer, Großdeutschland, S. II 259 sowie vgl. den Bericht des ORR Hartmann über die Wiederaufnahme des Betriebes der Sozialversicherungsanstalt in Königshütte vom 18.9.1939, in: ebd. Der Bericht auch in: BArch R 89/3204.

133 Bericht über die Besprechung im RAM vom 18.9.1939 durch ORR Hartmann, in: RfA-Archiv Nr.163. 
Reichsarbeitsministerium jedoch schon kurz darauf die Unterscheidung der deutschen und polnischen Rentenzahlungen zurück, nicht zuletzt, da Ost-Oberschlesien (und auch das Olsa-Gebiet) in Bälde zu deutschen Gebieten erklärt werden würden. Künftig sollten daher auch die polnischen Renten aus Reichsmitteln bezahlt werden. ${ }^{134}$

Gleichzeitig hatte aber die Zivilverwaltung in Ostoberschlesien unter der Prämisse, „dass die Renten zur Beruhigung der Bevölkerung unter allen Umständen gezahlt werden müssten“, die Zahlungen in die eigenen Hände genommen. Mit Hilfe der Landräte und Bürgermeister wurden daher Anfang Oktober aus Mitteln der Zivilverwaltung ohne Anerkennung eines Rechtsanspruches, aber auch ohne jegliche Unterscheidung, die Renten als Unterstützung weitergezahlt. ${ }^{135}$ Und da bereits erste Klagen von den Betroffenen über die Höhe der Renten laut geworden waren, die angesichts der nun rasant steigenden Lebenshaltungskosten erheblich an Wert verloren, erwog der in Kattowitz amtierende $\mathrm{CdZ}$ auch die Gewährung eines prozentualen Teuerungszuschlags zu den Renten. Dieses Ansinnen wurde jedoch nicht nur vom RfA-Beamten mit dem Hinweis abgelehnt, dass nach der zu erwartenden Übernahme der Renten durch das Reich kaum anzunehmen sein würde, dass Teuerungszuschläge weiter gewährt werden könnten und würden. ${ }^{136}$ Für die RfA ging es gleichzeitig aber auch um das Problem der Weiterzahlung der polnischen Renten im Reichsgebiet, die man bislang für Rechnung der polnischen Versicherungsträger ausgezahlt hatte. Das zahlenmäßige Ungleichgewicht war dabei erheblich gewesen: Während die RfA für 452 deutsche Rentner im ehemaligen Polen die Gelder bisher nach Warschau überwiesen hatte, hatte der polnische Versicherungsträger für 4913 polnische Rentner im Reich monatlich umgerechnet ca. 150.000 RM nach Berlin überwiesen. Aufgrund eines Erlasses des RAM wurden diese Renten zwar weitergezahlt, allerdings forderte die RfA nun von den Rentenberechtigten die Vorlage von Nachweisen, dass sie die deutsche Staatsangehörigkeit besäßen oder Volksdeutsche seien, d.h. deutsche Volkszugehörige fremder Staatsangehörigkeit. ${ }^{137}$ Deutscher Volkszugehöriger war in der damaligen Definition derjenige, der sich selbst als Angehöriger des deutschen Volkes bekannte, sofern dieses Bekenntnis durch bestimmte Tatsachen wie Sprache, Erziehung und Kultur bestätigt wurde. Dies konnte bzw. musste entweder durch die Gemeindebehörde oder die Ortspolizei oder aber durch die NSDAP, NSV und andere Gliederungen der Partei erfolgen. Manche Betroffene empfanden dies als Zumutung, auf die sie mit deutlichem Zynismus antworteten.

„Durch Ihre Ausführungen“, so konstatierte man jedoch in der RfA bürokratischnüchtern, ,ist dieser Beweis nicht erbracht. Wir bedauern, Ihnen bis dahin die Rente

134 Vgl. Vermerk Hartmanns über fernmündliche Mitteilung aus dem RAM vom 22.9.1939, in: ebd. 135 Vgl. Vermerk des RfA-Beamten in Königshütte vom 4.10.1939 sowie die Anweisung des Chefs der Zivilverwaltung in Kattowitz an die Landräte vom 3.10.1939, in: ebd.

136 Vgl. Bericht über die Besprechung beim CdZ vom 7.10.1939, in: ebd.

137 Schreiben der RfA an die LVA Schlesien vom 12.10.1939, in: ebd. 

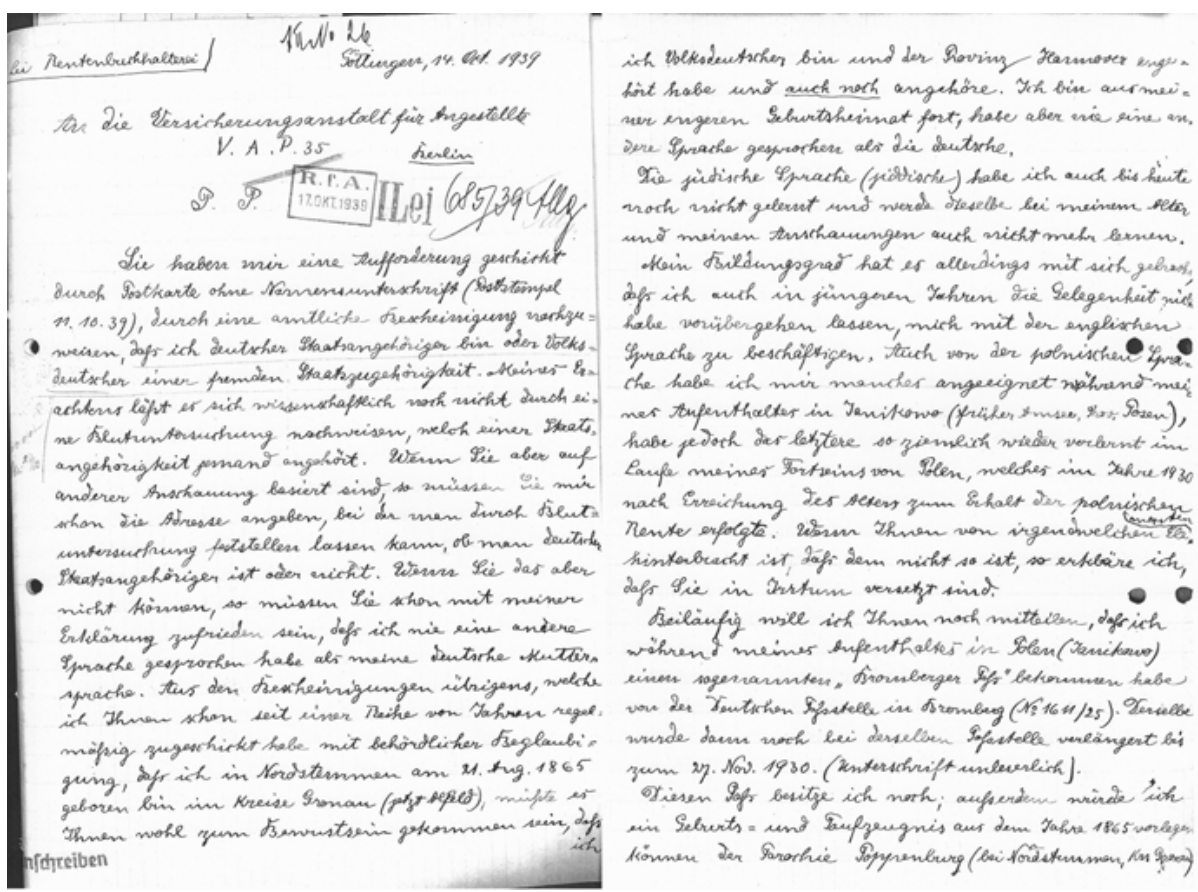

Abb. 55: Beschwerdebrief eines Versicherten vom 14. Oktober 1939 wegen des Volkstumsnachweises

nicht zahlen zu können. “138 Die Übergangsregelung bei der Organisation der Angestelltenversicherung und der Rentenzahlungen in Ostoberschlesien ging jedoch unvermittelt Ende Oktober zu Ende. In der Ruhrstraße erhielt man einen Anruf des RfABeamten aus Königshütte mit dem Hinweis, dass es seit dem 25. Oktober keinen Chef der Zivilverwaltung mehr gebe und dass damit auch kein Geld für die Zahlung der Novemberrenten zur Verfügung stehe - insgesamt benötigte man 437.000 RM. Die Mittel mussten nun von der RfA verauslagt werden. ${ }^{139}$ Am 6. November beauftragte das Reichsarbeitsministerium die RfA mittels Erlass dann formell mit der Durchführung der Sozialversicherung in Ostoberschlesien einschließlich der etwa hinzutretenden Gebiete. Dabei könne sie sich der bestehenden Anstalt in Königshütte bedienen. ${ }^{140}$ Diese firmierte nun als RfA, Amtsstelle Königshütte/OS. ${ }^{141}$ Dieser Auftrag, so heißt es in einem ergänzenden Erlass vom 21. Dezember, bezog sich auch auf die Verwaltung und Instandhaltung sämtlicher in diesen Gebieten vorhandener Vermögensanlagen des Pensions-Angestelltenversicherungsfonds in Warschau. Wie hoch diese Vermögensanlagen waren, wusste zu diesem Zeitpunkt jedoch niemand. Eine Regelung der

138 Schreiben der RfA vom 31.10.1939, in: ebd.

139 Vgl. Vermerk vom 7.11.1939, in: ebd.

140 Der Erlass vom 6.11.1939, in: ebd.

141 Vgl. dazu auch die Präsidialverfügung Grießmeyers vom 8.2.1940, in: RfA-Archiv Nr. 163 a. 
Rentenauszahlung und Durchführung der Angestelltenversicherung war jedoch, wie RfA-Direktor Koch auf einer Besprechung im RAM mitgeteilt bekam, zunächst nur für Ostoberschlesien beabsichtigt. Die Regelung für die übrigen wieder deutsch gewordenen Gebiete Polens blieb vorbehalten und polnische Renten sollten einstweilen nicht mehr gezahlt werden. ${ }^{142}$ Auch für Ostoberschlesien würde geprüft, ob künftig die Renten nur noch an Volksdeutsche zu zahlen wären. Es war beabsichtigt, dort zum 1. Januar 1940 generell das deutsche Sozialversicherungsrecht einzuführen und damit auch die entsprechenden Beiträge zu erheben. Die Frage, wie die bisherigen polnischen Beiträge bei künftigen Leistungen zu berücksichtigen waren, blieb offen. Es sollte zwar versucht werden, aus dem etwa vorhandenen Vermögen der Sozialversicherungsanstalt in Warschau eine Deckung der Anwartschaften zu erhalten, aber da diese vermutlich nur zu einem geringen Teil vorhanden war, wollte man zunächst feststellen, „ob und in welchem Ausmaß die Reichsregierung Leistungen aus der bisherigen polnischen Versicherung überhaupt gewähren will“. ${ }^{143}$ Die Beiträge zur polnischen Angestelltenversicherung hatten durchschnittlich acht Prozent des Entgelts betragen und waren damit um zwei Prozent höher gewesen als im Deutschen Reich. Damit fielen auch die polnischen Versicherungsleistungen durchschnittlich umfangreicher aus als die deutschen, ungeachtet der bestehenden Deckungslage. Eine wesentliche Herabsetzung der bisherigen Leistungen war, so vermutet man in der Ruhrstraße, eigentlich unvermeidlich, allerdings werde diese wohl aus politischen Gründen nicht erfolgen, so dass versicherungsmathematische Bedenken, die bei der RfA vorherrschten, zurücktreten mussten. Aus vielerlei Hinsicht war in Ostoberschlesien bei der Angleichung der bisherigen polnischen Renten an das Reichsniveau eine Anwendung von Maßnahmen und Regelungen, die in Österreich und im Sudetenland erfolgt war, nicht möglich, so dass alles auf eine weitere Differenzierung und Heterogenisierung anstelle des viel beschworenen einheitlichen Reichsrechts hinauslief.

Während das RAM die Dinge weiter in der Schwebe zu halten versuchte, wurde die Sozialversicherungsanstalt in Königshütte jedoch von Anfragen Versicherter und auch neuen Rentenanträgen geradezu überschwemmt. In den Büros türmten sich inzwischen über 1000 unerledigte Anträge, die schon aufgrund der ungeklärten Rechtslage nicht bearbeitet werden konnten, und täglich kamen neue Anträge hinzu. ${ }^{144}$ Niemand wusste zudem, wie die Akten- und Finanzlage der im Generalgouvernement liegenden Warschauer Hauptversicherungsanstalt war, die für die Klärung der vielen offenen Frage jedoch unabdingbar war. Mitte November 1939 reiste RfA-Direktor Koch selbst nach Königshütte und verschaffte sich einen Überblick über die verwaltungstechnischen wie organisatorischen Gegebenheiten und Probleme. Neben allen weitgehend offenen ideologischen Fragen der Anerkennung und Leistungszahlungen bei den

142 Vermerk Kochs vom 13.11.1939, in: RfA-Archiv Nr. 163.

143 Ebd.

144 Vgl. Bericht des RfA-Beamten aus Königshütte vom 17.10.1939, in: ebd. 
polnischen Renten drängte vor allem die logistische Frage der Zustellung nach einer Lösung. Nach wie vor war die RfA auf die Mithilfe von Landräten und Bürgermeistern angewiesen und alle Bemühungen richteten sich darauf, die Zahlung der Renten wenigstens ab Januar 1940 von Berlin aus tätigen zu können. ${ }^{145}$ Sie galten nach wie vor als vorläufige Leistungen. RfA-intern verständigte man sich schließlich auf die Verwaltungsübung, dass die vorliegenden Anträge, soweit sie von Volksdeutschen gestellt wären, nach polnischem Recht berechnet werden sollten und die Hälfte der berechneten polnischen Rente als Vorschuss gezahlt werden sollte. Eine Ablehnung selbst dieser geringen Vorschusszahlungen, so warnte der RfA-Beamte in Königshütte,

würde eine große Härte bedeuten, da auch die Fürsorgestellen die Zahlung von Unterstützungen ablehnen und diese Antragsteller immer wieder an die Sozialversicherungsanstalt verweisen. Nicht nur aus der näheren Umgebung von Königshütte werden die Leute hierhergeschickt, sondern auch aus der weiteren Umgebung. So sind Leute auf Anraten des Wohlfahrtsamtes 3 bis 4 Stunden zu Fuß hierhergekommen, weil sie kein Fahrgeld haben. Noch härter ist es, eine Hinterbliebenenrente abzuweisen, wenn schon Ruhegeld gezahlt worden ist. ${ }^{146}$

Bis Ende November 1939 wurden von der RfA Königshütte so immerhin 4483 polnische Renten im Umfang von insgesamt 140.430 RM vorgeschossen. ${ }^{147}$ Die Verwaltungspraxis, die vom RAM später auch offiziell, aber unter strenger Maßgabe der Bemessung des Vorschusses innerhalb der voraussichtlichen zukünftigen Rente gutgeheißen wurde, macht deutlich, dass es der RfA vor allem darum ging, die vielfach heterogenen und bislang oft nur bruchstückhaft bekannten Pläne im RAM über die endgültige Regelung der Rentenversicherung in den Ostgebieten in eine möglichst leicht und einfach zu gestaltende Durchführungsverordnung zu gießen. Das bedeutete etwa auch, dass die Rentenzahlung nicht an aufwändigen Volkstumsnachweisen festgemacht wurde; vielmehr wurden die Renten nicht nur an Volksdeutsche, sondern zumindest auch an die in Ostoberschlesien wohnenden Polen gezahlt. Die neuen Renten sollten nach deutschem Recht berechnet, für die polnischen Beiträge mithin auch die deutschen Steigerungsbeträge gewährt werden und die laufenden Renten sollten ebenfalls nach deutschem Recht umgerechnet werden. ${ }^{148}$ Da das RAM die RfA explizit zu einer Stellungnahme zu der Frage aufgefordert hatte, in welcher Weise bei der Überleitung der polnischen Angestelltenversicherung zunächst in Ostoberschlesien auf die deutsche Angestelltenversicherung etwaige Anrechnungen berücksichtigt werden sollten, besaß die Behörde durchaus eine potenzielle Einflussmöglichkeit auf die spätere gesetzliche Regelung. Diese wurde immer dringender, da es, wie RfA-Regierungsrat Gaber seinerseits bei einer Inspektionsreise nach Königshütte Ende No-

145 Vgl. den Bericht Kochs über „meine Feststellungen bei der Angestelltenversicherungsanstalt in Königshütte“ vom 13.11.1939, in: RfA-Archiv Nr. 163.

146 Schreiben der RfA Königshütte an die RfA Berlin vom 20.11.1939, in: ebd.

147 Vgl. den statistischen Vermerk, in: RfA-Archiv Nr. 165.

148 Vgl. das streng vertrauliche Schreiben der RfA Berlin an die RfA Königshütte vom 28.11.1939, in: RfA-Archiv Nr. 163. 
vember feststellte, nach wie vor Regionen und Gemeinden gab, in denen noch immer keine Rentenzahlungen erfolgt waren. ${ }^{149}$ Gaber war es allerdings auch, der dabei von sich aus die bislang noch von keiner Seite angesprochene Frage der Zahlung von Renten an Juden anschnitt. „Ich habe“, so notierte er, „soweit die Frage an mich gerichtet wurde, bisher stets erklärt, dass eine Zahlung an Juden nicht in Frage kommt. Ich bitte, auch hierüber um nähere Anweisung, da gerade im Dombrowaer Kohlengebiet teilweise über 50 Prozent Juden sind.“150

Bis Anfang Dezember hatte sich der Umfang der von der RfA geleisteten vorschussweisen Zahlungen an Rentenberechtigte in den ehemals polnischen Gebieten auf sechs Mio. RM summiert, die nach wie vor aus eigenen Mitteln vorgestreckt wurden. Welche endgültige Regelung getroffen werden würde und wie auch die Vergütung der Mittel erfolgen würde, war nach wie vor ungewiss, wie auch RfA-Vizepräsident Schaefer auf Nachfragen in der Beiratssitzung im Dezember 1939 eingestehen musste. ${ }^{151}$ Und mit Danzig, Ostoberschlesien und dem Warthegau standen weitere Bezirke und Gebiete an, die „viel neue Arbeit und neue Belastung [bedeuten]“ und für den RfA-Haushalt „neue Ungewissheiten und neue Fragezeichen bringen“. ${ }^{152}$ Anfang Dezember legte das RAM endlich einen Entwurf zur Regelung der Sozialversicherung in den Ostgebieten vor. ${ }^{153}$ Darin wurde erstens bestimmt, dass Rentenzahlungen deutscher Versicherungsträger an Berechtigte, die im Generalgouvernement wohnten, zunächst nicht aufgenommen würden. Die Zahlung von Renten an Berechtigte in den ehemaligen ostoberschlesischen polnischen Gebieten, die inzwischen der Provinz Schlesien eingegliedert worden waren, konnte dagegen, zweitens, ohne Rücksicht auf die bisherige Staatszugehörigkeit aufgenommen werden. Berechtigte, die sich offenkundig in deutschfeindlichem Sinne betätigt hatten, erhielten jedoch keine Rente. Drittens schließlich konnten Renten an Berechtigte in den übrigen ehemaligen polnischen Gebieten, d.h. im Reichsgau Danzig-Westpreußen, Reichsgau Posen und den der Provinz Ostpreußen eingegliederten Gebieten erst nach einer Einzelfallprüfung wiederaufgenommen werden. Diese musste vom Reichsstatthalter bzw. den zuständigen Regierungspräsidenten vorgenommen werden und sicherstellen, dass Renten hier grundsätzlich nur an Volksdeutsche erfolgten. „Nationalpolen“ konnten nur im Einzel- bzw. Ausnahmefall die Rente erhalten, auch wenn sie eigentlich rentenberechtigt waren. Zur Durchführung der Prüfungen hatten die Versicherungsträger in den genannten Gebieten entsprechende Listen mit den prinzipiell Berechtigten aufzustellen. Zur Regelung der Auszahlung der Renten der polnischen Versicherungsträger an Berechtigte erging ein eigener Erlass.

149 Vgl. Auszug aus dem Zwischenbericht über die Dienstreise nach Königshütte vom 24.11.1939, in: RfA-Archiv Nr. 165.

150 Ebd.

151 Vgl. Niederschrift der zehnten Beiratssitzung vom 11.12.1939, S. 8, in: BArch R 89/3470.

152 Ebd.

153 Vgl. den Erlass vom 7.12.1939, in: RfA-Archiv Nr. 128. 
Gleichsam flankierend dazu sandte das RAM an alle Versicherungsträger den Entwurf einer endgültigen „Verordnung zur Einführung der Reichsversicherung in den der Provinz Schlesien eingegliederten ehemals polnischen Gebieten“. Auch darin wurde die bereits in dem Erlass von Anfang Dezember deutliche Ausrichtung der Sozialversicherungspolitik auf die rassisch-völkischen Ziele des NS-Regimes sichtbar und festgeschrieben. Den Volksdeutschen und den deutschen Staatsangehörigen wurde darin „die ihnen gebührende Vorzugstellung gewährt, während fremdvölkische Volkszugehörige von besonderen Vorzügen ausgeschlossen bleiben“. ${ }^{154}$ Für die Umrechnung wurde als amtlicher Kurs statt ein Zloty = einer RM ein Kurs von eins Zloty zu 0,50 Reichspfennigen festgesetzt und die Renten wurden auf die Höhe des Reichsrechts herabgesetzt. Volksdeutsche und deutsche Staatsangehörige erhielten die Differenz zwischen der bisherigen und der umgerechneten Rente aus Mitteln des Reiches als Zusatzrente. Polnische Volkszugehörige erhielten jedoch nur die umgerechnete, massiv gekürzte Rente. Was das für die Betroffenen tatsächlich bedeutete, machte eine Berechnung einiger exemplarischer Fallbeispiele durch den RfA-Beamten in Königshütte deutlich, der die in seinen Augen brisanten Ergebnisse streng vertraulich per Eilboten an Vizepräsident Schaefer und Direktor Koch sandte. Nach polnischem Recht betrug demnach eine Rente umgerechnet 149 RM im Monat, nach neuem deutschem Recht jedoch nur noch 64,88 RM. ${ }^{155}$ Weitere Fallbeispiele fielen ähnlich aus, d.h. die Berechnungen nach deutschem Recht ergaben noch nicht einmal die Hälfte der Renten nach polnischem Recht, in vielen Fällen war es sogar nur noch etwa ein Drittel. ${ }^{156}$ Das war eine willkürliche, aber vom RAM als Gesetzgeber bewusst gewollte Kürzung, die für die betroffenen ca. 1200 Rentenempfänger als untragbar erschien. Die zentrale Frage aber war, wie die deutsche Volkszugehörigkeit festgestellt werden sollte. In den Abschnitten der künftigen Regelung fehlte zudem eine Bestimmung darüber, welchen Zuschlag die Volksdeutschen erhalten sollten. Und dann schuf das neue Recht auch innerhalb dieser Gruppierung ein deutliches Unrecht zwischen Altund Neurentnern, denn die neu berechneten, aber bereits laufenden Altrenten waren bei weitem besser als die Renten, die sich aus neuen Versicherungsfällen ergaben. ${ }^{157}$

An diesen Privilegierungen bzw. Diskriminierungen des Gesetzes nahm man bei der RfA in Berlin allerdings keinen Anstoß. Die Beamten dort trieb vielmehr das Problem der hinreichenden regionalen Abgrenzung der Berechtigten und vor allem die Umrechnungsfrage um. Da für den größten Teil der Rentner die Umrechnung eine sehr erhebliche Herabsetzung der Rentenbezüge zur Folge hatte, waren viele Berufungen zu erwarten, die das Umrechnungsverfahren erheblich verzögern und wahrscheinlich für lange Zeit noch die Beibehaltung der Dienststelle in Königshütte not-

154 Entwurf vom 12.12.1939, in: RfA-Archiv Fach 119, Nr. 1.

155 Vgl. Schreiben der RfA Königshütte an die RfA Berlin vom 4.12.1939, in: RfA-Archiv Nr. 163.

156 Vgl. dazu etwa den Fall eines polnischen Rentners, der von der RfA bis Dezember nach altem Recht umgerechnet 139,70 RM erhalten hatte, seit 1. Januar 1940 jedoch nur noch 53,40 RM ausbezahlt bekam.

157 Vgl. Schreiben der RfA Königshütte an die RfA Berlin vom 18.12.1939, in: ebd. 
wendig machen würden. Daher schlug man vor, Rechtsmittel gegen den Umrechnungsbescheid einfach auszuschließen. ${ }^{158}$ Zwischen RAM und RfA gab es auch weiterhin eine vielfältige Abstimmung und Kommunikation, wie die zahlreichen handschriftlichen Vermerke von RfA-Direktor Koch bezeugen.

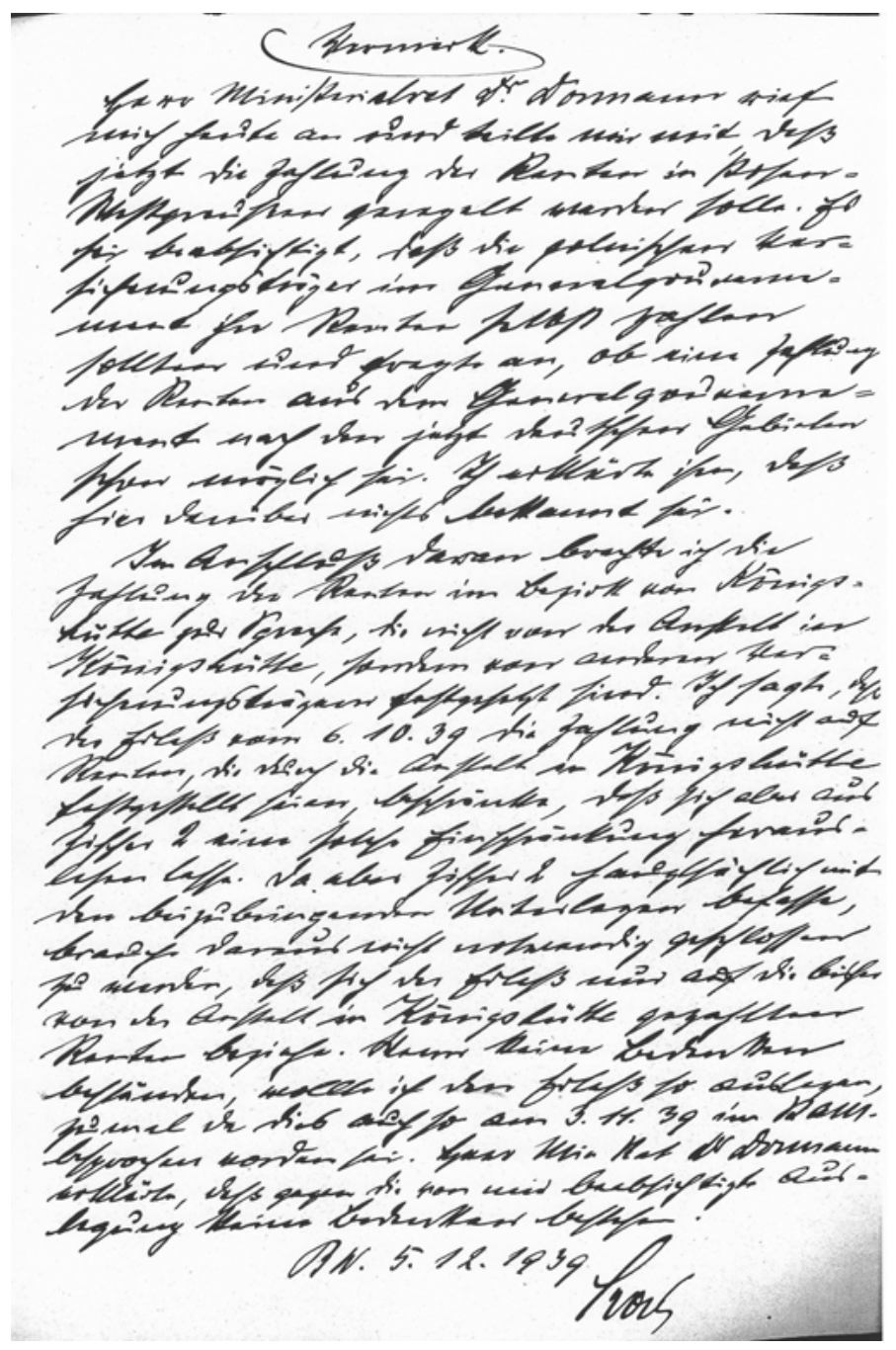

Abb. 56: Handschriftlicher Vermerk von RfA-Direktor Koch vom 5. Dezember 1939

158 Vgl. Vermerk Kochs als Äußerung zu dem Entwurf vom 15.12.1939, der dann auch in einem entsprechenden Schreiben Grießmeyers an das RVA Niederschlag fand, in: RfA-Archiv Fach 119, Nr. 1. 
Am 16. Januar 1940 erließ das RAM dann die Verordnung über die Einführung der Reichsversicherung in Ostoberschlesien mit allen bereits im Entwurf enthaltenen Unterscheidungen zwischen volksdeutschen und polnischen Renten. Nur wenig später sandte Grießmeyer seitens der RfA an das RVA eine lange Liste mit noch offenen Fragen, deren Regelung man zur Umsetzung der Angestelltenversicherung in einer möglichst bald zu erlassenden Durchführungsverordnung für unabdingbar hielt. ${ }^{159}$ Ein Punkt dabei war, dass die neu zu berechnenden Renten gemäß der Verordnung erst zum 1. Januar 1940 gewährt werden konnten und keine rückwirkende Geltung vorgesehen war. Das widersprach jedoch der Tatsache, dass die laufenden Renten bereits vom 1. September 1939 an von der RfA übernommen worden waren. Eine entsprechende nachträgliche Bewilligung und Neuberechnung der Renten erschien daher im Interesse der Betroffenen (deutschen) Rentner nur billig. Kopfzerbrechen verursachte darüber hinaus auch der versicherungsrechtliche Status der Angestellten aus dem Altreich, die bald in größerer Zahl vom Reich in die verschiedenen, im Zuge der Besatzungsherrschaft aufgebauten, Behörden der Ostgebiete abgeordnet worden waren. Da das Angestelltenversicherungsgesetz dort bisher noch nicht eingeführt worden war, verloren diese nun plötzlich ihre Versicherungspflicht und damit auch die entsprechenden Beitragsanteile der bisherigen Arbeitgeber. ${ }^{160}$ Um dem abzuhelfen, machte sich die RfA daher gegenüber dem RAM für eine Ausdehnung der Versicherungspflicht auch über die Reichsgrenzen hinaus stark. Ungeklärt war auch, ob und welche Spruchbehörde in Streitfällen in den neuen Gebieten zuständig war, was darauf verweißt, dass die Forderung der RfA nach Ausstellung nicht berufungsfähiger Bescheide über die neu festgesetzten Renten vom RAM nicht beachtet worden war. Zudem lagen bereits zahlreiche Anträge auf Beitragserstattung nach Reichsrecht vor, ohne dass aber geregelt gewesen wäre, ob und inwieweit hierbei eine Erstattung der polnischen Beiträge gewährt werden könnte - was die RfA schon aus verwaltungspragmatischen Gründen befürwortete.

Die groß verkündete Auszahlung der neuen Renten zum Januar 1940 funktionierte aber auch wegen anhaltender logistischer Probleme bei Rentenlisten, Adressenverzeichnis und Postzustellung nur leidlich. Am 23. Januar schickte der RfA-Beamte in Königshütte geradezu einen Hilferuf nach Berlin, da mindestens 300 Januarrenten offenbar immer noch nicht ausgezahlt waren, „denn die Rentner sind schon zum zweiten und dritten Male hier gewesen und werden durch die Not getrieben immer wieder hier erscheinen, um wegen Auszahlung der Rente nachzufragen. Bei dieser Sachlage ist an ein geordnetes Arbeiten nicht mehr zu denken. " ${ }^{\text {"161 }}$ Dazu kamen nun vermehrt dringende Anfragen von Ortsbürgermeistern und kommunalen Wohlfahrtsämtern, die von der RfA-Amtsstelle die Rückzahlung der in der Übergangszeit zwischen September und Dezember 1939 übernommenen Vorschusszahlungen an die

159 Vgl. Schreiben vom 13.2.1940, in: BArch R 89/3204.

160 Vgl. dazu das Schreiben der RfA an den Generalgouverneur für die besetzten polnischen Gebiete vom 18.2.1940, in: RfA-Archiv Fach 119, Nr. 1.

161 Schreiben vom 23.1.1940, in: RfA-Archiv Nr. 163 a. 
(auch polnischen) Rentner forderten. Ende Januar reiste daher erneut RfA-Direktor Koch nach Königshütte, um sich einen direkten Eindruck von der Geschäftslage bei der Sozialversicherungsanstalt zu verschaffen und Möglichkeiten einer eventuellen Entlastung zu finden. Demnach erschien es zweckmäßig, in Königshütte nur noch die unerledigten Sachen durch Bescheide abzuarbeiten, die Umrechnung der laufenden Renten aber in Berlin vorzunehmen, sobald die Akten dorthin transportiert worden wären. ${ }^{162}$ Kopfzerbrechen machte aber vor allem die Frage der gesetzlich vorgeschriebenen Feststellung der deutschen Volkszugehörigkeit. „Die Umrechnung kann jetzt auch deswegen noch nicht in Angriff genommen werden, weil der Nachweis der deutschen Volkszugehörigkeit, [der für die Höhe der Rente ausschlaggebend ist], noch nicht erbracht werden kann“, notierte Koch in seinem Bericht. ${ }^{163}$ Auf Nachfrage beim zuständigen Regierungspräsidenten in Kattowitz erfuhr man, dass die Feststellungen der deutschen Volkszugehörigkeit noch gar nicht begonnen hatten. Man rechnete dort unumwunden mit einer langen Zeit für die erforderlichen Maßnahmen, „unter Umständen [wird die Feststellung] mehrere Jahre dauern““. ${ }^{164}$ Der Regierungspräsident hielt es daher auch wegen der zu befürchtenden Beunruhigung der Rentner für erforderlich, von dem im Gesetz vorgeschriebenen Procedere abzuweichen, die Renten in der bisherigen Höhe uneingeschränkt an alle Berechtigten einstweilen weiterzuzahlen und die Rentner erst nachträglich zum Nachweis der deutschen Volkszugehörigkeit aufzufordern.

Das Vorgehen des Regierungspräsidenten schlug erhebliche Wellen und illustriert exemplarisch an einem kleinen, für alle Betroffenen aber nicht unbedeutenden Problemfeld die sich im Laufe des Krieges ergebenden Macht- und Kompetenzkonflikte zwischen zentralen Reichsbehörden (in diesem Fall das RAM), diversen Parteistellen und den zivilen/militärischen Besatzungs- und Verwaltungsbehörden, in die die RfA nun als zuständiger Versicherungsträger hineingezogen wurde. Am 2. Februar erließ der Kattowitzer Regierungspräsident eine entsprechende Verfügung über das zeitliche Procedere von Rentenneuberechnung, Auszahlung und Nachweis der deutschen Volkszugehörigkeit, der sich auch die RfA in ihrem Verwaltungsverfahren zunächst unterwarf. Die Renten wurden nun nach den neuen Bestimmungen unabhängig von der Volkstumszugehörigkeit der Berechtigten umgerechnet und neu festgestellt, und den deutschen Rentnern blieb es dann überlassen, nachträglich unter Vorlage des entsprechenden Nachweises die Zusatzrente zu beantragen. ${ }^{165}$ Das war nicht unbedingt im Sinne der betroffenen Rentner, die damit ja zunächst einmal mit den gekürzten umgerechnete Renten auskommen mussten. Unruhe und Beschwerden waren damit vorprogrammiert, so dass der Regierungspräsident bald eine andere Vorgehensweise präferierte: Von den Versicherungsträgern sollten Listen aller in Frage kommenden Rentenempfänger angefordert werden, von denen er dann aufgrund der

162 Vgl. Bericht über die Dienstreise vom 30.1. bis 2.2.1940, in: ebd.

163 Ebd.

164 Ebd.

165 Vgl. Schreiben der RfA Berlin an die RfA Königshütte vom 22.2.1940, in: RfA-Archiv Nr. 163 a. 
Berichte der örtlichen Organe diejenigen streichen wollte, die unter keinen Umständen für eine Zusatzrente in Frage kamen. Aufgrund dieser „,negativen Auslese“ sollten dann - vorläufig - die unbedenklichen Rentenempfänger die Zusatzrente von Amtswegen erhalten. ${ }^{166}$ Von den Invalidenversicherungsträgern wurde dieser Plan als undurchführbar abgelehnt, für die RfA jedoch erschien er durchaus praktikabel und würde „durch die Ermöglichung eines sofortigen abschließenden Rentenbescheids eine Beunruhigung der Versicherten vermeiden und eine wesentliche Arbeitsersparnis bedeuten“. ${ }^{167}$ Die RfA befand sich allerdings insofern in einer misslichen Lage, als das Reichsarbeitsministerium, wie man gegenüber Direktor Koch auf einer Besprechung Anfang Februar klargestellt hatte, das Vorgehen des Regierungspräsidenten in Kattowitz nicht billigte. ${ }^{168}$ Es gelte auf jeden Fall auszuschließen, so die Haltung im RAM, dass Polen in den Genuss der höheren (bzw. bisherigen) Renten kämen. Allerdings war man bereit, vorläufig anstelle eines amtlichen Volkstumsnachweises die Vorlage einer Bescheinigung einer deutschen Dienststelle oder Parteistelle im Sinne einer Glaubhaftmachung zu akzeptieren.

Doch die Angelegenheit war damit noch nicht erledigt. Anfang März 1940 lud der Regierungspräsident in Kattowitz zu einer eingehenden Besprechung des strittigen Verfahrens ein, bei der neben Vertretern der Invaliden-, der Unfallversicherung und der Reichsknappschaft auch der Polizeipräsident und der NSDAP-Kreisleiter sowie zwei hochrangige Beamte der RfA teilnahmen. ${ }^{169}$ Das vorgeschlagene Listenverfahren wurde dabei nach intensiver Diskussion wieder fallen gelassen, da auch dieses, insbesondere für die Invalidenversicherungsträger mit ihren ca. 70.000 Rentenempfängern monatelang dauern würde. Es meldete sich dabei auch der örtliche Kreisleiter der NSDAP zu Wort, er halte es bemerkenswerterweise für

untragbar und ungerecht in der Verordnung vom 16. Januar 1940, dass die Polen weniger bekommen sollen als die Volksdeutschen. Ebenso wie die Löhne müsste auch die spätere Versorgung für beide gleich sein. Es sei bereits große Unzufriedenheit über die Regelung der Verordnung entstanden. ${ }^{170}$

Die Partei lege Wert darauf, dass alle die erhöhten Renten bekämen, mit Ausnahme derjenigen, die auf der Aussiedlungsliste stünden, d.h. wegen deutschfeindlichen Verhaltens evakuiert werden würden. Man könne doch sagen, dass letzen Endes „999/ 10 Prozent der Bevölkerung“ der neuen Gebiete als deutsche Volkszugehörige anerkannt werden würden. ${ }^{171}$ Diesem Votum stimmte auch der örtliche Polizeipräsident $\mathrm{zu}$, der die unterschiedliche Behandlung der Volksdeutschen und der Polen bei den

166 Vgl. Schreiben der RfA Königshütte an die RfA Berlin vom 28.2.1940, in: ebd.

167 Ebd.

168 Vgl. Vermerk Kochs über die Besprechung im RAM vom 6.2.1940, in: ebd.

169 Vgl. dazu die Niederschrift der Besprechung vom 5.3.1940, in: BArch R 89/3204 sowie auch RfAArchiv Nr. 163 a.

170 Ebd.

171 Vgl. ebd. 
Renten für äußerst bedenklich hielt und dazu riet, ohne Rücksicht auf Verluste die gleichen Renten zu zahlen. Alle Anwesenden kamen daraufhin zu dem einvernehmlichen Schluss, dass eigentlich die gesamte Bevölkerung der neuen Gebiete als volksdeutsche anzusehen war und daher ohne jeglichen Nachweis auch allen Rentenempfängern bis auf weiteres und vorläufig die Zahlung der höheren Renten gewährt werden sollte.

Zum Schluss ersuchte der Vertreter des Regierungspräsidenten zur Verhinderung weiterer Beunruhigung der Bevölkerung noch darum, jetzt über die deutsche Volkszugehörigkeit überhaupt nicht mehr zu reden und zu schreiben und die Streitfrage gar nicht mehr zu erwähnen, insbesondere auch die Bevölkerung nicht mehr darauf hinzuweisen. ${ }^{172}$

Doch das Reichsarbeitsministerium machte einen Strich durch diese Rechnung. Ende März mussten sich RVA wie RfA einen Rüffel über das geplante Abweichen von der doch mit Direktor Koch besprochenen Vorgehensweise gefallen lassen. Auf den Nachweis der Volkszugehörigkeit oder zumindest die Glaubhaftmachung könne nicht verzichtet werden, ansonsten sei die Zusatzrente nicht zu zahlen, so hieß es kategorisch aus dem Ministerium. ${ }^{173}$ Die RfA wurde daher über das RVA offiziell angewiesen, so zu verfahren und auch der Regierungspräsident von Kattowitz bekam entsprechende Post aus dem RAM.

Tatsächlich hatte sich die RfA jedoch beim RVA abgesichert und dem Regierungspräsidenten gegenüber betont, dass man ohne Ermächtigung durch die Aufsichtsbehörde keine Befugnis habe, mit der unterschiedslosen Weiterzahlung der Renten fortzufahren. Nach der Besprechung in Kattowitz bat man daher beim RVA umgehend um Entscheidung darüber, wie nun verfahren werden sollte angesichts des Dilemmas zwischen politisch bedenklich erscheinendem Einfordern eines Volkszugehörigkeitsnachweises und unerwünschter Auszahlung der verminderten umgerechneten Renten an die deutschen Volkszugehörigen. ${ }^{174}$ Nach Ansicht der Behörde drängte die Zeit, da an die nicht volksdeutschen Rentner bereits und bis zur Durchführung der Umrechnung „erhebliche Beträge zu Unrecht“ ausgezahlt sein würden, wobei man, auch aus verwaltungsorganisatorischen Gründen grundsätzlich auf eine Rückforderung verzichten wollte. Die RfA schwenkte denn auch umgehend auf die Haltung der vorgesetzten Aufsichtsbehörde ein. Ende Mai 1940 informierte Grießmeyer den Regierungspräsidenten in Kattowitz darüber, dass dessen Meinung über die Gewährung von Zusatzrenten an deutsche Volkszugehörige rechtlich irrig sei, es vielmehr darum gehe,

dass die Renten der Berechtigten fremder Volkszugehörigkeit gekürzt werden müssen. Da wir einstweilen alle laufenden Renten in bisheriger Höhe weitergezahlt haben, obwohl sie den

172 Ebd. Vgl. dazu auch das Schreiben des Regierungspräsidenten an die RfA über das geplante Procedere vom 12.3.1940, in: ebd.

173 Vgl. Vermerk vom 5.4.1940 über ein Telefonat mit dem RAM, in: ebd.

174 Vgl. das Schreiben Grießmeyers an das RVA vom 16.3.1940, in: RfA-Archiv Nr. 163 a. 


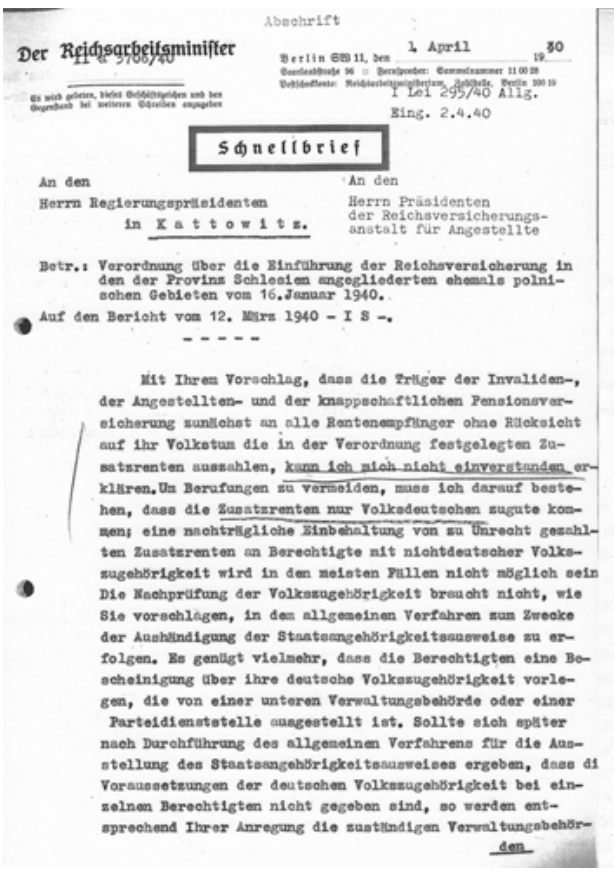

Uen d1e Versioherungstrilger benachriohtigem, dealt die Zahlung der zusatzrente elngestellt werden kann. Auf die $\mathrm{Br}-$ atattung der etwa su Un echt gezahlten Zusatzrenten kann dann verzlehtet werden.

Auch auf den Geblete der Unfallvereloherung muss 1oh daran feathelten, dass die Unrechnung der Renten orst exfolgt, wenn der Bereohtigte die genannte Bescheinigung e1ner unteren Verwaltungebehrrde oder einer Parteldienstatelle vorlegt.

Wonn hiernaoh der Hachwe1s der Volkszugehorigkelt von dem allgezeinen Verfahren fur die Aushlindigung der Stantsangehbrigke1tesuewelse abgetrennt und in einfacheter Form belgebracht' wird, so wird es mgglloh sein, den Volked schen in kellrzester Zelt die hoheren Lelstuncen zukommen zu lassen. Im Ubrigen welse loh daraus hin, daes sioh in den ubrigen elngegliederten Ostgobleten und in Genoralgouvernement für die besotzten polnieohen Geblete das vereinfachte Verfahren Pur den Nachwols der deutschen Volkesugehrrigke1t bewlihrt hat.

Abb. 57: Schnellbrief des RAM an den Regierungspräsidenten in Kattowitz vom 1. April 1940 betr. Einführung der Rentenversicherung in den angegliederten polnischen Gebieten

Rentnern, die nicht deutsche Volkszugehörige sind, in dieser Höhe nicht mehr zustehen, ist für uns die Feststellung der Volkszugehörigkeit besonders dringlich, um weitere Überzahlungen an solche Rentner möglich zu vermeiden. ${ }^{175}$

Entgegen den Wünschen des Regierungspräsidenten drängte man nun auch auf eine umgehende öffentliche Information der Betroffenen und sandte schließlich Ende April eine offizielle Aufforderung seitens der RfA an die Rentner zur sofortigen Nachweisbeibringung. Grießmeyer ging sogar so weit, den Regierungspräsidenten für die Verzögerungen des Verfahrens verantwortlich zu machen:

Da die Rente in der bisherigen Höhe nur noch den Rentnern deutscher Volkszugehörigkeit gezahlt werden kann, werden diese Rentner geschädigt, wenn ihnen die Beschaffung des Nachweises erschwert wird. Wir werden demnächst mit der Umrechnung der laufenden Renten beginnen. Allen Rentnern, die nicht in der Lage sind, ihre deutsche Volkszugehörigkeit nachzuweisen, können wir dann nur noch die umgerechnete meistens erheblich niedrigere Rente auszahlen, solange sie nicht den Nachweis der deutschen Volkszugehörigkeit erbringen. ${ }^{176}$

175 Schreiben vom 25.5.1940, in: RfA-Archiv Nr. 163 a. Vgl. auch den zunehmend konfrontativen Schriftwechsel der RfA mit dem Regierungspräsidenten zwischen März und Juni 1940, in: ebd.

176 Ebd. 
In der Folgezeit verhielt sich die RfA bei der Anerkennung der Volkszugehörigkeitsnachweise dann weit radikaler und kompromissloser als die örtlichen Parteistellen. Der Ortsgruppenleiter von Teschen setzte sich etwa vehement für die Anerkennung der sogenannten Slonsaken ein, d.h. deutschfreundliche Schlesier, „die vielleicht ihre Deutschstämmigkeit nicht so leicht nachweisen können“, bei denen es sich aber „um wirklich deutschfreundliche Leute handelt““ ${ }^{177}$ Dutzende einfache Bescheinigungen von Parteistellen wurden von der RfA jedoch als ungenügend abgelehnt. ${ }^{178}$
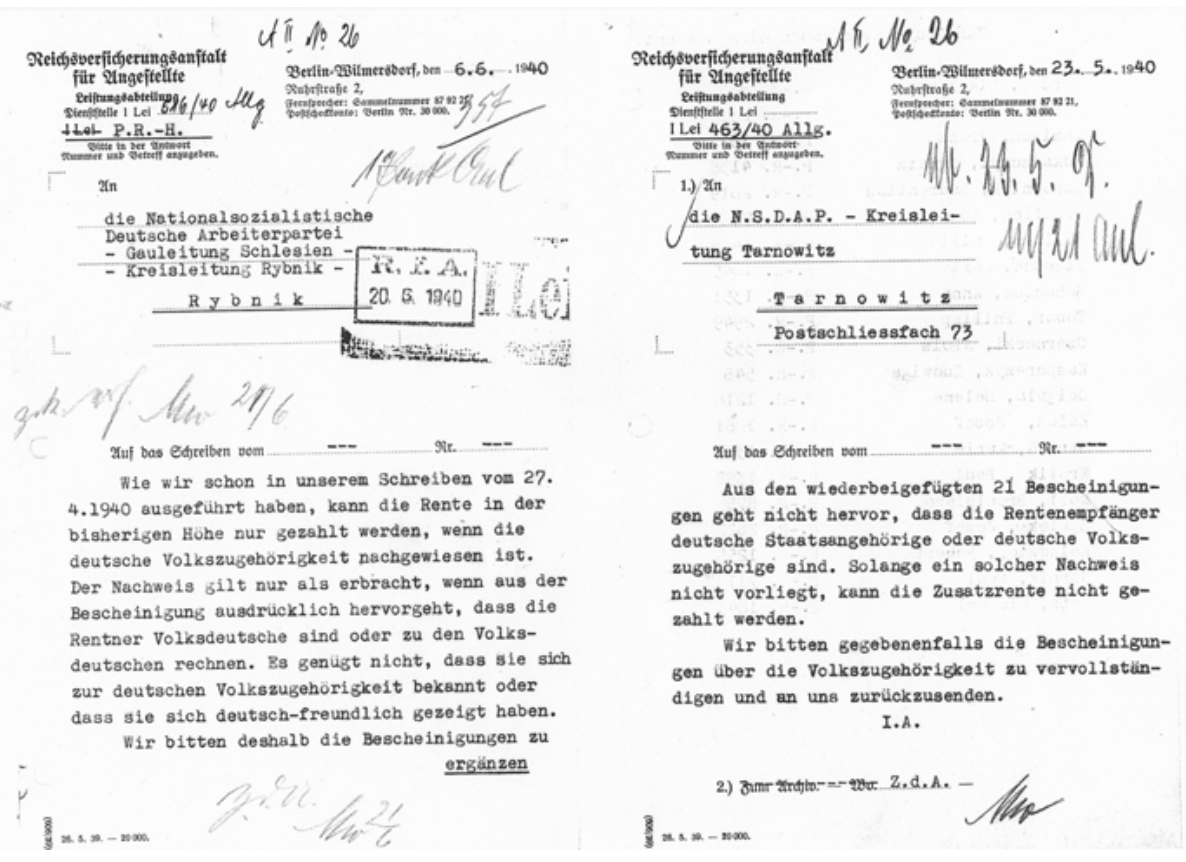

Abb. 58: Schreiben der RfA an Parteistellen wegen nicht anerkannter Nachweise der deutschen Volkszugehörigkeit vom Mai/Juni 1940

Um sich abzusichern, legten die RfA-Beamten dem Reichsarbeitsministerium sogar eine Reihe von eingegangenen und als unzureichend empfundenen Volkszugehörigkeitsbescheinigungen vor. ${ }^{179}$ Dennoch bekam die RfA immer wieder Schreiben verschiedener Parteistellen und NS-Amtsträger, die Einspruch gegen die ablehnenden Bescheide bzw. die Nichtanerkennung der Volkszugehörigkeitsnachweise durch die Behörde erhoben.

177 Schreiben der NSDAP-Ortgruppenleitung an die RfA vom 18.6.1940, in: RfA-Archiv Nr. 163 b. $178 \mathrm{Vgl}$. dazu auch das genervte Schreiben des NSDAP-Kreisleiters von Bendzin an die RfA vom 13.7. 1940, in: ebd.

179 Vgl. dazu den ausführlichen Vermerk vom 5.6.1940, in: RfA-Archiv Nr. 163 a. 
Die Umrechnung und Auszahlung der Renten sollte sich bis in den Frühsommer 1941 verzögern. Das lag zum einen am eher schleppenden Eingang der Volkszugehörigkeitsnachweise. Ende Juni 1940 waren von den insgesamt 4895 Ruhegeldempfängern erst 2746 Nachweise oder hinreichende Bescheinigungen über ihre deutsche Volkszugehörigkeit eingegangen, bei 1949 prinzipiell Berechtigten fehlten noch die Nachweise, ca. 200 galten explizit als „nichtvolksdeutsch“. Bei den insgesamt 2179 Empfängern von Hinterbliebenenrente sah es ähnlich aus, allerdings war hier die Quote der nicht eingegangenen oder nicht volksdeutschen Nachweise mit 781 niedriger. ${ }^{180}$ Da der Prozentsatz der noch fehlenden Nachweise mit 44,3 bzw. 35,8 deutlich über dem Bevölkerungsanteil der Polen in den ostoberschlesischen Gebieten lag, war davon auszugehen, dass eine noch erhebliche Anzahl volksdeutscher Rentner mit ihrer Nachweiserbringung im Rückstand war und daher nur die niedrige polnische Rente erhielt. Zum anderen aber fehlte nach wie vor eine hinreichende Gesetzesgrundlage. „Von der Umrechnung ist bisher deshalb abgesehen worden, weil noch Ausführungsbestimmungen zu erwarten sind“, heißt es lapidar in einem Schreiben der RfA an den Landrat von Teschen von Mitte März 1941. ${ }^{181}$ Dazu kam, dass die Auszahlung der Renten in den verschiedenen Gebieten und Gemeinden, die zum Verantwortungsbereich der Amtsstelle Königshütte gehörten, lange Zeit geradezu abenteuerlich war. Zahlreiche Rentner erhielten trotz inzwischen aufgenommener Postüberweisung nach wie vor keine Zahlungen, so dass bei der Post erst mühsam durch Laufzettel der Verbleib der Renten eruiert werden musste. ${ }^{182}$ In einer Reihe von Landkreisen war nach wie vor kein Postzahlungsverkehr möglich, so dass die Renten hier persönlich durch polnische Angestellte, ausgestattet mit hohen Bargeldbeträgen, in die Orte gebracht werden mussten. Einige der Gebiete waren höchst unsicher und viele Bürgermeister sprachen kein Wort Deutsch. Zudem war mancherorts auch noch gar nicht entschieden, ob einzelne Gebietsteile bei Oberschlesien verbleiben oder dem Generalgouvernement angegliedert würden. Zudem befanden sich die Akten der in diesen Regionen wohnenden Rentner in Warschau und Lemberg. Dass die Rentenauszahlung angesichts all dessen „etwas unübersichtlich ist“, wie der RfA-Beamte in seinem Reisebericht notierte, war daher maßlos untertrieben. ${ }^{183}$

Ende Juli 1940 fand daher im Reichsarbeitsministerium eine Besprechung mit den beteiligten Versicherungsträgern statt, in der an Hand der bisherigen praktischen Erfahrungen bei der Durchführung der Reichsversicherung in den oberschlesischen Gebieten „Material“ für eine eventuell notwendig werdende Durchführungsverordnung gewonnen werden sollte, „,auch soweit es sich ergänzend um die Schaffung

180 Vgl. den Vermerk vom 29.6.1940, in: RfA-Archiv Nr. 165.

181 Das Schreiben vom 12.3.1941, in: RfA-Archiv Nr. 163 b.

182 Vgl. dazu den Bericht von Amtsleiter Minow an Grießmeyer über die Dienstreise vom 2. bis 9.3., in: RfA-Archiv Nr. 163 a.

183 Ebd. 
völlig neuen Rechts handelt““ ${ }^{184}$ Ziel seien eine möglichste Verwaltungsvereinfachung und ein Ausschalten bisher polnischer Rechte als Grundlage laufender Rentengewährung. ${ }^{185}$ Aber die dann im Dezember 1940 durch das Reichsarbeitsministerium vorgelegte Verordnung regelte zunächst nur die genaue Höhe der Zusatzrenten. Demnach wurden je nach Rentenhöhe gestaffelt zwischen 72 und 96 RM jährlich zusätzlich gewährt, das waren in den meisten Fällen ganze sieben RM mehr im Monat. ${ }^{186}$ Bei den Witwen und Waisen fielen die Zusatzrenten entsprechend niedriger aus. Sämtliche Versicherungsträger waren sich denn auch einig, dass angesichts der geringen Zusatzrenten die Verwaltungsarbeit für die Neuberechnung eigentlich nicht lohnte und sich eine weitere Erhöhung auf Dauer aus sozialen Gründen nicht vermeiden lassen würde. Von Seiten der betroffenen Gauleiter waren schon entsprechende Vorstöße gekommen. ${ }^{187}$ Doch die Bedenken stießen im RAM auf taube Ohren. Erst jetzt konnte die RfA die Umrechnung der Renten auf stabiler gesetzlicher Grundlage durchführen. Selbst im Dezember 1941 war allerdings ein Teil der übernommenen Renten der deutschen Volkszugehörigen noch immer nicht umgerechnet, was bedeutete, dass ein Teil der polnischen Rentner nach wie vor die höheren und zum Teil noch immer nach polnischem Recht festgesetzten Renten erhielt. ${ }^{188}$ Nach dem von der Rentenbuchhalterei der RfA im Juni 1941 erstellten statistischen Überblick über die erfolgten Rentenauszahlungen im ehemaligen Ostoberschlesien waren bis dahin an 5393 Ruhegeldempfänger und 2633 Hinterbliebene Renten gezahlt worden. ${ }^{189}$ Von den insgesamt 8026 Berechtigten hatten 1092 den Nachweis der deutschen Volkszugehörigkeit nicht erbracht, bei weiteren 449 Rentnern ergab der Prüfungsprozess die Nichtzugehörigkeit zum deutschen Volk. Etwas mehr als 1500 polnische Rentner waren daher Opfer der NS-ideologisch begründeten, willkürlichen Rentenkürzungen geworden, und dass diese Diskriminierungsmaßnahme trotz aller verwaltungstechnischen Probleme letztlich doch noch realisiert werden konnte, war der erfolgreichen Mitwirkung der RfA zu „verdanken“.

Der Blick auf die Entwicklung der durchschnittlichen Rentenhöhe zeigt dabei, dass die neuen ostoberschlesischen Renten für die „Volksdeutschen“ trotz der Zusatzrenten zwar deutlich unter dem Niveau des Altreichs lagen, dass sich diese aber im Laufe der Zeit stark annäherten. ${ }^{190}$

184 Vermerk zur Besprechung durch den RfA-Beamten in Königshütte vom 23.7.1940, in: RfA-Archiv Nr. 165.

185 Vgl. ebd.

186 Vgl. den Erlass des RAM vom 4.12.1940, in: RfA-Archiv Nr. 128.

187 Vgl. dazu die Niederschrift einer Besprechung über die weitere Einführung der Reichsversicherung in Ostoberschlesien vom 2.4.1941, in: BArch R 89/3204.

188 Vgl. dazu auch die Abteilungsverfügung vom 10.5.1941, in: RfA-Archiv Nr. 26.

189 Vgl. Vermerk vom 21.6.1941, in: RfA-Archiv Nr. 30.

190 Vgl. dazu auch die entsprechende Anfrage des RAM an die RfA vom 1.9.1941, in: RfA-Archiv Nr. 202. 
Tab. 22: Entwicklung der durchschnittlichen Rentenhöhe im Vergleich von Altreich, „Ostmark"e und Sudetenland sowie Ostoberschlesien/Polen (1940 bis 1942)

\begin{tabular}{lllll}
\hline Jahr & Gebiet & Ruhegeld & Witwenrente & Waisenrente \\
\hline Ende 1940 & Altreich & 63,75 & 29,13 & 20,97 \\
& "Ostmark“ & 99,02 & 50,31 & 34,61 \\
& Sudetenland & 94,90 & 47,34 & 30,14 \\
\hline Ende 1941 & Altreich & 74,0 & 30,29 & 21,78 \\
& "Ostmark“ & 109,22 & 51,81 & 37,02 \\
& Sudetenland & 103,13 & 52,57 & 30,19 \\
& Ostoberschlesien & 67,34 & 30,92 & 21,56 \\
\hline Ende 1942 & Altreich & 66,80 & 29,08 & 21,48 \\
& "Ostmark“ & 114,91 & 47,36 & 31,36 \\
& Sudetenland & 99,79 & 44,07 & 27,60 \\
& Ostoberschlesien & 65,12 & 21,50 & - \\
\hline
\end{tabular}

Quelle: Handschriftliche Zusammenstellung, in: RfA-Archiv Nr. 79 sowie Geschichtsbericht der RfA für 1941, S. 4.

Dennoch erhielten die Gauleiter wie verschiedene andere Parteistellen „fortgesetzt“ Beschwerden über die unzulänglichen Renten, unter anderem mit dem Verweis auf die angeblich höheren Leistungen im Altreich.

Im April und Juli 1941 wandte sich unter anderem Rudolf Wiesner, SS-Oberführer in Oberschlesien und Reichstagsmitglied, gleich zwei Mal an die RfA. Einmal beschwerte er sich über die ungerechte Behandlung von Witwen, deren Männer sich „auch in schwerster polnischer Zeit" zum deutschen Volkstum bekannt hatten, aber erst nach dem 3. September 1939 gestorben waren, weshalb die Ehefrauen nur eine um ein Vielfaches kleinere Hinterbliebenenrente erhielten als jene Witwen, deren Männer vor dem 3. September gestorben waren. „Es ist hier bestimmt eine Lücke im Gesetz vorhanden, die im Widerspruch zum wirklichen Leben steht“, und daher müsse die RfA den erstgenannten Witwen gleichfalls die höhere Rente zugestehen. ${ }^{191}$ Später beschwerte er sich dann erneut bei der RfA, diesmal im Namen von 13 Pensionisten des Privatbeamtenstandes, „deutschen Volksgenossen“, die seinerzeit bei der österreichischen und später bei der polnischen Pensionsanstalt versichert gewesen waren und schon unter polnischen Zeiten Ruhegeld bezogen hatten. Sie seien bei Wiesner vorstellig geworden und hätten sich über ihre niedrigen Renten beklagt. Während andere Pensionen wie z.B. bei der Reichsbahn und Post, aber auch bei den anderen staatlichen Behörden inzwischen langsam aufgewertet worden seien und bis zu 80 Prozent der ehemaligen polnischen Rentenbezüge betrügen, sei bei den Pensionisten der Reichsversicherungsanstalt für Angestellte eine Aufwertung nicht erfolgt. ${ }^{192}$

191 Das Schreiben vom 8.4.1941, in: RfA-Archiv Nr. 163 b.

192 Vgl. das Schreiben Wiesners vom 5.7.1941, in: ebd. 


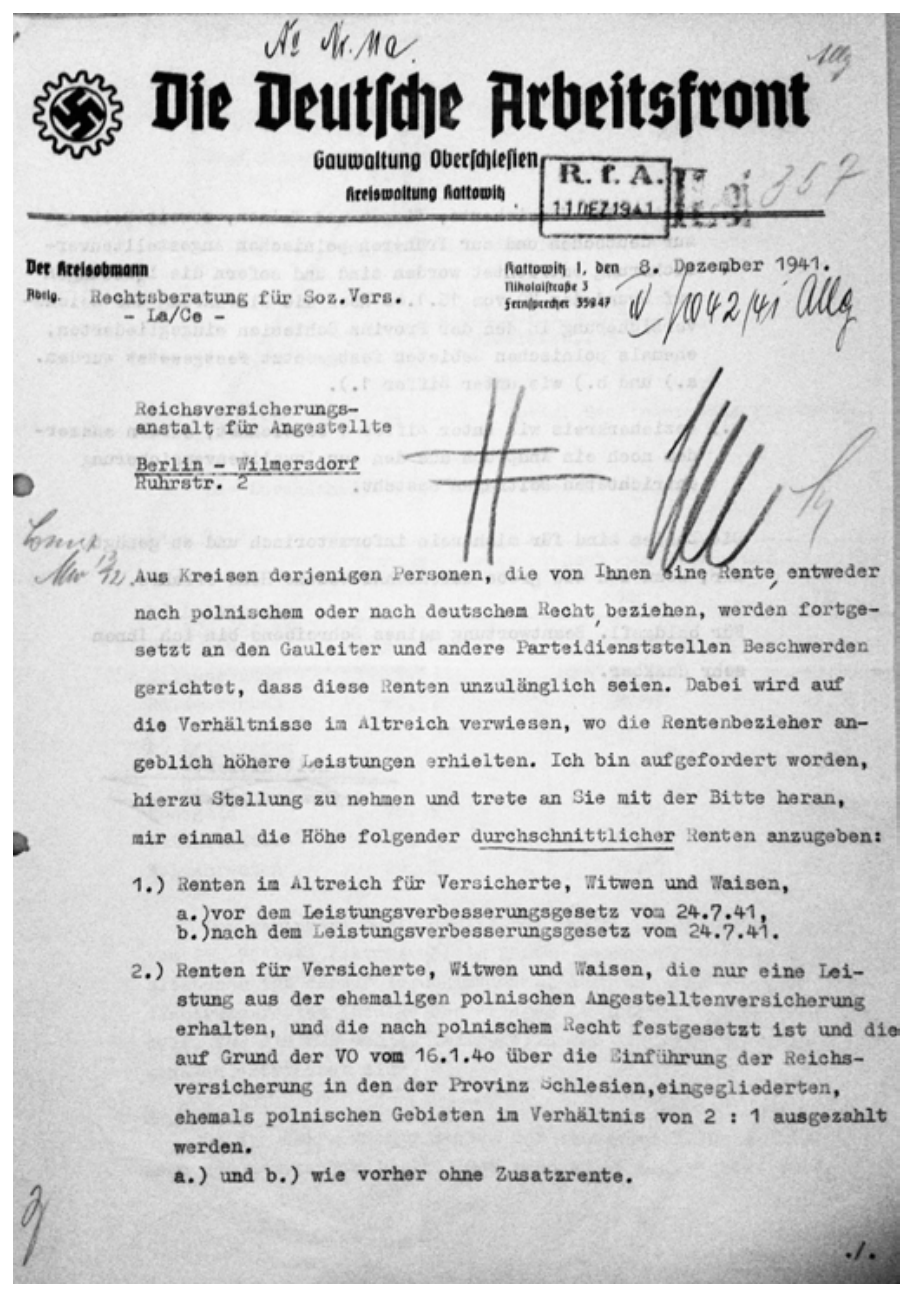

Abb. 59: Beschwerde der DAF-Rechtsberatungsstelle Kattowitz vom 8. Dezember 1941 über unzulängliche Renten

Die umfangreichen und komplexen Maßnahmen zur Angestelltenversicherung in den besetzten Gebieten Polens waren damit noch nicht zu Ende. Bereits im Mai 1940 begannen die Überlegungen im Reichsarbeitsministerium zur Regelung der Rentenzahlungen in den übrigen polnischen Landesteilen, die schließlich am 22. Dezember 1941 in die sogenannte Ostgebietsverordnung, ergänzt durch das am 26. August 1942 erlassene „Polenstatut“ mündeten. Doch ehe es dazu kam, musste sich die RfA mit den Forderungen der Haupttreuhandstelle Ost auseinandersetzen, die im Januar 1941 - aufgrund einer Verordnung über die Behandlung von Vermögen der Angehörigen des ehemaligen polnischen Staates - auch die Anmeldung und Erfassung der 
polnischen Rentenempfänger und deren Ruhegelder verlangte. ${ }^{193}$ Erst nach längeren Verhandlungen und einer Intervention des Reichsarbeitsministeriums wurden im Juni die polnischen Renten von einer Beschlagnahme ausgenommen. Eine Umsetzung der Forderung wäre allerdings, wie die RfA gegenüber der Haupttreuhandstelle betonte, schon an der verwaltungstechnischen Unmöglichkeit gescheitert, die entsprechende Gruppierung aus dem riesigen Bestand von insgesamt mehr als 600.000 Rentenempfängern herauszusuchen. ${ }^{194}$ Gleichzeitig musste man sich auch mit der Anwendung der nun auch in den Ostgebieten geltenden Bestimmungen des Ruhens von Rentenzahlungen wegen staatsfeindlicher Betätigung auseinandersetzen. Als Stichtag für eine Beurteilung entsprechender Rentenzahlungen wurde der 1. September 1939 festgelegt, da aus naheliegenden Gründen Handlungen aus der Zeit davor schlecht den Tatbestand der staatsfeindlichen Betätigung erfüllen konnten. „Namentlich wird die nationalpolitische Einstellung gegen das Deutschtum und die Mitgliedschaft bei deutschfeindlichen Vereinen für sich allein noch nicht genügen, um eine staatsfeindliche Betätigung festzustellen“, heißt es dazu in einem Rundschreiben des RAM an die Sozialversicherungsträger. ${ }^{195}$ Allerdings wurden, anders als im Reich, die ehemals polnischen Renten von Berechtigten, die sich in Konzentrationslagern befanden, nicht an deren Ehefrauen überwiesen - weder ganz noch teilweise. Ausgenommen waren nur die Fälle, in denen die Ehefrau mit der vermeintlich deutschfeindlichen bzw. staatsfeindlichen Betätigung in keinem Zusammenhang stand und vor allem deutscher Volkszugehörigkeit war. ${ }^{196}$

Im Juli 1941 ging es zudem um die Anwendung des ersten Leistungsverbesserungsgesetzes, und bemerkenswerterweise wurden die damit verbundenen Zuschläge auch im Falle der übernommenen Renten in den eingegliederten Gebieten gewährt, in Ostoberschlesien auch der Rentner nichtdeutscher Volkszugehörigkeit. ${ }^{197}$ Offen blieb zunächst jedoch, ob der Zuschlag auch an Rentner polnischer Volkszugehörigkeit im Generalgouvernement gezahlt werden sollte. „Bis auf weiteres“ sollten dort jedoch erst einmal keine Erhöhungen an rentenberechtigte Polen gezahlt werden. ${ }^{198}$ Das war eine deutliche Diskriminierung, denn für Rentenberechtigte im Ausland und im Protektorat Böhmen und Mähren galt dies nicht; sie kamen in den Genuss der Erhöhungen. Grundsätzliche Unklarheit herrschte zu diesem Zeitpunkt im Reichsarbeitsministerium auch über die Krankenversicherung der Rentner, die man für die eingegliederten Ostgebiete gesondert - in welcher Weise auch immer - regeln wollte. ${ }^{199}$

193 Vgl. dazu den RfA-internen Vermerk vom 4.1.1941, in: RfA-Archiv Nr. 127.

194 Vgl. Schreiben der RfA vom 19.1.1941, in: ebd.

195 Das Rundschreiben vom 10.4.1941, in: RfA-Archiv Nr. 26.

196 Vgl. Rundschreiben des RVA vom 28.5.1940, in: RfA-Archiv Nr. 163 b.

197 Vgl. Notiz Kochs über das Ergebnis der Besprechung im RAM vom 15.7.1941, in: RfA-Archiv Nr. 30.

198 Rundschreiben des Reichsverbands Deutscher Rentenversicherungsträger vom 29.7.1941, in: RfAArchiv Nr. 163 b.

199 Vgl. Vermerk Kochs über das Ergebnis einer Aussprache im RAM vom 23.6.1941, in: RfA-Archiv Nr. 30 a. 
Unklarheiten gab es auch in einem weiteren Punkt. Bei der RfA türmten sich im August 1941 etwa 600 unerledigte Anträge auf Beitragserstattungen von ostoberschlesischen bzw. polnischen Beiträgen, die aber gemäß dem Erlass des RAM vom Januar 1940 nur an Volksdeutsche der Invalidenversicherung gehen konnten. Angestelltenversicherte waren davon ausgenommen; für sie sollte eine Regelung später erfolgen. Da jedoch, wie RfA-Direktor Koch aus dem RAM vertraulich erfuhr, die geplante Ostgebiets-Verordnung „wegen der ungeklärten Rechtsstellung der Polen auf nicht absehbare Zeit aufgeschoben ist“, intervenierte die RfA beim RVA, um hier eine vorgezogene vorläufige Regelung auch für die Volksdeutschen der Angestelltenversicherung zu erhalten. ${ }^{200} \mathrm{Zu}$ all dem kamen noch Differenzen zwischen RfA, der LVA Danzig-Westpreußen und auch der LVA Wartheland über die Auslegung der diversen Erlasse des Reichsarbeitsministers. So warnte Grießmeyer Mitte Oktober 1941 in einem Schreiben an das RAM:

Die unterschiedliche Behandlung der Volksdeutschen und Rückgeführten in der Anwendung der Reichsversicherung innerhalb der eingegliederten Gebiete [durch die jeweiligen Versicherungsträger] führt zu erheblichen verwaltungstechnischen Schwierigkeiten und wird von den Beteiligten nicht verstanden. Wir bitten daher, auf eine einheitliche Behandlung [...] hinzuwirken. ${ }^{201}$

Besonders kompliziert wurde es in denjenigen Fällen von Rentenberechtigten, in deren Versicherungsbiographie sich Beitragszeiten und Ansprüche nach deutschem, polnischem, österreichischem und tschechoslowakischem Sozialversicherungsrecht überschnitten oder ergänzten. Die Irrwege der Kriegseroberungen durch die Wehrmacht brachten es im Übrigen auch mit sich, dass polnische Staatsangehörige und Staatenlose im Ausland - d.h. im damaligen Sprachgebrauch „Nationalpolen“ -nach dem Hinfälligwerden des deutsch-polnischen Sozialversicherungsvertrags von 1934 eigentlich keine Rente mehr erhalten konnten. Nun aber erhielten sie doch weiterhin Bezüge von der RfA, da wie im Fall einer Witwenrentenbezieherin, die in Belgien lebte, dieses Land, zumindest nach Meinung der zuständigen RfA-Beamten, seitdem es im deutschen Machtbereich lag, nicht mehr als feindliches Ausland behandelt werden konnte. Daher war die Rente weiterzuzahlen - vorausgesetzt allerdings, die Ermittlungen ergäben, dass das Verhalten des Rentenberechtigten politisch einwandfrei und nicht deutschfeindlich gewesen wäre. ${ }^{202}$

Die Ostgebietsverordnung führte schließlich die Reichsversicherung nach der bereits erfolgten Durchführung in Ostoberschlesien mit Stichtag zum 1. Januar 1942

200 Vgl. Vermerk Kochs vom 18.8.1941, in: RfA-Archiv Nr. 43 b.

201 Schreiben vom 16.10.1941, in: RfA-Archiv Nr. 163 b.

202 Vorher waren die polnischen Staatsangehörigen den deutschen hinsichtlich des Ruhens der Rente bei Aufenthalt im Ausland gleichgestellt und daher weiter rentenberechtigt). Vgl. zu dem Fall das Schreiben der RfA an das RVA vom 23.12.1940, in: BArch R 89/3414. 
auch in den übrigen ehemals polnischen Gebieten ein. ${ }^{203}$ Der lange und komplexe Gesetzgebungsprozess, der sich über fast zwei Jahre hingezogen hatte, macht dabei geradezu exemplarisch das durchaus eingespielte Zusammenwirken der verschiedenen Akteure aus Partei, Reichsarbeitsministerium und Verwaltungsbürokratie der Versicherungsträger deutlich. Tatsächlich hatte das RAM bereits im Mai 1940 einen ersten Entwurf einer Verordnung zur einheitlichen Einführung der Reichsversicherung in den eingegliederten Ostgebieten vorgelegt und die Versicherungsträger um beschleunigte Zustimmung gebeten, „da die beteiligten Kreise, insbesondere der Reichsstatthalter in Danzig und Posen, auf eine schnelle Einführung der Reichsversicherung in den eingegliederten Ostgebieten entscheidend Wert [legen]“. ${ }^{204}$ Es erscheine nicht mehr tragbar, das polnische Sozialversicherungsrecht in den Ostgebieten aufrechtzuerhalten. RfA-Direktor Koch hatte darauf eine Reihe von Änderungsvorschlägen gemacht und auch auf Unklarheiten und Lücken des geplanten Gesetzes hingewiesen. Angesichts der geplanten Unterscheidung der Rentenberechtigungen bei deutschen und fremden Volkszugehörigen sei zu erwarten, dass sich bei den Ansprüchen auf Leistungen Streitigkeiten darüber ergeben werden, ob der Berechtigte Volksdeutscher war oder nicht.

Da die Feststellung der deutschen Volkszugehörigkeit Aufgabe der politischen Behörden ist und deren Entscheidung wahrscheinlich nicht der Nachprüfung durch die Sozialversicherungsträger und durch die Spruchbehörden der Sozialversicherung unterworfen werden soll, halte ich zur Vermeidung aussichtsloser Berufungen eine Bestimmung in der Verordnung für angezeigt, dass die Organe und die Spruchbehörden der Sozialversicherung an die Entscheidung der Verwaltungsbehörde über die Volkszugehörigkeit gebunden sind,

heißt es in der Notiz. ${ }^{205}$ Zudem sei nicht geregelt, wie die polnischen Beiträge für die Beitragserstattung berücksichtigt werden sollten.

Im August 1940 legte das RAM dann einen neuen Entwurf der geplanten Ostgebietsverordnung vor, in dem hinsichtlich der Gewährung von Versicherungsleistungen die Unterschiede zwischen deutschen und polnischen Volkszugehörigen noch verschärft worden waren. Insgesamt schätze man die Zahl der betroffenen polnischen Rentner auf 120.000 mit einer monatlichen Rentenbelastung von etwa 1,7 Mio. RM; der überwiegende Teil von ihnen fiel dabei unter die Invalidenversicherung. Überhaupt war die Verordnung nun, wie die Vertreter des RAM in einer Besprechung verkündeten, gegenüber dem ersten Entwurf völlig geändert worden und sollte nun auch die bereits ergangene Verordnung über die Einführung der Sozialversicherung in Schle-

203 Vgl. dazu W. Dobbernack, ORR im Reichsarbeitsministerium, Die Einführung der Reichsversicherung in den eingegliederten Ostgebieten, in: Amtliche Nachrichten für die Reichsversicherung 1942, Nr. 3 und 4, S. 1-16, in: RfA-Archiv Fach 34, Nr. 4.

204 Schnellbrief des RAM vom 15.5.1940, in: RfA-Archiv Fach 119, Nr. 1.

205 Vermerk Kochs vom 27.5.1940, der in einen Brief Grießmeyers an das RAM am 29.5.1940 einfloss, in: ebd. 
sien ersetzen. ${ }^{206}$ Für die Versicherungsträger gestaltete sich das unberechenbare Hin und Her des RAM im Gesetzgebungsprozess als einigermaßen verwirrend, aber dennoch befasste man sich in der RfA mit ebenso großer Beharrlichkeit wie Ausdauer wieder mit den vielen versicherungsrechtlichen Details des neuen Entwurfs. ${ }^{207}$ Es folgten zahllose weitere Entwürfe und Besprechungen im Reichsarbeitsministerium, an denen die RfA-Beamten beteiligt waren. Auf der Besprechung Ende April 1941 etwa wurde wieder einmal eine Neufassung zahlreicher Paragraphen präsentiert, die sich vor allem um die rassisch-völkische Unterscheidung der Versicherungsberechtigten drehte - Volksdeutsche, eine sogenannte Mittelschicht (Kaschuben, Slonsaken, Litauer) und Nationalpolen. Dies macht deutlich, wie stark sich die Gesetzgebungstätigkeit der RAM-Ministerialbürokratie inzwischen an den Erklärungen des Stellvertreters des Führers - des Reichsführers SS als zuständigem Reichskommissar für die Festigung des Deutschen Volkstums - und des Reichsinnenministeriums orientierte und sich den dort geäußerten Vorstellungen unterordnete. ${ }^{208}$ Über die geplanten Diskriminierungsmaßnahmen gegenüber den Polen in den Ostgebieten - die Polen im Altreich sollten davon ausgenommen bleiben - wurde dabei ungeschminkt gesprochen und alle Versicherungsträger waren daran beteiligt, das Unrecht in handhabbare Verwaltungspraktiken und Verordnungen zu gießen.

Einzig der Leiter der LVA Schlesien übte im Januar 1942 massive Kritik an dem bisher vorliegenden Entwurf, indem er auf eine drohende Absurdität der Verordnung hinwies. Die Anerkennung der deutschen Volkszugehörigkeit sollte diesmal mittels Eintragung in eine Deutsche Volksliste erfolgen, aber die in Abteilung 3 dieser Liste eingetragenen ehemaligen polnischen Staatsangehörigen sollten die deutsche Staatsangehörigkeit nicht schon durch die Aufnahme in die Volksliste erhalten, sondern erst durch die viel später erfolgende Einbürgerung. Bis dahin fielen sie unter den Status von „Schutzangehörigen“, für die die Bestimmungen der Ostgebietsverordnung jedoch nicht gelten sollten. Da aber etwa 70 Prozent der Einwohner des ostoberschlesischen Gebiets unter diese Kategorie fielen, ergäbe sich die absurde Situation, dass diese zunächst von den Bestimmungen der Ostgebietsverordnung ausgeschlossen und versicherungsrechtlich diskriminiert würden, nach erfolgter Einbürgerung jedoch als Volksdeutsche plötzlich wieder zum privilegierten Versichertenkreis gehörten. Das würde große Unzulänglichkeiten hinsichtlich der Beitragsentrichtung durch die Arbeitgeber zur Folge haben, die zwischen deutschen und polnischen Volkstumszugehörigen, aber zudem auch noch innerhalb der ersteren Gruppe nach der Einreihung in der Volksliste zu unterscheiden hätten.

Dieses Ergebnis würde [zudem] zweifellos geeignet sein, schwere politische, soziale und wirtschaftliche Beunruhigung unter der gesamten Bevölkerung hervorzurufen, da die Erreichung der

206 Vgl. dazu die Niederschrift der Besprechung im RAM vom 8.8.1940, in: BArch R 89/3206. 207 Vgl. dazu das vierseitige Schreiben mit Vorschlägen und Anregungen zur Ostgebietsverordnung vom 7.9.1940, in: ebd.

208 Vgl. Vermerk von ORR Hartmann über die Besprechung im RAM am 25.4.1941, in: ebd. 
sozialversicherungsrechtlichen Vorteile einen wesentlichen Gesichtspunkt für das Betreiben der Eintragung in die Deutsche Volksliste darstellt. ${ }^{209}$

Man änderte daher kurzfristig die Kriterien und die in Abteilung 3 der Volksliste Eingetragenen erhielten ebenfalls die deutsche Staatsbürgerschaft, allerdings auf Widerruf.

Als die Ostgebietsverordnung schließlich in Kraft trat, wurde die bereits in Ostoberschlesien erprobte Unterscheidung nach Staats- bzw. Volkstumszugehörigkeit, für die sich je unterschiedliche Begünstigungen oder aber auch Benachteiligungen hinsichtlich der Rentenversicherung ergaben, auch auf die übrigen Gebiete ausgedehnt. Zum privilegierten Personenkreis zählten neben den deutschen Staatsangehörigen auch jene ehemaligen polnischen Staatsangehörigen, die durch Aufnahme in die Abteilung 1 oder 2 der Deutschen Volksliste die deutsche Staatsangehörigkeit erworben hatten. Der Nachweis der Volkstumszugehörigkeit war damit kaum weniger aufwändig und kompliziert als im Fall von Ostoberschlesien. Unter den benachteiligten Personenkreis fielen die sogenannten Schutzangehörigen und Staatenlosen polnischen Volkstums. Für sie galten Sonderbestimmungen, die dann aber erst am 26. August 1942 mit dem sogenannten „Polenstatut“ erlassen wurden und zum 1. Oktober in Kraft traten. Im Einzelnen sah dieses Statut vor, dass erstens vom Stichtag an anstelle der Leistungen der Reichsversicherung nur noch Unterstützungen gewährt würden, auf die zudem kein Rechtsanspruch bestünde. Und zweitens würden die Schutzangehörigen und Staatenlosen polnischen Volkstums künftig ausschließlich nach den Vorschriften der Invalidenversicherung behandelt, d.h. die polnischen Angestellten würden unabhängig von den früher erworbenen Ansprüchen und Beitragszahlungen den polnischen Arbeitern gleichgestellt. Sie mussten daher künftig Beiträge zur Invalidenversicherung leisten; bei der Beitragshöhe machte sich das nicht bemerkbar, denn inzwischen galt in der AV wie der IV ein einheitlicher Beitragssatz von 5,6 Prozent des Entgelts. Aber sie erhielten nun eigene Versicherungsbzw. Quittungskarten der IV mit dem Stempelaufdruck „Pole“.210

Nicht alle Polen waren von all dem gleichermaßen betroffen. Zum einen wurde scharf zwischen alten Versicherungsfällen und neu zu bewilligenden Renten unterschieden. Dazu kam, dass Angehörige polnischen Volkstums, die sogenannten „alteingesessenen Polen“ sowie die polnischen Volkszugehörigen, die aufgrund bestimmter Richtlinien des Reichskommissars für die Festigung deutschen Volkstums besonders behandelt wurden, nicht unter das „Polenstatut“ fielen. Die ehemaligen polnischen Rentenversicherten wurden mithin nach rassisch-völkischen Kriterien in heterogene Gruppierungen aufgesplittert, für die je unterschiedliche rentenversiche-

209 Vgl. das Schreiben des LVA-Leiters an das RAM vom 6.1.1942, in: RfA-Archiv Fach 119, Nr. 1 sowie dazu auch den Aufsatz von Landesrat Riemann über „Die Leistungen der Rentenversicherung in den eingegliederten Ostgebieten“, in: Deutsche Rentenversicherung 15 (1943), Nr. 2, S. $12-15$ und S. 21-25, hier S. 13.

210 Vgl. ebd., sowie auch Mischkowsky, S. $75 \mathrm{ff}$. 
rungsrechtliche Bestimmungen galten. Über die jeweilige zahlenmäßige Größe der Gruppierungen gibt es in den Akten der RfA und des RVA keine Angaben. Dennoch gab die RfA nun faktisch den Großteil der bisher unter ihre Verwaltung gefallenen polnischen Versicherten und Rentner an die jeweiligen Landesversichertenanstalten ab. Ende April 1941 bat daher unter anderem der zuständige Beamte der LVA Schlesien bei der RfA um Auskunft über die ungefähre Anzahl der laufenden RfA-Renten, die man infolge des „Polenstatuts“ zu übernehmen hatte - sowohl die ehemals polnischer Rentner als auch eventuelle Neurenten von Nationalpolen. ${ }^{211}$ Die erste Frage konnte der zuständige RfA-Beamte mit Verweis auf die rund 1000 Ruhegeldempfänger und ca. 500 Hinterbliebenenrentenempfänger beantworten, über die Neurenten konnte er jedoch keinerlei Angaben machen, „weil diese Rentner nicht besonders geführt werden, sondern sich unter den 650.000 Rentnern befinden““. ${ }^{212}$ Die Anfrage ist wohl auch ein Indiz dafür, dass praktisch kein Wissen darüber bestand, wie der jeweils andere Versicherungsträger die „Polenrentensache“ handhabte.

Mit dem „Polenstatut“ war nun die formalrechtliche Grundlage für die einheitliche, auf alle ehemaligen polnischen Ostgebiete ausgedehnte sozialversicherungsrechtliche Diskriminierung und Exklusion geschaffen worden. Es galt mithin auch für die eingegliederten Gebiete Ostoberschlesiens. Mit der Ostgebietsverordnung vom 22. Dezember 1941 wurde mithin auch der bis dahin dauernde schwebende Rechtszustand im Warthegau und im Gebiet Danzig-Westpreußen beendet und hier nun anstelle des bis dahin noch gültigen polnischen Versicherungsrechts die Reichsversicherung eingeführt mit neuer Zuständigkeit der RfA für die versicherten Angestellten und Rentner. Erst durch die Ostgebietsverordnung wurden die auch zwei Jahre nach der Besetzung Polens vielfach noch immer geltenden und weiter angewendeten Teile des polnischen Sozialversicherungsrechts endgültig beseitigt. ${ }^{213}$

Die RfA war bei der Umsetzung der diskriminierenden Maßnahmen des „Polenstatuts“ vom RAM im Übrigen erheblich unter Druck gesetzt worden. Bereits im Januar wurde man durch fernmündliche Mitteilung zu einer beschleunigten Durchführung gedrängt. In einem internen Vermerk des zuständigen RfA-Beamten über den Inhalt des Telefonanrufs aus dem RAM heißt es:

Wir sind nach § 1 Abs. 1 der VO verpflichtet, die Rentenzahlung an Schutzangehörige und Staatenlose polnischen Volkstums baldmöglichst einzustellen, ohne Rücksicht darauf, ob die für diese in Kürze bevorstehende Sonderregelung durch den „Polenstatut“ schon vorliege. Der Kreis dieser Personen sei bereits in Abschnitt 5 XV der VO über das Strafrecht gegen Polen und Juden vom 4. Dezember $1941 \mathrm{zu}$ Grunde gelegt und [...] näher abgegrenzt. ${ }^{214}$

211 Vgl. das Schreiben an die RfA Königshütte vom 30.4.1941, in: RfA-Archiv Nr. 163 b.

212 Vgl. das Antwortschreiben der RfA vom 8.5.1941, in: ebd.

213 Zur partiellen Weiteranwendung polnischen Rechts vgl. etwa die Abteilungsverfügung vom 14.5. 1941, in: RfA-Archiv Nr. 26.

214 Vermerk vom 2.1.1942, in: BArch R 89/3206. 
Gleichzeitig bemühten sich jedoch alle beteiligten Versicherungsträger um die verwaltungsrechtlichen wie -organisatorischen Details der Umsetzung der Ostgebietsverordnung, und die zuständigen Gauleitungen sowie die Parteikanzlei in München saß dabei entweder direkt oder indirekt immer mit am Tisch und brachte entsprechende „Wünsche“ vor. ${ }^{215}$ Das Protokoll einer am 5. März 1942 abgehaltenen großen Besprechung zur Ostgebietsverordnung listet etwa auf elf Seiten einen umfassenden Fragenkatalog über aufgetretene Detailprobleme auf. ${ }^{216}$ Dabei ging es unter anderem um die versicherungsrechtliche Einstufung und Behandlung der im Generalgouvernement wohnenden Polen, die in einem der übrigen Ostgebiete arbeiteten. Sie galten als Staatenlose polnischen Volkstums, aber die Frage war, ob ihnen nun die Unterstützungen gemäß „Polenstatut“ zu gewähren seien, obwohl diese bisher von der Hauptanstalt für Sozialversicherung in Warschau gezahlt worden seien. Und müsste die Zahlung der Unterstützung bei Aufgabe der Arbeit in den eingegliederten Ostgebieten und bei Rückwanderung ins Generalgouvernement wieder aufhören? ${ }^{217}$

Die Anwendung der eigentlich versicherungsfremden völkischen Kriterien war mithin reichlich vertrackt. Zudem wurde rasch deutlich, dass die praktische Umsetzung nicht nur Probleme in der Leistungsgewährung bereitete, sondern auch bei der Beitragserhebung, was vor allem auch die RfA betraf. Diese war bis dahin im Warthegau und im Gebiet Danzig-Westpreußen nicht mit der Beitragseinziehung von Angestelltenbeiträgen befasst gewesen, wurde mit Einführung der Reichsversicherung nun aber dafür in Zusammenarbeit mit den Krankenkassen zuständig. Erst seit Januar 1943 waren daher auch die Überwachungsbeamten der RfA in diesen Gebieten tätig. ${ }^{218}$ Angesichts der in den Verordnungen vielfach unklaren Kriterien und Abgrenzungen der jeweiligen unterschiedlichen Volkszugehörigkeits-Status waren unter anderem die inzwischen im Beitragsverfahren mit einbezogenen Krankenkassen nicht in der Lage, eine Unterscheidung bei den Versicherten zu treffen. Eine Differenzierung nach dem Namen schied von vornherein aus, da viele Volksdeutsche rein polnische Namen, viele Polen aber auch rein deutsche Namen trugen, wie der Leiter der AOK in Bromberg gegenüber Grießmeyer feststellte. ${ }^{219}$ Auch die Arbeitgeber konnten beim besten Willen nicht feststellen, welcher angestelltenversicherungspflichtige Mitarbeiter Schutzangehöriger oder Staatenloser polnischen Volkstums war, selbst wenn man die Volkstumsreferenten bei den Gauleitungen als „Experten“ einschaltete. Aufgrund man-

215 Vgl. dazu das Schreiben der LVA Danzig-Westpreußen an Grießmeyer vom 14.1.1942 mit der Einladung zu einer Besprechung aller beteiligten Landesversicherungsanstalten, die sich am Tag zuvor bereits auf einer Besprechung bei der Gauleitung der NSDAP über Wünsche der Parteikanzlei in München informiert hatten, in: RfA-Archiv Nr. 165 a.

216 Vgl. Niederschrift über die Besprechung im RAM vom 5.3.1942, in: RfA-Archiv Fach 119, Nr 1. 217 Vgl. dazu auch den siebenseitigen Vermerk über „Zweifelsfragen zum Polenstatut“, in: BArch R $89 / 3207$.

218 Vgl. dazu das Rundschreiben an die Überwachungsbeamten über den Überwachungsdienst in den neuen Ostgebieten vom 13.10.1942, in: RfA-Archiv Fach 34, Nr. 4.

219 Vgl. das Schreiben vom 23.1.1942, in: RfA-Archiv Fach 119, Nr. 1. 
gelnder Koordination der verschiedenen Verwaltungen waren etwa im Bereich der Gebiete um Danzig-Westpreußen bereits tausende Versicherungskarten an die dortigen Arbeitgeber ausgegeben worden, die mit dem Kleben von Versicherungsmarken begonnen hatten. Und dabei handelte es sich überwiegend um volks-, balten-, wolhynien- und bessarabiendeutsche Arbeitgeber, die von dem deutschen Sozialversicherungsrecht im Gegensatz zu den reichsdeutschen Arbeitgebern „nicht die geringste Kenntnis besitzen“. ${ }^{220}$ „Sie werden“, so prophezeite der AOK-Leiter aus Bromberg daher Grießmeyer, „mit den hiesigen unerfahrenen Arbeitgebern die größten Überraschungen erleben. “221 Zur Vereinfachung des Verfahrens bat der AOK-Leiter daher die RfA um die Genehmigung zur Ausstellung von Versichertenkarten zur Angestelltenversicherung ohne Unterscheidung der Staatsangehörigkeit, was man dort jedoch mit Verweis auf die Gesetzeslage ablehnte.

Die Versicherungsträger erwiesen sich aber auch in der Folgezeit als willfährige Akteure, wenn es darum ging, weiter an einer verwaltungsmäßig handhabbaren Version der diskriminierenden Gesetzesmaßnahmen zu feilen und unklare oder gar widersprüchliche Passagen in der Ostgebietsverordnung wie im „Polenstatut“ des RAM zu beseitigen. Seit Dezember 1941 fanden in der RfA regelmäßige interne Besprechungen zwischen den beteiligten Beamten und Fachreferenten statt. ${ }^{222}$ Dazu kam ein intensiver Austausch zwischen den Versicherungsträgern, wie etwa die Besprechung über die Durchführung des Polenerlasses am 19. und 20. Oktober $1942 \mathrm{im}$ Haus der Reichsknappschaft, an der auch die RfA mit ihren beiden wichtigsten „Polenrenten-Experten“ vertreten war. Dabei wurde unter anderem moniert, dass von dem Erlass nicht diejenigen polnischen Rentner erfasst würden, die zwar in den eingegliederten und eroberten Ostgebieten wohnten, aber Leistungen von einem Versicherungsträger des Altreichs erhielten. Diese verschiedene Behandlung der Rentenempfänger hielt man für nicht gerechtfertigt. Ungeklärt war auch die Behandlung von Schutzangehörigen und Staatenlosen polnischen Volkstums, die eine Leistung von einem früheren polnischen Versicherungsträger oder einem Versicherungsträger des Reichs bezogen und am Stichtag im Altreich wohnten. Diese Handhabung bedürfe „dringend einer Regelung, da hier die Leistung unverändert vorläufig weitergezahlt [wird]““.223 Die Fälle, in denen polnische Rentner noch in den Genuss von unveränderten Zahlungen kamen, waren offensichtlich nicht gering, sonst hätte man sich damit wohl kaum so eingehend befasst. Genaue Zahlen legte aber niemand vor.

220 Ebd. Vgl. dazu auch das Schreiben des Reichsstatthalters in Danzig-Westpreußen an die RfA vom 28.1.1942 sowie des Leiters der Sozialversicherungsanstalt Krakau vom 18. 2.1942, in: RfA-Archiv Fach 34, Nr. 3.

221 Schreiben vom 23.1.1942, in: RfA-Archiv Fach 119, Nr. 1.

222 Vgl. dazu den Vermerk einer Besprechung vom 30.4.1942 mit „Erläuterungen zur Ostgebietsverordnung“ sowie die Besprechungsniederschrift vom 18.12.1942, in: RfA-Archiv Nr. 164. Vgl. auch den Vermerk mit „weiteren Erläuterungen zur OstgebietsVO“ vom 3.5.1943, in: ebd.

223 Niederschrift der Besprechung über die Durchführung des „Polenstatuts“ vom 19./20. Oktober 1942, in: RfA-Archiv Nr. 165 a. 
Wie auch immer, die Versicherungsträger monierten die ungleiche Anwendung des Unrechts bei den polnischen Versicherten und Rentnern und plädierten für eine deutliche Ausweitung der diskriminierenden Maßnahmen. Einvernehmlich wurde beschlossen, das „Polenstatut“ - vorbehaltlich einer anderweitigen Regelung durch das RAM - in Eigeninitiative auch auf die Gruppierung der nationalpolnischen Rentner anzuwenden.

Das Hauptproblem, das die Versicherungsträger mit Ostgebietsverordnung und „Polenstatut“ hatten, war eher verwaltungstechnischer Art. Die Durchführung des „Polenstatuts“ in der jetzigen Fassung verursache, so beklagten sich die RfA-Beamten, äußerst viel, im Augenblick noch nicht zu überblickende Verwaltungsarbeit. Eine glatte und reibungslose Durchführung sei nicht möglich; die geforderte und immer wieder in den Vordergrund gestellte Vereinfachung „lässt auch das Polenstatut vermissen“. ${ }^{224}$ Im Übrigen müsse „ganz allgemein pflichtgemäß ausgesprochen werden, dass die fortwährenden Neuerungen und die zunehmenden Komplizierungen der Bestimmungen die Durchführung der Sozialversicherung ernstlich gefährden“.225 Diese Bemerkung verwies auf ein tatsächlich akuter werdendes Problem, denn nicht nur die Versicherungsträger als verwaltungsmäßige Exekutoren der Rentengesetze, sondern offenbar auch die zuständigen Beamten im Reichsarbeitsministerium hatten offensichtlich den Überblick über die inzwischen zahllosen Verordnungen, Erlasse, Ergänzungsbestimmungen, Durchführungsverordnungen und Gesetzesmaßnahmen, die allein $\mathrm{zu}$ den Ostgebieten erlassen worden waren, verloren. Zahlreiche Widersprüche innerhalb der Verordnungen, aber vor allem zwischen den gesetzlichen Bestimmungen waren nicht zuletzt darauf zurückzuführen, dass einzelne Maßnahmen wie etwa auch die Ostgebietsverordnung schon lange geplant und entworfen worden waren. Das Inkrafttreten verzögerte sich dann aber aus unterschiedlichen Gründen um viele Monate. Während dieser Zeit wurden aber zahlreiche andere Verordnungen und Gesetze erlassen, die eigentlich Rückwirkungen auf Geltungsbereiche und Fristen der noch im Entwurf- oder Beratungsstadium sich befindenden Verordnungen hatten, ohne dass dies berücksichtigt worden wäre und ohne dass etwaige überholte Passagen gestrichen worden wären. ${ }^{226}$

Die polnischen Rentner in Ostoberschlesien hatten bis dahin immerhin weiterhin Renten erhalten, wenn auch nur noch einen Bruchteil ihrer früheren Ansprüche. An ihre Schicksalsgenossen im Generalgouvernement dagegen waren praktisch seit Kriegsausbruch keine Ruhegelder mehr gezahlt worden und nach der Besetzung durch die Deutschen waren Rentenzahlungen deutscher Versicherungsträger an Polen in diesem Gebiet generell verboten. Auch nach der Ostgebietsverordnung galten diese nicht als „Schutzangehörige polnischen Volkstums“ wie in den anderen dem Reich eingegliederten Gebieten, sondern als „Staatenlose polnischen Volkstums“. Grund-

224 Ebd., S. 7.

225 Ebd.

226 Vgl. dazu den kritischen Hinweis des Ostgebietsexperten der RfA in seinem Vermerk vom 18.12. 1942, in: RfA-Archiv Nr. 164. 
sätzlich wurde im Generalgouvernement zwar schon im Januar 1940 per Erlass verfügt, dass die Zahlung von Renten deutscher Versicherungsträger an Berechtigte deutsche Staatsangehörige und - per Bescheinigung als solche ausgewiesene Volksdeutsche „unverzüglich aufgenommen“ würden, im Juni ergänzt durch eine Verordnung zur Einführung der deutschen Sozialversicherung für die dort lebenden deutschen Staatsangehörigen, womit das versicherungsrechtliche Territorialitätsprinzip durchbrochen wurde. Ergänzend dazu erfolgten jedoch noch 1940 eine Reihe von Verordnungen, in denen die diskriminierenden Prinzipen der späteren „Polenstatuts“ bereits vorweggenommen wurden. Sämtliche Ansprüche und Leistungen aus der polnischen Sozialversicherung wurden zum 1. März 1940 als erloschen erklärt und an ihre Stelle Unterstützungen ohne Rechtsanspruch gesetzt. ${ }^{227}$ Ein Problem war allerdings, dass prinzipiell der Verlust der Staatszugehörigkeit auch die im Generalgouvernement wohnenden deutschen Volkszugehörigen (Volksdeutschen) betraf, die spätestens seit der Ostgebietsverordnung als „Staatenlose deutschen Volkstums“ firmierten. Der Generalgouverneur war ermächtigt, diese Deutschen einzubürgern, da es hier auch keine Deutsche Volksliste gab. Viele dieser deutschen Volkszugehörigen erlangten auf diesem Wege wegen des zeitaufwändigen Einbürgerungsprozesses allerdings erst Ende 1943, Anfang 1944 die deutsche Staatsbürgerschaft. ${ }^{228}$ Im Generalgouvernement blieb daher das polnische Sozialversicherungsrecht mit seinem höchst komplizierten Beitragsrecht und vielen anderen, vom deutschen Recht abweichenden Leistungen unter alleiniger Zuständigkeit der Warschauer Hauptanstalt für Sozialversicherung weitgehend in Geltung. Mit der Ostgebietsverordnung ergaben sich dann ab November 1942 im Generalgouvernement bei genauerem Hinsehen für die dortigen Angestellten drei verschiedene Versicherungen unterschiedlichen Rechtsumfangs: die polnische AV für Polen, die AV der deutschen Volkszugehörigen bei der Hauptanstalt in Warschau für deutsche Volkszugehörige und die deutsche AV bei der RfA für deutsche Staatsbürger. ${ }^{229}$ Besondere Bestimmungen galten im Übrigen hier auch für die im Generalgouvernement beschäftigten westeuropäischen Zwangsarbeiter wie Italiener, Slowaken, Niederländer, Belgier und Franzosen. Sie unterlagen den Bestimmungen der deutschen Sozialversicherung, die in der Verordnung vom 4. August 1941 über die Sozialversicherung in den besetzten Gebieten erlassen worden waren. Einheimische polnische Zwangsarbeiter waren davon jedoch ausgenommen, auch wenn sie bei einer deutschen Firma arbeiteten. ${ }^{230}$ Allerdings fanden die Vor-

227 Vgl. dazu die zweite Verordnung über die Sozialversicherung im Generalgouvernement vom 7.3. 1940 sowie die dritte Verordnung vom 19.9.1940, in: Mitteilungen der RfA Nr. 6, 1940, S. 21-22 bzw. Nr. 11, S. 41-42. Vgl. auch Julius von Medeazza, Deutsche Sozialpolitik im Generalgouvernement, in: NS-Sozialpolitik 7 (1940), S. 196-200.

228 Vgl. Mischkowsky, S. $93 \mathrm{ff}$.

229 Vgl. ebd., S. 103.

230 Vgl. die Verordnung vom 4.8.1941 und die dazu entworfene ausführliche Begründung, in: BArch R 89/3172 sowie auch den Aufsatz von ORR Bogs über „Die Verordnung über die Sozialversicherung in 
schriften des Angestelltenversicherungsgesetzes, wie erwähnt, durchaus Anwendung auf die im Altreich in entsprechenden Tätigkeiten eingesetzten nicht kriegsgefangenen polnischen Zwangsarbeiter. Die z. B. bei der Stadt Berlin als Pfleger tätigen Polen unterlagen der AV-Pflicht, für sie waren auch Beiträge an die RfA zu entrichten. ${ }^{231}$

Gleichsam flankierend zu den Diskriminierungs- und Entrechtungsmaßnahmen gegen die polnischen Versicherten und Rentner erfolgten nicht zuletzt auch weitere Maßnahmen gegen Juden, die diese von jeglichem Rentenempfang ausschlossen, unabhängig von ihren früher erworbenen Ansprüchen. In einem Rundschreiben hatte das RAM am 8. März 1941 wie erwähnt verfügt, dass „Renten an Juden im Generalgouvernement nicht zu zahlen sind“. ${ }^{232}$ Nur wenig später erließ dann auch der Regierungspräsident in Kattowitz am 17. Mai eine Verordnung, wonach die Vorschriften über die Einführung der Reichsversicherung in den ostoberschlesischen Gebieten auf Juden nicht anzuwenden seien. ${ }^{233}$ Dabei war es einerlei, ob der Betroffene die deutsche Staatsangehörigkeit oder eine ausländische Staatsangehörigkeit besaß oder staatenlos war. Die Versicherungsträger wurde aufgefordert, sämtliche Leistungen an Juden, soweit dies nicht bereits geschehen, umgehend einzustellen, und die RfA machte sich ihrerseits sofort daran, den Erlass zu befolgen und umzusetzen. An sämtliche Landräte wurden Listen mit den jeweils dort wohnenden Rentenempfängern versendet und und um Kennzeichnung der Juden und Rücksendung der Liste gebeten denn nach wie vor war bei der RfA nicht bekannt, wer unter den ostoberschlesischen Rentnern Jude war. ${ }^{234}$ Tatsächlich kamen aus den verschiedenen Landkreisen Listen mit jeweils zwischen 20 und 30 jüdischen Ruhegeld- oder Hinterbliebenenrentenempfängern, die, so der Rückschluss, bis dahin offenbar tatsächlich noch Zahlungen durch die RfA erhalten hatten. ${ }^{235}$ Das Problem der „Judenrenten“ war auch Gegenstand der Besprechung im RAM Anfang März 1942. „Wie soll verfahren werden“, so fragten Vertreter der Versicherungsträger, „wenn aus dem Altreich in die Ostgebiete umgesiedelte Juden Überweisungen ihrer laufenden Reichsversicherungsrente oder Feststellung einer neuen Reichsversicherungsrente beantragen?“236 Die Antwort der Reichsamtsministerialbeamten darauf verwies wieder einmal auf den „in Kürze“ zu erwartenden besonderen Erlass zur Behandlung der Juden. Bis dahin seien die Anträge liegen zu lassen. Die zunächst als Verfügung der jeweiligen Regierungspräsi-

den besetzten Gebieten“, in: Amtliche Nachrichten für die Reichsversicherung 1941, S. II 389-392, in: RfA-Archiv Fach 18, Nr. 3.

231 Vgl. dazu auch Mischkowsky, S. 80.

232 Rundschreiben vom 8.3.1941, in: RfA-Archiv Fach 34, Nr. 4.

233 Vgl. die Verordnung vom 17.5.1941, in: RfA-Archiv Nr. 163. Am 7. April 1942 erfolgte dann durch den Regierungspräsidenten eine gleichlautende Verordnung, die sich auf die nun in Ostoberschlesien geltende Ostgebietsverordnung bezog.

234 Vgl. dazu das Schreiben an den Landrat von Blachstädt vom 20.6.1941, in: RfA-Archiv Nr. 167. 235 Vgl. die verschiedenen Listen, in: ebd.

236 Niederschrift über die Besprechung im RAM vom 5.3.1942, in: RfA-Archiv Fach 119, Nr 1. 
denten erlassene Einstellung von Rentenzahlungen an Juden wurde dann im Juni 1942 auch durch das RAM allgemein bestätigt. ${ }^{237}$

Die Vorschriften der Reichsversicherung fanden mithin auf Juden in den eingegliederten Ostgebieten grundsätzlich keine Anwendung, allerdings mussten formal nach wie vor für beschäftigte Juden Sozialversicherungsbeiträge nach den reichsrechtlichen Vorschriften entrichtet werden. ${ }^{238}$ Wovor man im Reichsgebiet noch zurückschreckte, praktizierten Reichsarbeitsministerium und die Verwaltungsbehörden ungehemmt mit diesem ,Judenerlass“ in den Ostgebieten, indem dieser die Juden aus der Rentenversicherung ungeachtet ihrer erworbenen Ansprüche ausschloss. Diese umfangreichen Maßnahmen gegen Polen und Juden in der Rentenversicherung legen mithin den Schluss nahe, dass es die später von der Ministerialbürokratie des RAM behaupteten, und teilweise später auch von der Forschung übernommenen, angeblichen Vorbehalte im Reichsarbeitsministerium gegen die nationalsozialistische Rassen- und Volkstumspolitik nicht gegeben hat. Und die RfA machte sich auch hier zum willfährigen Gehilfen der Exklusion. Im April 1942 wurde in einer Abteilungsverfügung vorgeschrieben, dass künftig bei neuen Rentenanträgen aus den eingegliederten Ostgebieten vor Bescheiderteilung festzustellen sei, ob die Berechtigten arisch seien. „Da uns nicht bekannt ist, welche unserer Rentenempfänger in den betreffenden Gebieten wohnen und wer davon Jude ist, wir aber annehmen, dass dies dort bekannt ist“" bat man abermals die örtlichen Behörden um Mithilfe. ${ }^{239}$ Sämtliche Landräte und Bürgermeister wurden über den neuen Erlass informiert und dazu aufgefordert, „möglichst bald“ ein Verzeichnis der örtlichen Juden an die RfA zu schicken. ${ }^{240}$ Die Antworten aus den Amtsstellen in den Ostgebieten waren diesmal jedoch höchst unzulänglich und enthielten Rückmeldungen, die die RfA von ihren Nöten, gleichsam im Voraus unberechtigte jüdische Rentenempfänger zu identifizieren, nicht befreite. Viele Bürgermeister und Ortspolizeistellen meldeten inzwischen Fehlanzeige und verwiesen auf die Probleme und den Aufwand, eine gewünschte „Judenliste“ aufzustellen. ${ }^{241}$ Das Versicherungsamt des Landkreises Beuthen-Tarnowitz meldete Mitte Juli 1942 ganze zwei jüdische RfA-Rentenbezieher, wobei der einen Rentnerin bereits die Rentenzahlung eingestellt worden war, wie die RfA-Beamten bei der Überprüfung feststellten, und der andere Rentner als Mischling in Kategorie 3 der Volksliste registriert war und daher die Ruhegeldzahlung inzwischen wieder erhielt. ${ }^{242}$ Die

237 Vgl. dazu auch Mischkowsky, S. 54 und auch Kirchberger, S. $129 \mathrm{ff}$.

238 Vgl. dazu auch das Schreiben des RAM vom 13.3.1943, in: RfA-Archiv Fach 34, Nr. 4 sowie auch die Verordnung, in: Mitteilungen der RfA Nr. 5, 1943, S. 15.

239 Abteilungsverfügung vom 22.4.1942, in: RfA-Archiv Nr. 163 c.

240 Vgl. dazu exemplarisch das Schreiben der RfA an den Oberbürgermeister des Stadtkreises Königshütte vom 22.4.1942, in: ebd.

241 Vgl. dazu etwa das Schreiben der Ortspolizei Königshütte an die RfA vom 4.5.1942 sowie des Landrats von Teschen vom 13.5.1942, in: RfA-Archiv Nr. 163 c.

242 Vgl. die entsprechenden handschriftlichen Notizen auf dem Schreiben des Versicherungsamtes, in: ebd. 
Schwierigkeiten auch der anderen Versicherungsträger, in den Ostgebieten die jüdischen Bezugsberechtigten zu identifizieren, führte im September 1942 schließlich beim Reichsverband der gewerblichen Berufsgenossenschaften zu einer Initiative, die Reichspost bzw. Postanstalten bei den Ermittlungen jüdischer Rentenbezieher einzusetzen. Für die rentenauszahlenden Postbeamten würden die Gesuchten an dem gelben Stern ohne weiteres erkenntlich sein. ${ }^{243}$ Die Idee des Berufsgenossenschaftsverbandes war gar nicht so originell, denn eine entsprechende Aktion hatte offenbar bereits zwei Mal für die LVA Oberschlesien stattgefunden. Auf jeden Fall erklärte sich die RfA im Dezember bereit, sich an der neuerlichen Aktion zu beteiligen.

Da jedoch alle Versicherungsträger, veranlasst auch durch ständige entsprechende Verlautbarungen aus dem RAM, davon ausgegangen waren, dass „in Kürze“ eine für das ganze Reichsgebiet geltende Verordnung über die Sonderbehandlung von Juden und Zigeunern in der Reichsversicherung in Kraft treten würde, sah man von der Sonderaktion gegen jüdische Rentenbezieher in Ostoberschlesien ab. ${ }^{244}$

Die Jahre 1943 und 1944 waren für die RfA von anhaltenden verwaltungsorganisatorischen Problemen geprägt, aber auch von zunehmenden Routinen und bürokratischer Effizienz bei der weiteren Durchführung der Angestelltenversicherung in den Ostgebieten. Die LVA Danzig-Westpreußen und die RfA vereinbarten etwa im August 1943 eine gegenseitige Information über Widerrufe von Staatsangehörigkeit bei denjenigen Rentenberechtigten, die in Abteilung 3 und 4 der Deutschen Volksliste eingetragen waren und damit nun unter das „Polenstatut“ fielen, um Überzahlungen bei Renten $\mathrm{zu}$ vermeiden. ${ }^{245}$ Noch immer gab es eine verwirrende Flut von Verordnungen und Maßnahmen zur Sozialversicherung in den Ostgebieten, mit denen die Exklusion der Polen und Juden einerseits weiter verschärft wurde, die aber andererseits auch von „neueren Absichten“ geprägt waren, „den ehemaligen polnischen Versicherten ihre höheren Ansprüche aus der polnischen Versicherung möglichst zu erhalten“, wie die RfA im Dezember 1943 in einem Brief zum Problem der Berechnung übernommener polnischer Renten notierte. ${ }^{246}$

Zeitgleich bahnten sich im Frühsommer 1943 Konflikte mit den Parteistellen an. Im Juni 1943 beschwerte sich der Gauleiter von Oberschlesien in einem Brief beim Reichsarbeitsministerium darüber, dass die Vorschriften über den Geltungsbereich der Ostgebietsverordnung beim RVA wie bei allen Versicherungsträgern „neuerdings eine Auslegung gefunden [haben], die für zahlreiche Volksdeutsche meines Gaues zu einem unhaltbaren Ergebnis führt“. ${ }^{247}$ Bekanntlich sollte die Verordnung für Schutzangehörige und Staatenlose polnischen Volkstums keine Anwendung finden und daher war es Verwaltungspraxis der Versicherungsträger gewesen, Volksdeutschen erst dann die

243 Vgl. Schreiben des Reichsverbands an das RVA vom 8.9.1942, in: ebd.

244 Vgl. Schreiben des RVA vom 8.1.1943, in: BArch R 89/15158.

245 Vgl. das Schreiben der LVA Danzig-Westpreußen an die RfA vom 23. 8.1943, in: RfA-Archiv Nr. 128. Vgl. darin auch eine entsprechende Liste von Betroffenen vom 4.8.1944.

246 Das Schreiben vom 2.12.1943, in: BArch R 89/3208.

247 Das Schreiben vom 21.6.1943, in: ebd. 


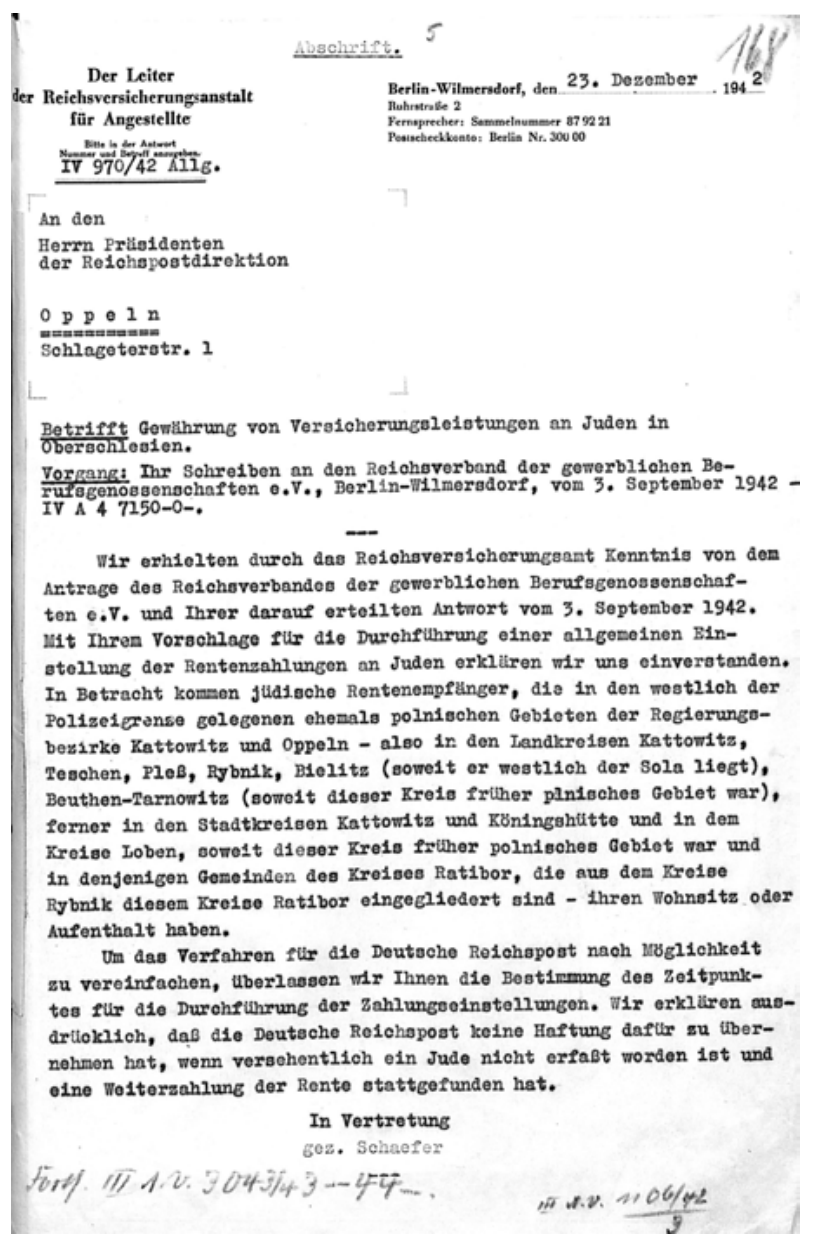

Abb. 60: Schreiben Grießmeyers vom 23. Dezember 1942 betr. Gewährung von Versicherungsleistungen an Juden in Oberschlesien

Leistungen zuzuerkennen, wenn sie in die deutsche Volksliste aufgenommen wären. Das Reichsarbeitsministerium hatte sich dann aber auf Intervention des Gauleiters davon überzeugen lassen, dass die „besonderen Verhältnisse in meinem Gau eine andere Handhabung der Bestimmungen“ verlangten und deshalb verfügt, dass die Leistungen zwar grundsätzlich vom Tag der Eintragung in die Volksliste an zu gewähren seien, „dass aber der späteste Termin für den Leistungsbeginn der in der Verordnung genannte Stichtag wäre“. ${ }^{248}$ Aufgrund dieser Auslegung zahlten RfA wie LVA die Renten bereits bei Vorliegen einer vorläufigen Bescheinigung über die polnische Volkstumszugehörigkeit. Zum Jahresbeginn 1943 hatte es dann aber beim RVA einen Sinneswandel 
gegeben, aufgrund dessen die Versicherungsträger dazu übergegangen waren, vor der Aufnahme in die Volksliste jede Leistungsgewährung kategorisch abzulehnen, auch wenn die sonstigen versicherungsrechtlichen Voraussetzungen gegeben wären. Das hatte in den eingegliederten Gebieten Oberschlesiens in den Augen des Gauleiters zu „völlig untragbaren Folgen“ geführt, zumal das Aufnahmeverfahren in die Deutsche Volksliste immer noch im Gang war. Durch diese Änderung der Verwaltungspraxis war eine aus der Sicht der NS-Machthaber höchst unerwünschte unterschiedliche Behandlung der Volksdeutschen eingetreten, denn während die einen bereits ihre Leistungen erhielten, blieb sie den anderen versagt. „Vor allem muss ich es ablehnen“, so führte der Gauleiter dazu weiter aus, „dass dadurch Volksdeutsche meines Gaus bis zur endgültigen Eintragung in die Volksliste praktisch wie Polen behandelt werden. Dies führt zu einer völlig unnötigen Erschwerung der Eindeutschungsarbeit.“249 Viele Ehemänner und Söhne dieser davon betroffenen „Volksdeutschen“ dienten zudem bereits in der Wehrmacht, da sich die hier zuständigen Stellen bei der Überprüfung der Volkstumszugehörigkeit nicht so viel Mühe gemacht hatte. Damit drohte der in den Augen des Gauleiters geradezu katastrophale Fall, dass den Hinterbliebenen eines gefallen Volksdeutschen die Rentenleistung durch die Versicherungsträger verweigert würde. Der bürokratische Rigorismus produzierte nicht das erste Mal unbeabsichtigte Folgen, die den Zielen der regionalen NS-Funktionäre ebenso zuwiderliefen wie denen des NS-Regimes insgesamt.

Das Reichsarbeitsministerium reagierte erst über ein Jahr später, im November 1944, auf die sich offenbar häufenden Probleme mit der versicherungsrechtlichen Behandlung von denjenigen Polen, über deren Aufnahme in die Deutsche Volksliste noch nicht entschieden worden war. Es wurde bestimmt, dass die Betroffenen zwar rechtlich Schutzangehörige minderen Rechts seien, aber von den Versicherungsträgern nicht als Schutzangehörige polnischen Volkstums angesehen werden dürften.

Es ist daher nichts dagegen einzuwenden, dass ehemals polnische Staatsangehörige, über deren Antrag auf Aufnahme in die Deutsche Volksliste noch nicht entschieden ist, bis zur endgültigen Entscheidung der Volkslistendienststelle im Rahmen der Reichsversicherung auch dann als Versicherte nichtpolnischen Volkstums behandelt werden, wenn sie keine der vorgeschriebenen Bescheinigungen besitzen. ${ }^{250}$

Erst wenn ein endgültig ablehnender Bescheid der Volkslistendienststelle vorlag, waren die Versicherungsträger dazu verpflichtet, die Leistungsgewährung nach dem für die Versicherten nichtpolnischen Volkstums geltenden Recht einzustellen und das sogenannte Polenstatut anzuwenden. Noch im November 1944 wurde mithin weiter an Details der Umsetzung der Ostgebietsverordnung gefeilt und diese im Sinne der völkisch-rassischen Ziele des NS-Regimes weiter optimiert. ${ }^{251}$ Im Mai 1943 bereits war

249 Ebd., S. 2.

250 Schreiben des RAM an das RVA vom 11.11.1944, in: RfA-Archiv Fach 34, Nr. 4.

251 Vgl. dazu das Schreiben des RAM vom 29.3.1944, in: RfA-Archiv Fach 18, Nr. 3. 
vom RAM ein Gesetzentwurf für die von den Versicherungsträgern schon länger geforderte besondere Behandlung von Polen in der Reichsversicherung vorgelegt worden, der sich stark an den „Polenstatut“ in den Ostgebieten anlehnte und nun auch die Polen im Altreich einer entsprechenden „Sonderregelung“ unterwarf. ${ }^{252}$

Im Juli 1943 legte das RAM die bereits früher erwähnte „Zweite Verordnung über Leistungsverbesserungen in der Rentenversicherung“ vor, die am 12. Oktober 1943 in Kraft trat und mit Stichtag 1. Januar 1944 die Rentenerhöhungen über das Altreich hinaus auch für die Alpen- und Donauregionen, die ehemaligen tschechoslowakischen Gebiete und die eingegliederten Ostgebiete gewährte. ${ }^{253}$ Berechtigte konnten nun einen erhöhten Grundbetrag von 840 RM jährlich sowie vor allem auch ab 1. Oktober 1943 eine weitere Zusatzrente erhalten. ${ }^{254}$ Sie betrug beim Ruhegeld im Durchschnitt 32 RM monatlich, bei der Witwenrente 16 RM und bei den Waisen 12,50 RM. Die genaue Höhe war jedoch nach Höhe der jeweiligen Rente gestaffelt. ${ }^{255}$ Für die RfA war das mit einer erheblichen Mehrbelastung verbunden, da die Erhöhungen nicht pauschal erfolgten, sondern für jede Rente gesondert berechnet werden mussten. Nach überschlägiger Rechnung waren infolge der Verordnung knapp 76.000 übernommene und 28.000 neu festgestellte Renten, insgesamt mithin über 100.000 Renten neu zu berechnen, wovon mit knapp 40.000 Renten (23.398 Ruhegeldern, 14.762 bzw. 1534 Witwen- und Waisenrenten) mehr als ein Drittel auf die Ostgebiete entfiel. ${ }^{256}$ Neben den Leistungen wurden durch die Verordnung ab Januar 1944 aber auch die Versicherungsbeiträge in den Ostgebieten von acht auf zehn Prozent der Entgelte erhöht. ${ }^{257}$ Die neuen Beitragsregelungen machten allerdings auch die Ausgabe neuer Versicherungskarten notwendig, die - versehen mit dem roten Aufdruck „Nur für die eingegliederten Ostgebiete gültig“ - im Lauf des Jahres 1944 durch die RfA ausgegeben wurden. ${ }^{258}$ Die Vereinnahmung der Beiträge und die Abführung an den jeweiligen Versicherungsträger klappte allerdings nur leidlich. Im August 1944 musste sich nach Beschwerden der RfA das RAM einschalten, da bislang nicht genau geregelt

252 Vgl. dazu den Schnellbrief des RAM vom 7.5.1943, in: RfA-Archiv Fach 119, Nr. 1, auch in: BArch R 2/18562.

253 Vgl. dazu den Entwurf vom 7.7.1943, in: RfA-Archiv Nr. 36 und die VO selbst vom 12.10.1943, in: Mitteilungen der RfA Nr. 1, 1944, S. 1-2.

254 Diese hatte anders als die „Zusatzrenten“ vom Dezember 1940 einen eigenständigen Charakter. 255 Vgl. Vermerk der RfA vom Oktober 1943, in: RfA-Archiv Nr. 200. Mitte Juni 1942 hatte das RAM schon einmal einen Entwurf einer Verordnung über Leistungsverbesserungen der Rentenversicherung vorgelegt, der sich nur auf die eingegliederten Gebiete bezog. Darin waren Verbesserungen im Gesamtumfang von rund 105 Mio. RM vorgesehen, ohne dass aber die einzelnen Maßnahmen genauer spezifiziert worden wären. Vgl. Schreiben bzw. Vermerk des Reichsfinanzministeriums vom 16.6.1942, in: BArch R 2-18562.

256 Vgl. das Schreiben der RfA an das RAM vom 20.7.1943 mit Kommentaren zu dem Verordnungsentwurf, in: RfA-Archiv Fach 111, Nr. 10. Zu den Zahlen vgl. die Statistik vom 30.6.1943, in: RfA-Archiv Nr. 200.

257 Vgl. dazu auch Mischkowsky, S. $71 \mathrm{ff}$.

258 Vgl. Schreiben der RfA an den Überwachungsbeamten in Breslau vom 11.5.1944, in: RfA-Archiv Fach 34, Nr. 3. 
war, dass die Landesversicherungsanstalten die an sie abgeführten Beiträge für sämtliche Angestellte in den eingegliederten Ostgebieten auch an die RfA weiterleiteten und vor allem nach welcher Schlüsselung dies erfolgen sollte. Die LVA Wartheland in Posen hatte zwar monatliche Zahlungen nach Berlin geleistet, allerdings nur auf der Grundlage eigener, grober Schätzungen. Die LVA Danzig-Westpreußen hatte sogar bislang überhaupt keine Zahlungen an die RfA vorgenommen. ${ }^{259}$

Eine endgültige Vermögensauseinandersetzung zwischen der RfA mit der Warschauer Sozialversicherungsanstalt, auf die man in der Ruhrstraße angesichts der aufgelaufenen erheblichen Mittel durchaus hoffte, fand im Übrigen letztlich nie statt. Am 8. April 1940 war dies erstmals auch Gegenstand der Beiratssitzung gewesen, aber schon damals hatte Grießmeyer auf die Frage eines Beiratsmitglieds, ob die RfA als Ausgleich für die Zahlungen nach Ostoberschlesien von der ehemaligen polnischen Sozialversicherung ein gewisses Vermögen erwarten könne, lakonisch geantwortet, dass nach den bisherigen Feststellungen mit irgendwelchem Kapital nicht zu rechnen sei. Die RfA habe lediglich einigen Grundbesitz in Kattowitz übernommen. ${ }^{260}$ Ende November 1941 hatte dann die Haupttreuhandstelle Ost die Versicherungsträger darüber informiert, dass von den ursprünglich durch diese zu Auszahlungszwecken an die polnische Postsparkasse gezahlten ca. 600.000 RM nur noch ein Bruchteil vorhanden war, da etwa 500.000 RM im Zuge diverser Aufrechnungen zwischen den Forderungen und Schulden der Deutschen Reichsbank und der ehemaligen Bank Polski zweckentfremdet worden und damit verloren waren. ${ }^{261} \mathrm{Im}$ August war es dann offensichtlich zumindest zu einer Teilübernahme gekommen, denn das bisher nur treuhänderisch verwaltete Vermögen der früheren polnischen Angestelltenversicherung in Ost-Oberschlesien war nunmehr, wie die RfA in ihrem Geschäftsbericht für 1943 darstellt, nach einem Erlass des RAM auf die RfA übergegangen. ${ }^{262}$ Eine genaue Summe wurde aber nicht genannt. Mitte April 1944 informierte das Reichsarbeitsministerium die Versicherungsträger schließlich über ein Abkommen zwischen der Haupttreuhandstelle Ost und der Regierung des Generalgouvernements, dessen Gegenstand die Vermögensauseinandersetzung zwischen dem Reich bzw. der Reichsversicherung und dem Generalgouvernement, sprich der Hauptanstalt für Sozialversicherung in Warschau war. Das RAM selbst war weder an den Vorverhandlungen noch am Abschluss beteiligt. ${ }^{263}$ Demnach sollte die Warschauer Anstalt 650 Mio. Zloty, umgerechnet also ca. 325 Mio. RM, an die Reichsversicherung und ihre Träger bezahlen; doch wann und wieviel davon auf die RfA entfallen würde, war nach wie vor ungeklärt. Irgendwelche Transaktionen kamen aufgrund der Kriegsentwicklung dann auch nicht mehr zustande.

259 Vgl. Schreiben der RfA an das RAM über das RVA vom 9.8.1944, in: ebd.

260 Vgl. Niederschrift der elften Beiratssitzung vom 8.4.1940, S. 17, in: BArch R 89/3470.

261 Vgl. das Schreiben der Haupttreuhandstelle Ost vom 28.11.1941, in: RfA-Archiv Nr. 163.

262 Vgl. Geschäftsbericht 1943, S. 4, in: BArch R 89/3513.

263 Vgl. dazu den Vermerk des RAM vom 17.4.1944, in: BArch R 89/3208. 
Es war letztendlich eine ganze Fülle von Erlassen und Verordnungen, mit denen das RAM erst nach und nach die in den einzelnen besetzten Ostgebieten gültigen polnischen Rechtsvorschriften in der Sozialversicherung ,ausmerzte“ bzw. in deutsches Versicherungsrecht überleitete. Ob die annektierten Gebiete dabei tatsächlich ein sozialversicherungspolitisches Experimentierfeld für eine Besatzungspolitik waren, deren Maßnahmen nach dem erwarteten „Endsieg“ mehr oder weniger auch in den anderen Gebieten praktiziert worden wären, sei dahingestellt. ${ }^{264} \mathrm{Im}$ Generalgouvernement waren sicherlich die rassisch-völkisch begründeten diskriminierenden und exkludierenden Maßnahmen in der Rentenversicherung am ausgeprägtesten realisiert worden. Unbestritten ist, dass die Rentenversicherungsmaßnahmen und das Agieren der RfA als Exekutions- und Umsetzungsbehörde für die Eindeutschungs- und Germanisierungsmaßnahmen des NS-Regimes instrumentalisiert wurden. Allerdings zeigt die Beschwerde des Gauleiters von Oberschlesien, dass es vielfach nicht intendierte Effekte gab, sprich ein eher amivalenter Erfolg der Rentenpolitik in den besetzten Ostgebieten zu verzeichnen war, sowohl was die Privilegierungen der „Volksdeutschen“ wie auch was die versicherungsrechtliche Schlechterstellung der rassisch und völkisch „Minderwertigen“ anging. Die Entscheidungs- und Verwaltungsprozesse bei der Einführung der Angestelltenversicherung in den ehemaligen Gebieten Polens sind hier deshalb ausführlich rekonstruiert worden, da sich damit erst das ganze Ausmaß und die Art und Weise erkennen lassen, dass und wie eigentlich vom NS-Regime einfach gedachte rassisch-völkisch begründete Exklusion und Diskriminierung sowie die Produktion von Unrecht mit erheblichem bürokratischem Aufwand verbunden waren; vor allem dann, wenn wie im Fall der Angestelltenversicherung versucht wurde, dies alles in scheinbar formrechtlich korrekte Verordnungen und Gesetze zu gießen. Und nicht selten verstrickte man sich dabei wie gesehen auch in die eigenen Widersprüche und stieß an die Grenzen behördlicher Arbeitsprozesse und Verwaltungspraktiken. Die RfA steht dafür geradezu exemplarisch.

\subsection{Statistischer Rückblick: Rentenbewegungen, Versicherungs- und Beitragsleistungen in der Angestelltenversicherung 1939 bis $1944 / 45$}

Die Zahl der Versicherten in der Angestelltenversicherung war auch im Krieg weiter gestiegen, von 5,8 Mio. (1939) auf ca. sieben Mio. (1944/45), d. h. um etwa 20 Prozent. Dazu trugen die demographische Entwicklung, das anhaltende quantitative Wachstum der Angestelltenberufe und schließlich die geographische Integration der besetzten und eingegliederten Gebiete bei.

264 Vgl. dazu Hans Umbreit, Die deutsche Herrschaft in den besetzten Gebieten 1942-1945, S. 111, in: Das Deutsche Reich und er Zweite Weltkrieg, hrgg. vom Militärgeschichtlichen Forschungsamt, Bd. 5/2, Stuttgart 1999 und auch mit ähnlicher These für das Generalgouvernement Kirchberger, S. $127 \mathrm{ff}$. 
Tab. 23: Zahl der RfA-Versicherten 1939 bis 1944

\begin{tabular}{ll}
\hline Jahr & Zahl der Versicherten insg. \\
\hline 1939 & 5,8 Mio. \\
\hline 1940 & 6,3 Mio. \\
\hline 1941 & 6,7 Mio. \\
\hline 1942 & 7,0 Mio. \\
\hline 1943 & 7,0 Mio. \\
\hline 1944 & 7,0 Mio. \\
\hline
\end{tabular}

Zusammengestellt nach den Angaben in: RfA-Berichte zur Entwicklung der AV im Jahr $1939 \mathrm{ff}$. Vgl. auch Scharf, Die Entwicklung der Angestelltenversicherung in Zahlen, in: Die Angestelltenversicherung 3 (1956), S. 269-276.

Seit 1942 war allerdings erstmals nach den langen Jahren der Zunahme eine Stagnation der Versichertenzahlen zu verzeichnen. Die Zahlen lassen allerdings kaum ahnen, welche Dynamik sich innerhalb des Versichertenbestandes und einzelner Versichertengruppierungen verbirgt, sei es bei der statistisch leider nicht erfassten Zubzw. Abnahme von weiblichen und männlichen Versicherten oder infolge des Hinzukommens der Handwerker. Im Grundsatz blieb die Angestelltenversicherung auch im Krieg klassisch beitragsfinanziert. Die Beitragsleistungen kletterten von 1939 bis 1943 von 0,8 auf 1,3 Mrd. RM (d. h. um über 50 Prozent). 1941 wurde erstmals die Marke von einer Mrd. RM an Beitragseinnahmen übersprungen, obwohl die zur Wehrmacht eingezogenen Angestellten beitragsfrei waren und damit als Zahler ausfielen. Ausgeglichen wurde dies unter anderem durch die besonders dynamisch ausfallende Beitragseinnahmenentwicklung in der „Ostmark“, dem Sudetenland sowie den übrigen eingegliederten Gebieten nach der vollen Integration in die deutsche Kriegswirtschaft. Auch die Beitragseinnahmen durch die versicherungspflichtigen Handwerker schlugen erst im Laufe des Krieges durch. Erst 1944 setzte ein leichter Rückgang der Beitragseinnahmen ein. Die Bedeutung der Zinseinnahmen schrumpfe dabei angesichts der staatlich verordneten Zinssenkungen deutlich von 17,2 Prozent (1939) auf zwölf Prozent (1943) der Gesamteinnahmen, stieg dann aber 1944/45 wieder an. Die schrumpfenden Zinseinnahmen waren laufend Thema in den Beiratssitzungen der RfA, denn das starke Anwachsen der Zahl der Reichsanleihen, die die RfA kaufen musste, drückte auf die einst relativ hohe Durchschnittsverzinsung des RfA-Kapitals. Auf dem Papier war der RfA zwar gestattet, im Neugeschäft für Darlehen 4,5 Prozent Zinsen zu verlangen, ,aber leider hat dies keine praktische Bedeutung, da wir unsere verfügbaren Mittel in 3,5 prozentigen Reichswerten anlegen müssen“, wie Grießmeyer 
auf der Beiratssitzung im April 1943 beklagte. ${ }^{265}$ Dennoch war die RfA auf dem verbliebenen Kapitalmarkt bis dahin ein einflussreicher Mitspieler mit Handlungsspielräumen gewesen, dessen seinerseits im Januar 1941 vorgenommene Zinssenkung für Darlehen von 4,5 auf 4 Prozent erhebliche Proteste bei den konkurrierenden Banken ausgelöst hatte. Aus dem Reichswirtschaftsministerium, so sei damals Grießmeyer bedeutet worden, werde er in Bälde einen „nicht ganz freundlichen Brief wegen [dieser] Zinssenkung bekommen; dort häuften sich Klagen von Instituten des Realkredits, die sich durch das Vorgehen der Sozialbversicherungsträger gestört fühlen“, ${ }^{266}$ so Grießmeyer auf einer Beiratssitzung.

Von wachsendem Einfluss auf die Gesamteinnahmen waren aber vor allem die Erstattungen und Reichszuschüsse, die zwischen 100 und über 200 Mio. RM jährlich schwankten. Ein Teil speiste sich dabei aus den jährlichen Überweisungen der Arbeitslosenversicherung, die 1939 noch knapp 170 Mio. RM betrugen, bis 1943 dann aber auf 262,5 Mio. RM anstiegen. ${ }^{267}$ Dazu kamen seit 1941 die Reichszuschüsse infolge der Leistungsverbesserungsgesetze, die 1941 zunächst nur knapp 27 Mio. RM betrugen, 1943 dann aber auf 422,2 Mio. RM hochschnellten. Ergänzend erfolgten 1943 noch 545,5 Mio. RM an Erstattungen von den Invalidenversicherungsträgern und dem Reich als anteilige Kosten für Wanderversicherte. ${ }^{268}$ So erklärt sich auch der hohe Gesamterstattungsbetrag im Jahr 1943 von über 970 Mio. RM. Allerdings zahlte das Reich nicht in bar, sondern in Schuldverschreibungen, was den Bestand der RfA an Reichsanleihen weiter aufblähte.

Tab. 24: Gesamteinnahmen der RfA 1939 bis 1944/45 (in Mio. RM) ${ }^{269}$

\begin{tabular}{lllll}
\hline Jahr & Beitragsleistungen & Zinsen & $\begin{array}{l}\text { Erstattungen / } \\
\text { Reichszuschüsse }\end{array}$ & Insgesamt \\
\hline 1939 & 854,4 & 200,1 & 102,9 & 1157,4 \\
\hline
\end{tabular}

265 Niederschrift der Beiratssitzung vom 12.4.1943, S. 3, in: BArch R 89/3471. Weitere Zinsdebatten auch auf der Beiratssitzung am 8.4.1940, S. 11, in: BArch R 89/3470.

266 Grießmeyer auf der Beiratssitzung vom 21.4.1941, S. 4, in: BArch R 89/3470.

267 Vgl. die Angaben bei Mörschel, S. 644. Zu den komplizierten Finanzausgleichregelungen zwischen den Versicherungsträgern vor allem bei den Wanderversicherten vgl. auch den Bericht der RfA über die Forderungen und Verpflichtungen der RfA gegenüber den übrigen Versicherungsträgern vom 23.4.1941, in: RfA-Archiv Nr. 26. Vgl. auch den Vermerk über eine Besprechung im RVA über die Pauschalisierung der Erstattungsansprüche aus Renten von Wanderversicherten vom 17.3.1943, in: RfAArchiv Nr. 38. Vgl. dazu auch weitere Vermerke und Schriftwechsel, in: RfA-Archiv Nr. 200.

268 Vgl. dazu den Rechnungsabschluss der RfA für 1943, in: RfA-Archiv Nr. 79.

269 Vgl. dazu RfA-Archiv Nr. 10. Der nachträgliche Rechnungsabschluss für die Zeit vom 1.1.1944 bis 8.5.1945 kommt auf 1,47 Mio. RM, d.h. im Monatsdurchschnitt auf 91,8 Mio. RM oder allein auf 1944 berechnet 1,1 Mrd. RM, also etwas niedriger als veranschlagt. Auch die ursprünglich geplanten Zinseinnahmen waren deutlich höher als die realen 345,975 Mio. RM. Zusammengestellt nach den Angaben in: wie oben sowie Rechnungsabschluss der RfA für das Geschäftsjahr 1939ff., in: BArch R 89/3470 und Rechnungsabschluss der RfA für das Geschäftsjahr 1943, in: RfA-Archiv Nr. 79, vgl. auch Rechnungs- 
Tab. 24: Gesamteinnahmen der RfA 1939 bis 1944/45 (in Mio. RM) (Fortsetzung)

\begin{tabular}{lllll}
\hline Jahr & Beitragsleistungen & Zinsen & $\begin{array}{l}\text { Erstattungen / } \\
\text { Reichszuschüsse }\end{array}$ & Insgesamt \\
\hline 1940 & 966,0 & 232,1 & 170,6 & 1368,7 \\
\hline 1941 & 1094,2 & 266,3 & 233,8 & 1594,3 \\
\hline 1942 & 1178,6 & 295,0 & 175,8 & 1649,5 \\
\hline 1943 & 1319,3 & 317,4 & 970,2 & 2606,9 \\
\hline $1944^{\star}$ & 1102,5 & 273,8 & 195,6 & 1572,0 \\
\hline
\end{tabular}

* Voranschlag der RfA für das Geschäftsjahr 1944 als geplante Einnahmen 1.306,452.

Auch die Zusatzrenten in den eingegliederten Gebieten wurden aus Mitteln des Reichs finanziert; sie schlugen dann vor allem $1944 \mathrm{zu}$ Buche. ${ }^{270}$ Allerdings lehnte es das Reichsfinanzministerium offenbar im Dezember $1944 \mathrm{ab}$, den hier inzwischen aufgelaufenen Erstattungsforderungen der RfA über 60,7 Mio. RM nachzukommen, sondern forderte die Aufstellung eines Tilgungsplanes, der sich bis zum Jahr 1954 erstrecken sollte. ${ }^{271}$ Monatlich erhielt die RfA daher erst einmal vom Reich nur ca. 500.000 RM erstattet und musste für den hohen Restbetrag aus eigenen Mitteln in Vorleistung gehen, die dann bei Kriegsende auch gänzlich verloren waren.

Auch die Gesamtausgaben der RfA stiegen im Krieg deutlich, aber weit weniger stark als die Einnahmen. Hinter der Zunahme von 404 Mio. RM auf 675 Mio. RM zwischen 1939 und 1944 verbarg sich eine deutliche kriesgbedingte Umschichtung der einzelnen Rentenarten - insbesondere der Berufsunfähigkeits- und Hinterbliebenenrenten gegenüber den Altersrenten -, auf die bereits oben hingewiesen wurde und die sich zahlenmäßig jedoch nur schwer erfassen lassen. Der anteilsmäßige Vergleich im Jahr 1942 mit dem Vorjahr wirft ein kurzes Schlaglicht auf die Dynamiken dieser Entwicklung. Die Zunahme gewährter und ausgezahlter Altersruhegelder betrug demnach 22 Prozent, die der Invalidenrenten 32 Prozent, diejenige der Berufsunfähigkeitsrenten infolge von Kriegsverletzungen jedoch 1000 Prozent; die normalen Witwen- und Waisenrenten stiegen um 64 Prozent, die kriegsbedingten Hinterbliebenenrenten nahmen dagegen um 350 Prozent zu. ${ }^{272}$ Der Krieg selbst schlug mithin in den Rentenausgaben, insbesondere für Invaliden- und Hinterbliebenenrenten, erst

abschluss der RfA für die Zeit vom 1.1.1944 bis 8.5.1945 sowie auch die Angaben bei Mörschel, S. 640 . $\mathrm{Zu}$ den statistischen Erhebungen der monatlichen Markenverkäufe vgl. RfA-Archiv Fach 13, Nr. 1.

270 Vgl. auch Schreiben der RfA an das RVA zum Erstattungsprocedere vom 7.9.1944, in: RfA-Archiv Nr. 118.

271 Der Plan, in: ebd.

272 Vgl. dazu die Zahlen im Jahresbericht der RfA für 1942, in: BArch R 89/3471. 
mit deutlicher Verzögerung in den Zahlen durch. Dies hatte selbst bei der RfA-Leitung angesichts offenbar anderslautender Erwartungen für Verwunderung (und Erleichterung) gesorgt. ${ }^{273}$ Seit 1942 jedoch erfolgten markante Mehrausgaben infolge des Hochschnellens kriegsbedingter Leistungsfälle, die bis Kriegsende anhielten. Zwischen 1933 und 1941 waren die Rentenbewilligungen der RfA wegen Berufsunfähigkeit laufend gesunken, seit 1942 setzte hier jedoch ein deutlicher Umschwung ein. Monat für Monat gingen nun in der Ruhrstraße über 1500 Anträge auf Berufsunfähigkeitsrenten ein. ${ }^{274}$ Die positiv beschiedenen Anträge auf Ruhegeld wegen Berufsunfähigkeit infolge von Kriegsverletzungen, die bei der RfA in der sogenannten Kriegsliste statistisch erfasst wurden, stiegen von zunächst 40 (1940) auf 12.478 (1943) und erfuhren vermutlich in der Folgezeit eine weitere rasante Erhöhung, die aber statistisch nicht mehr überliefert ist. ${ }^{275}$ Die Anpassung des Versicherungsrechts an die Kriegsverhältnisse, die sich ja nicht nur in Rentenerhöhungen (bzw. Rücknahme der früheren Kürzungen) niederschlug - sondern auch in der Verlängerung der Verjährungsund Ausschlussfristen, den Erleichterungen hinsichtlich der Erhaltung der Anwartschaft und der Erfüllung der Wartezeit, in der Krankenversicherung der Rentner und schließlich in den vielfach ungedeckten Rentenleistungen an die tausenden neu hinzukommenden Rentner in den eingegliederten und besetzten Gebieten -, brachte für die RfA zwar erhebliche Mehr- und Zusatzkosten, ohne allerdings zumindest kurzfristig die Bilanz zu belasten.

Tab. 25: Ausgaben der RfA für gesetzliche Pflichtleistungen (Renten und einmalige Zahlungen) und Heilverfahren 1939 bis 1944 (in Mio. RM) ${ }^{276}$

\begin{tabular}{lllll}
\hline Jahr & Renten & Einmalige Zahlungen & Heilfürsorge & Insgesamt \\
\hline 1939 & 404,2 & 32,5 & 33,6 & 470,3 \\
\hline 1940 & 431,2 & 30,2 & 31,5 & 492,9 \\
\hline 1941 & 483,9 & 28,7 & 35,9 & 548,5 \\
\hline 1942 & 548,8 & 24,7 & 39,7 & 613,2 \\
\hline 1943 & 665,3 & 21,5 & 42,8 & 729,6 \\
\hline
\end{tabular}

273 Vgl. Niederschrift der Beiratssitzung vom 8.4.1940, S. 4, in: BArch R 89/3470.

274 Vgl. dazu auch den Bericht auf der Beiratssitzung vom 12.4.1943, S. 13, in: BArch R 89/3471.

275 Vgl. die Angaben in: RfA-Archiv Nr. 80.

276 Betr. 1944: Laut Gewinn- und Verlustrechnung sowie Rechnungsabschluss der RfA für die Zeit vom 1.1.1944 bis 8.5.1945 erfolgten 900,6 Mio. RM an Rentenzahlungen, d.h. im Monatsdurchschnitt 56,3 Mio. RM. Im Voranschlag für 1944 waren jedoch nur 638 Mio. RM als Rentenausgaben geplant. Nimmt man den Monatsdurchschnitt von 56,289 Mio. RM an gezahlten Renten, so ergeben sich real 1944 mit 675,5 Mio. RM auf jeden Fall deutlich höhere Leistungsausgaben als geplant und veranschlagt. Vgl. dazu RfA-Archiv Nr. 10. 
Tab. 25: Ausgaben der RfA für gesetzliche Pflichtleistungen (Renten und einmalige Zahlungen) und Heilverfahren 1939 bis 1944 (in Mio. RM) (Fortsetzung)

\begin{tabular}{lllll}
\hline Jahr & Renten & Einmalige Zahlungen & Heilfürsorge & Insgesamt \\
\hline $1944^{*}$ & 675,5 & 20,5 & 57,0 & 753,0 \\
\hline
\end{tabular}

* Berechnet nach der nachträglich erstellten Gewinn- und Verlustrechnung sowie aufgrund des Rechnungsabschlusses der RfA für die Zeit vom 1.1.1944 bis 8. Mai 1945. Zusammengestellt nach den Angaben in: Siehe oben.

Auch die Aufwendungen für Heilfürsorgemaßnahmen stiegen kriegsbedingt deutlich an und verdoppelten sich nahezu zwischen 1939 und 1944/45 von 33,6 auf 57 Mio. RM. Bis 1940 war die RfA per Gesetz nur dazu ermächtigt, Mittel für Heilverfahrenbereitzustellen, wenn es galt, dadurch eine drohende Berufsunfähigkeit des Versicherten abzuwenden, hinauszuschieben oder eine bereits eingetretene wieder zu beheben. Durch Verfügung vom 13. September 1941 wurden aber dann alle Versicherungsträger auch ermächtigt, Erholungskuren an Versicherte zu vergeben, die infolge der Anstrengungen der Kriegsarbeit erholungsbedürftig geworden waren. Das bisherigen Kriterium der Berufsunfähigkeit wurde damit stillschweigend um den Begriff der „Arbeitseinsatzfähigkeit“ erweitert. ${ }^{277}$ Bei der RfA firmierten die in diesem Zusammenhang erfolgten Maßnahmen unter dem Begriff „Sozialerholungswerk“. Doch ungeachtet der Tatsache, dass damit den Versicherungsträgern ein weiterer Gestaltungs- und Handlungsspielraum in der Gesundheitsfürsorge eingeräumt worden war, gab es Probleme bei der praktischen Durchführung der neuen kurzfristigen Kuren. Die RfA sah sich nun einem zusätzlich verschärften Wettbewerb mit den verschiedenen anderen Gesundheitsorganisationen wie Krankenkassen, Fürsorgeverbände, NSV und DAF um die knappen Plätze in geeigneten Erholungsstätten ausgesetzt. ${ }^{278}$ Bis Frühjahr 1942 war es gelungen, gerade einmal 120 Betten für selbst durchgeführte Erholungskuren zu ergattern, die übrigen gewährten Kuren mussten mit Hilfe der Landesversicherungsanstalten durchgeführt werden. Diese Maßnahmen waren nur ein Teil weiterer Bemühungen des NS-Regimes, die Träger der Rentenversicherung für Zwecke der vorbeugenden Gesundheitsfürsorge und zur „Gesunderhaltung des Volkes“ in die Pflicht zu nehmen, vor allem bei der Finanzierung des Kampfes gegen die „Volkskrankheit“ Tbc, den Krebs, die Geschlechtskrankheiten, das Rheuma sowie die Gefahren von Tabak und Alkohol. ${ }^{279}$ Die Tbc-Verordnung vom 8. September 1942, durch die die Landesfürsorgeverbände zur Durchführung der Tbc-Bekämpfung verpflichtet

277 Vgl. dazu die Niederschrift der Beiratssitzung vom 8.12.1941, S. 3, in: BArch R 89/3471.

278 Vgl. dazu die Klagen, in: ebd., S. 15-18. Vgl. dazu auch die eindrucksvolle Schilderung dieses „Bettenkampfes“ und die verlorenen und im Gegenzug nur wenigen dazugewonnenen Betten durch Vizepräsident Schaefer auf der Beiratssitzung vom 20.4.1942, S. 17-20, in: BArch R 89/3471.

279 Vgl. dazu auch ebd., S. 4. 
worden waren, machte es dann aber notwendig, umfangreiche Richtlinien zur gegenseitigen Abgrenzung des Umfangs der den Rentenversicherten und ihren Angehörigen zu gewährende Leistungen zu schaffen, die dann künftig unter dem Schlagwort „Tuberkuloseversorgungswerk“ der Rentenversicherungsträger liefen. ${ }^{280} 1941$ stellte die RfA dafür 267.000 RM, 1942 dann 360.000 RM zur Verfügung. ${ }^{281}$ Knapp eine Mio. RM wurden 1942 zudem für die Rachitis- und Vitamin-C-Prophylaxe von Säuglingen und Kleinkindern ausgegeben. ${ }^{282}$

Diese Ausweitung der Funktionen und Aufgaben der Rentenversicherungsträger auf die Gesundheitsfürsorge, die sie damit in eine wachsende Konkurrenz zu den Krankenkassen brachte, fand offenbar bei der RfA-Leitung durchaus positive Resonanz, denn Vizepräsident Schaefer begrüßte schon auf der Beiratssitzung im Dezember 1941 die neuen Richtlinien zur Tbc-Bekämpfung als Maßnahme, durch die den Versicherungsträgern möglichst umfassend die Aufgabe der Tbc-Bekämpfung übertragen werden würde. ${ }^{283}$ RfA-Präsident Grießmeyer war zusammen mit dem Präsidenten der LVA Sachsen, Möbius, dann auch Mitglied des neu gegründeten Reichstuberkuloseausschusses geworden, was Grießmeyer diverse zusätzliche Dienstreisen nach Italien, in die Schweiz und in die Slowakei einbrachte. ${ }^{284}$ Tatsächlich wurden die Rentenversicherungsträger mit Wirkung vom 1. April 1943 dazu verpflichtet, für den Kreis ihrer Versicherten und deren Angehörigen eine gleichwertige Tuberkulosehilfe sicherzustellen und zu gewähren, wie dies sonst die Gaufürsorgeverbände zu übernehmen gehabt hätten. Das bedeutete aber auch in vielen Fällen anstelle der bisherigen Bezuschussung die Übernahme der Vollfinanzierung. ${ }^{285}$ Und die neuen Kompetenzen führten zu Konflikten mit den anderen Tuberkulose-Experten außerhalb der Rentenversicherungsträger, die sich - wie Möbius sich im Mai 1943 gegenüber dem RVA beschwerte - in Person des zweiten Präsidenten des Reichstuberkuloseausschusses, Prof. Kayer-Petersen, in diversen Aufsätzen „wegwerfend über [deren] Leistungen im Tuberkulose-Abwehrkampf“ äußerten. ${ }^{286}$ Auch unter den Versicherten gab es zahlreiche Unzufriedene, die sich gegenüber der RfA entweder über die $\mathrm{Ab}$ lehnung ihres Antrags beschwerten oder die „völlig wertlosen Kuraufenthalte bei mangelhaftem und ungenügendem Essen“ angesichts der herausgeworfenen Millionensummen kritisierten, die besser für Rentenerhöhungen ausgegeben werden sollten. ${ }^{287}$ Über von der RfA praktizierte Sonderreglungen bei Heilverfahrensanträgen von

280 Vgl. dazu das Rundschreiben und die Richtlinien vom 10.6.1943, in: RfA-Archiv Nr. 231 und auch Bonz-MS, S. 256.

281 Vgl. dazu auch das Rundschreiben des RVA an die Rentenversicherungsträger vom 30.11.1940 über die Reichsaufgaben der vorbeugenden Gesundheitsfürsorge 1941 und die dazu von jedem Träger aufzubringenden Mittel, in: BArch R 89/3460.

282 Vgl. Geschäftsbericht der RfA für 1942, S. 5, in: BArch R 89/3471.

283 Vgl. Niederschrift der Beiratssitzung vom 8.12.1941, S. 17, in: BArch R 89/3471.

284 Vgl. Schreiben Grießmeyers an das RVA vom 10.1.1942, in: BArch R 3901/103525, Teil 1, Bd. 3.

285 Vgl. dazu die Niederschrift der Beiratssitzung vom 12.4.1943, S. 23, in: ebd.

286 Vgl. das Schreiben Möbius' an das RVA vom 10.5.1943, in: BArch R 89/2639.

287 Vgl. dazu etwa die Zuschrift vom 1.10.1943, in: RfA-Archiv Nr. 90. 
Juden, wie sie etwa im Oktober 1941 im Ständigen Ausschuss des Reichsverbands Deutscher Versicherungsträger diskutiert und einvernehmlich beschlossen wurden, findet sich in den hierzu allerdings nur rudimentär überlieferten Akten der RfA nichts. ${ }^{288}$

Der Umfang der gestellten Heilverfahrensanträge und auch der Anteil der Genehmigungen hat sich allerdings im Krieg kaum verändert. 1939 waren 183.959 Anträge in der Ruhrstraße eingegangen, dann sank mit Kriegsausbruch die Zahl der Anträge auf Gesundheitsfürsorge zunächst deutlich (um ca. 20 Prozent), ehe 1941 und vor allem 1942 mit 201.680 Anträgen ein Anstieg verzeichnet wurde; aber bereits im Jahr darauf waren es wieder 183.261 Heilverfahrensanträge, von denen konstant etwas über 31 Prozent Jahr für Jahr von der Heilverfahrensabteilung der RfA bewilligt wurden. ${ }^{289}$ Die RfA kämpfte dabei vor allem mit erheblichen kriegsbedingten Reduzierungen ihres verfügbaren Bettenbestandes in den Sanatorien, Bädern und Heilanstalten, da erhebliche Kapazitäten durch die Militärverwaltung beschlagnahmt worden waren. Eine Reihe von Anstalten war geschlossen oder zu Lazaretten umgewandelt worden. ${ }^{290}$ Im Frühjahr 1943 war es der RfA allerdings gelungen, sich in der Schweiz eine größere Anzahl von Plätzen in Schweizer Lungenheilstätten zu sichern, nachdem man dort schon früher in einer Davoser Klinik Belegbetten für Augentuberkulose gehabt hatte. ${ }^{291}$ Die tatsächliche Inanspruchnahme und Belegung mit RfAVersicherten scheiterte dann jedoch zunächst kurzfristig an Devisenproblemen. Erst im Sommer 1943 konnte mit der Belegung begonnen werden. Die RfA brachte insgesamt etwa 300 tuberkulös erkrankte Versicherte in der Schweiz in 15 verschiedenen Kurhäusern unter, wobei sich im Herbst die Beschwerden von dort Untergebrachten unter anderem über fehlende deutsche Zeitungen, schlechtes Essen, ungeheizte Zimmer und die Separierung von den Privatpatienten - offenbar derart häuften und auch Gehör bei Parteistellen fanden, dass Grießmeyer Anlass sah, im November 1943 eine dienstliche Inspektionsreise nach Davos zu beantragen. ${ }^{292}$

288 Vgl. Niederschrift der Sitzung vom 2./3.10.1941, S. 9, in: RfA-Archiv Fach 64, Nr. 3. Juden sollten demnach nur noch Heilverfahren wegen ansteckender Tuberkulose bewilligt werden. Alle übrige Fälle wie etwa die Gewährung von Zahnersatz sollten, selbst auf die Gefahr hin, dass Invalidität einträte, abgelehnt werden. Es fehlen entsprechende Informationen, die Rückschlüsse auf die Bewilligungspraxis der RfA zuließen, was an der bereits erwähnten Aktenüberlieferungslücke der Heilverfahrensabteilung liegt.

289 Bei den Anträgen auf ständige Heilverfahren waren die Bewilligungsquoten aber mit ca. 60 Prozent deutlich höher. Vgl. zu den Zahlen die Angaben in den Geschäftsberichten der RfA für 1939 bis 1944, in: BArch R 89/3471. Vgl. auch Bericht von Vizepräsident Schaefer auf der Beiratssitzung vom 11.12.1939, S. 8 f. und auf der Beiratssitzung vom 2.12.1940, S. 15f., in: BArch R 89/3470. Vgl. auch die Zahlen der Vorlagen an die beratenden Ärzte von 1931 bis 1943, in: RfA-Archiv Nr. 53.

290 Vgl. dazu auch die Niederschrift der Beiratssitzung vom 8.4.1940, S. 18, in: BArch R 89/3470. 291 Vgl. Niederschrift der Beiratssitzung vom 12.4.1943, S. 24, in: BArch R 89/3471.

292 Vgl. das Schreiben Grießmeyers an das RAM vom 9.10.1943 sowie die Schreiben des Berliner NSVHauptamtes an die RfA vom 1. und 2. Oktober 1943, in: BArch R 89/3467. 
Der Schwerpunkt der laufenden Renten lag naturgemäß im Altreich, wo sich der Rentenbestand zwischen 1939 und 1944/45 nahezu verdoppelte, auch aufgrund der Tatsache, dass alle neu festgestellten und erteilten Renten - auch in der „Ostmark“, dem Sudetenland und den übrigen eingegliederten Gebieten - als Reichsrenten liefen und nur noch die, von Jahr zu Jahr aufgrund der demographischen Entwicklung sinkenden, laufenden übernommenen Renten regional aufgeschlüsselt wurden. Ende 1941 gab es insgesamt noch 85.056 Renten aus Gebieten außerhalb des Altreichs, 1943 dagegen waren es nur noch 73.138 Renten nach „altem“ übernommenem Recht.

Tab. 26: Entwicklung der laufenden Renten nach Regionen 1939 bis 1944

\begin{tabular}{lllllll}
\hline Jahr & Altreich & „Ostmark“ & Sudetenland & $\begin{array}{l}\text { Ostoberschlesien/ } \\
\text { Polen }\end{array}$ & Danzig & $\begin{array}{l}\text { Elsass-Lothringen } \\
\text { und Luxemburg }\end{array}$ \\
\hline 1939 & 493.947 & 48.871 & 26.454 & - & - & - \\
\hline 1940 & 530.794 & 47.381 & 26.245 & 8.097 & 2.500 & - \\
\hline 1941 & 573.115 & 46.439 & 26.492 & 8.744 & 2.612 & 7.510 \\
\hline 1942 & 657.350 & 40.750 & 25.125 & 9.115 & 2.478 & 10.475 \\
\hline 1943 & 742.149 & 38.768 & 23.855 & 8.133 & 2.382 & 10.966 \\
\hline 1944 & 834.187 & 36.392 & 22.405 & 8.293 & 2.233 & k.A. \\
\hline
\end{tabular}

Quelle: Zusammengestellt und berechnet nach den Angaben in den Berichten der RfA über die Entwicklung der AV im Geschäftsjahr 1939, S. 3, 1941, S. 3 etc. sowie die monatliche Zusammenstellung der Ruhegeld- und Hinterbliebenenrentenempfänger für Dezember 1944, in: RfA-Archiv Fach 1001, Nr. 6-9 und Material zum Jahresbericht der Leistungsabteilung 1942 bzw. 1943, in: RfA-Archiv Nr. 79 und Nr. 80.

Jahr für Jahr gingen bei der RfA, wie etwa 1943, ca. 125.000 Rentenneuanträge ein, von denen zwar 100.000 (d.h. 80 Prozent) bewilligt wurden, was andererseits aber auch eine Ablehnung von 25.000 Anträgen bedeutet. Nicht nur die Versichertenbiographien hatten sich im Laufe der Zeit und durch den Krieg deutlich auseinanderentwickelt, sondern vor allem auch diejenige von Frauen (Arbeitseinsatz, Witwen, Geschiedene) und Männern (Kriegseinsatz). Eine wachsende Kluft gab es auch zwischen Versicherten und Rentenempfängern. Während Erstere im Zuge der inflationären Entwicklung und den gestiegenen Geld-Einkommen wie erwähnt zunehmend in die höheren Einkommensklassen wechselten und sich auch verstärkt um freiwillige Zusatzversicherungen mit entsprechenden Beitragszahlungen kümmerten, kämpften viele Rentner ungeachtet aller im Krieg erfolgten (bescheidenen) Rentenerhöhungen mit ihren geringen Ruhe- und Hinterbliebenenrenten um die Sicherung des täglichen Lebensunterhalts. Auch wenn viele Rentner durch Wiedereinstieg in das Berufsleben und rüstungswirtschaftliche Arbeitskräftemobilisierung zusätzliche Verdienste und Arbeitseinkommen hatten, so blieb das Rentenniveau im Krieg auch bei den Angestelltenrentnern niedrig. Die Durchschnittsrente in der Angestelltenversicherung be- 
trug zwischen 60 und 70 RM im Monat, bei Wanderversicherten waren es zwischen 70 und 80 RM. Witwen und Waisen mussten mit noch erheblich niedrigeren Renten auskommen. Die Renten erhöhten sich von 1939 bis 1941 gerade einmal um ca. 20 Prozent bei ungleich stärkerem Anstieg der Lebenshaltungskosten. 1942 trat sogar ein Rückgang der Durchschnittsrenten ein. Der Grund dafür war, dass nach § 17 des Leistungsverbesserungsgesetzes zur Erfüllung der Wartezeit schon ein einziger Beitrag zur Angestelltenversicherung genügte. Tatsächlich gab es dadurch zwar mehr Rentenberechtigte, aber mit oft nur geringen Leistungsansprüchen, sprich niedrigen Renten. Bei der Feststellung der Durchschnittsrente in den früheren Jahren waren nur Ruhegelder mit wenigstens 60 Beitragsmonaten zur Angestelltenversicherung berücksichtigt worden.

Tab. 27: Entwicklung der Durchschnittsrente (Vollrenten) 1939 bis 1942 (in RM pro Monat)

\begin{tabular}{llll}
\hline Jahr & Ruhegeld & Witwenrente & Waisenrente \\
\hline 1939 & & & \\
Angestelltenrentner & 62,04 & 30,20 & 22,62 \\
Wanderversicherter & 75,42 & 38,30 & 26,21 \\
\hline 1940 & & & \\
Angestelltenrentner & 63,75 & 29,13 & 20,97 \\
Wanderversicherter & 76,49 & 37,44 & 24,07 \\
\hline 1941 & & & \\
Angestelltenrentner & 74,00 & 30,29 & 21,78 \\
Wanderversicherter & 89,55 & 40,40 & 25,22 \\
\hline 1942 & & & \\
Angestelltenrentner & 66,80 & 29,08 & 21,48 \\
Wanderversicherter & 81,84 & 38,14 & 25,11 \\
\hline
\end{tabular}

Quelle: Vgl. die diversen statistischen Angaben, in: RfA-Archiv Nr. 79.

Die Zahlen verbergen aber auch hier die erheblichen Bewegungen, die sich Jahr für Jahr im Bestand der Rentenempfänger vollzogen - altersbedingte $\mathrm{Zu}$ - und Abgänge, durch Gesetzesänderungen verursachte oder kriegsbedingt ausgelöste Versicherungsfälle. Monat für Monat wurden tausende Rentenkonten gelöscht und neue angelegt. Auch von der tatsächlichen Struktur der Rentnereinkommen jenseits einfacher Durchschnittsberechnungen bekommt man keinen verlässlichen Eindruck. Ein kleines Schlaglicht hierauf erlaubt immerhin eine im März 1940 vorgenommene Sonderauswertung der RfA, in der sie aus einem Sample von knapp 264.000 Ruhegeldempfängern, das waren immerhin 75 Prozent des damaligen Gesamtbestandes, die jeweiligen Renteneinkommensklassen eruierte. Die maximal mögliche monatliche Höchstrente war demnach 131,60 RM Ruhegeld und 65,80 RM Witwenrente, minimal gab es 32,50 RM Ruhegeld, was praktisch kaum über dem Fürsorgesatz lag. 
Tab. 28: Schichtung der laufenden Angestellten-Ruhegelder, Stand 1. März 1940

\begin{tabular}{llll}
\hline Monatliche Ruhegelder & Männer & Frauen & Insgesamt \\
\hline 10 bis 50 RM & $26.652(14,1 \%)$ & $33.021(44,0 \%)$ & $59.673(22,6 \%)$ \\
\hline 51 bis 100 RM & $138.017(73,1 \%)$ & $40.935(54,6 \%)$ & $178.952(67,8 \%)$ \\
\hline 101 bis 150 RM & $23.744(12,5 \%)$ & $1.064(1,4 \%)$ & $24.808(9,4 \%)$ \\
\hline Über 150 RM & $420(0,2 \%)$ & $15(0,02 \%)$ & $435(0,1 \%)$ \\
\hline Insgesamt & $188.833(71,6 \%)$ & $75.035(28,4 \%)$ & $263.868(100 \%)$ \\
\hline
\end{tabular}

Quelle: Zusammengestellt und berechnet nach den Angaben im Vermerk vom 24.4.1940, in: RfAArchiv Nr. 79.

Das Augenfälligste der obigen Tabelle ist zunächst die im Vergleich zu 1937 anhaltende große Diskrepanz der Renteneinkommen zwischen Männern und Frauen. Weibliche Rentenempfänger rangierten nahezu ausschließlich in den niedrigen Ruhegeldbezugsklassen bis 50 RM und wenig darüber, während die Männer überwiegend deutlich höhere Ruhegelder bis 100 RM und mehr bezogen. Vergleicht man die Zahlen mit der Erhebung von 1937, dann hat sich nicht nur der Anteil der Frauen insgesamt an den Ruhegeldempfängern leicht, aber dennoch signifikant zu Lasten der Männer erhöht; die Schichtungsstruktur hat sich jedoch wohl auch aufgrund dieser Verschiebung tendenziell verschlechtert, d.h. der Anteil der Frauen, aber auch der Männer, in den unteren Renteneinkommensklassen bis 50 RM im Monat hat sich erhöht. ${ }^{293}$ Dabei beschwerten sich aber auch nach wie vor Angestelltenrentner mit fast $140 \mathrm{RM}$ im Monat massiv bei der RfA über die unzureichende Altersversorgung und forderten eine „zeitgemässe Erhöhung“ der Ruhegeldbezüge. ${ }^{294}$ Zahlenmäßig absolut gehörten die meisten Rentenempfänger bei den Männern zur Gruppe derjenigen, die zwischen 70 und 79 RM im Monat bezogen, bei den Frauen dagegen bekam die größte Zahl von ihnen gerade einmal zwischen 40 und 49 RM. Die überwiegende Mehrheit der Rentenempfänger lag tatsächlich in der Kategorie der Durchschnittsrenten, allerdings lag mit einem Viertel aller Angestelltenrentner ein nicht unbeträchtlicher Teil auch unterhalb des Durchschnittsniveaus. Leider fehlen Angaben, die Aufschluss darüber geben könnten, ob und wie sich diese Rentnerschichtung in den folgenden Kriegsjahren noch weiter veränderte.

Letztendlich war das Vermögen der RfA im Laufe des Krieges weiter deutlich angewachsen. Bei Kriegsende im Mai 1945 standen 10,2 Mrd. RM in den Büchern, das waren 125 Prozent mehr als 1939, wo ein Vermögen von 4,5 Mrd. RM verbucht worden war.

293 Vgl. dazu die Angaben in Kapitel 4.4.

294 Vgl. etwa das Schreiben vom 6.1.1943, in: RfA-Archiv Fach 111, Nr. 10. 
Tab. 29: Vermögensentwicklung der RfA 1939 bis 1944/45 (in Mrd. RM)

\begin{tabular}{ll}
\hline Jahr & \\
\hline 1939 & 4,527 \\
\hline 1940 & 5,361 \\
\hline 1941 & 6,368 \\
\hline 1942 & 7,366 \\
\hline 1943 & 9,249 \\
\hline $1944 / 45$ & 10,200 \\
\hline
\end{tabular}

Quelle: Zusammengestellt und berechnet nach den Angaben in den Geschäftsberichten $1939 \mathrm{ff}$, , bei Mörschel, S. 640 und Verwaltungsbericht 1945-1952, S. 38. Dort auch der Rechnungsabschluss für die Zeit vom 1.1.1944 bis 8.5.1945.

Rein rechnerisch bestand damit allerdings nach wie vor ein erheblicher Deckungsfehlbetrag, denn den 7,3 Mrd. Vermögen des Jahres 1942 standen, wie Grießmeyer auch auf einer Sitzung des Haushalts- und Rechnungsausschusses betonte, insgesamt Anwartschaften von zehn bis elf Mrd. RM gegenüber. ${ }^{295}$ Dazu kam, dass 1944/45 der Großteil mit 7,1 Mrd., mithin über 70 Prozent, nur aus Wertpapieren, sprich Reichsanleihen bestand, die mit Kriegsende wertlos wurden; jeweils etwas mehr als eine Mrd. setzte sich aus Darlehen bzw. Hypotheken zusammen. Der erzwungene Umschichtungsprozess der Anlagearten, gegen den sich Grießmeyer anfangs zu widersetzen versucht hatte, hatte sich damit rasant fortgesetzt, hatte der Anteil der Reichsanleihen bei Kriegsbeginn doch erst wenig mehr als 30 Prozent betragen, der Anteil des Reinvermögens insgesamt in Form von verbrieften Forderungen gegen das Reich jedoch schon 48,6 Prozent. ${ }^{296} 1940$ betrug dieser Anteil bereits 57 Prozent und dieser Trend setzte sich mit rasantem Tempo fort. Selbst von den lukrativen Reichbahnvorzugsaktien musste man sich im Laufe des Jahres 1940 trennen und den Gegenwert stattdessen in vierprozentige Reichsanleihen anlegen.

Gleichzeitig war die traditionelle Förderung des sozialen Wohnungsbaus aus Mitteln des RfA-Vermögens praktisch zum Stillstand gekommen. „Die Betätigung auf dem Markt für hypothekarische Beleihung von Bauvorhaben, die wir in früherer Zeit mit besonderem Eifer und Erfolg gepflogen haben“, so berichtete Grießmeyer im April 1942 dem Beirat, „,wird aller Voraussicht nach für längere Zeit nur in engstem Rahmen

295 Vgl. Auszug aus der Niederschrift des Haushalts- und Rechnungsausschusses vom 20.4.1942, in: RfA-Archiv Fach 13, Nr. 1.

296 Vgl. dazu den Jahresbericht der RfA für 1939, S. 5, in: BArch R 89/3470 und auch der Bericht Grießmeyers auf der Beiratssitzung vom 20.4.1942, S. 3, in: BArch R 89/3671. 
weitergeführt werden können. “297 Grund dafür waren die massiven Interventionen des NS-Regimes in den sozialen Wohnungsbau, wodurch der Bereich für einen Finanzierungsträger des freien Kapitalmarkts, wie ihn die RfA darstellte, völlig unrentabel geworden war. Obwohl Hauptanteilseigner und Eigentümer der Gagfah hatte die RfA von ihrer Wohnungsbaugesellschaft seit 1939 gleichfalls auf Geheiß des Wohnungsbaukommissars keine Dividende mehr erhalten. ${ }^{298}$ Schon auf der Beiratssitzung im April 1939 hatte Grießmeyer mit deutlich kritischem Unterton vermieden, von einer Kapitalanlagepolitik der RfA zu sprechen, da es an entsprechendem Betätigungsfeld fehle.

Die Ströme des Sparkapitals können sich in Deutschland gegenwärtig nicht ein Bett nach eigenem Gefallen suchen, sie werden nach einheitlichem Plan gelenkt vom Willen der Reichsregierung, vom Willen des Reichsfinanz- und Reichswirtschaftsministers. Es gibt keinen freien Kapitalmarkt $[\mathrm{mehr}] .{ }^{299}$

Sosehr sich Grießmeyer auch gegen die erzwungene Zurverfügungstellung der RfARücklagen für Reichsanleihen und damit für die ungedeckte Rüstungs- und Kriegsfinanzierung wehrte, so blieb ihm nichts anderes übrig, als Jahr für Jahr gegenüber dem Beirat den Vollzug der Maßnahmen mit den entsprechenden Folgen für die Vermögensstruktur der RfA zu vermelden. Dennoch hatte man behördenintern im Januar 1940, wohl auch vor dem Hintergrund der damaligen allgemeinen Annahme eines baldigen erfolgreichen Kriegsendes, eine „Denkschrift über die voraussichtliche Entwicklung der Vermögenslage der Reichsversicherungsanstalt für Angestellte“ erstellt. ${ }^{300}$ In der 21-seitigen Ausarbeitung war bis 1990 ein Szenario der voraussichtlichen Beitragseinnahmen, Leistungszahlungen und anderen Ausgaben erstellt worden, um unter anderem die Frage zu beantworten, wie lange die RfA mit eigenen Mitteln, also ohne Beitragsübertragungen von der Arbeitslosenversicherung und ohne Reichsmittel ihren Verpflichtungen nachkommen könnte. Die Berechnungen ergaben, dass die RfA vor gewaltigen Herausforderungen stand, würden doch die Belastungen durch männliche und weibliche Ruhegeldempfänger mit 1,6 Mio. Rentnern im Jahr 1990 gegenüber ca. 240.000 Rentnern zum Zeitpunkt der Denkschrifterstellung sieben- bis achtmal größer sein. ${ }^{301}$ Allerdings gingen die RfA-Beamten von falschen Prognosen aus: Man rechnete mit deutlich sinkenden Zahlen weiblicher Versicherter und Rentner aufgrund des Ausscheidens durch Heirat, und vor allem spielte der Krieg mit seinen demographischen Folgen überhaupt keine Rolle in den Szenarien. Gemäß der Denkschrift hätten im Jahr 1948, immer ausgehend von stabilen Beitragssätzen, erstmals die Ausgaben die Beitragseinnahmen übertroffen, im Jahr 1956 hätten Bei-

297 Ebd.

298 Vgl. dazu die Niederschrift der Beiratssitzung vom 2.12.1940, S. 11, in: BArch R 89/3470.

299 Niederschrift der Beiratssitzung vom 17.4.1939, S. 5, in: ebd.

300 Die Denkschrift als gedruckte Fassung in der Bibliothek der DRV-Bund, Signatur II A 58824. 301 Vgl. ebd., S. 14. 
träge und Zinseinnahmen nicht mehr ausgereicht, die Ausgaben zu decken, und es hätte mit der Verflüssigung des Vermögens begonnen werden müssen, das im Jahr 1982 vollständig aufgebraucht gewesen wäre, so dass spätestens dann Zuschüsse des Staates notwendig gewesen wären. Das Problem hätte dann aber gelöst werden können, so die Schlussfolgerung der Denkschrift, wenn die gesetzlichen Beiträge um 55 Prozent erhöht worden wären. ${ }^{302}$

Die Zahlen der Vermögensentwicklung zeigen auch, dass sich der Krieg mit seinen wachsenden Finanzierungsanforderungen für die RfA im Zuge ihrer geographischen Ausbreitung praktisch nicht negativ niederschlug, obwohl die RfA bis auf Luxemburg ja in allen Ländern und Gebieten, in die sie ihre Aktivitäten und Zuständigkeiten ausdehnte, eher desolate Vermögensverhältnisse der dortigen früheren Versicherungsträger vorgefunden hatte. Von einer vielleicht auch bei den Beamten in der Vermögensverwaltung der RfA ursprünglich erwarteten Übernahme und Einverleibung größerer Vermögensbestände in den angegliederten, besetzten und eroberten Gebieten konnte keine Rede sein. ${ }^{303}$ Nennenswerten Zuwachs gab es im Zuge der Expansion allein beim Grundbesitz insbesondere aus dem Bestand der ehemals österreichischen, tschechischen und Danziger Angestelltenversicherungsträger, von denen ein Teil als nicht zur Daueranlage geeignete Objekte wieder verkauft wurde. ${ }^{304}$ 1938 stand noch Grundbesitz im Wert von 33,4 Mio. RM in den Büchern, 1941 waren es bereits 53,1 Mio. RM. ${ }^{305}$ Die Bilanz von 1942 verzeichnete weitere nicht spezifizierte Vermögensteile in Höhe von insgesamt 10,2 Mio. RM, die entweder bereits übernommen worden waren oder aber „,noch nicht endgültig vereinnahmt werden konnten“. ${ }^{306}$ Den Löwenanteil machten 3,985 Mio. RM der früheren Angestelltenversicherungsanstalt Wien aus, gefolgt von Vermögensteilen der Allgemeinen Pensionsanstalt Prag in Höhe von 2,6 Mio. RM, weitere 3 Mio. RM standen noch von den Pensionsinstituten in Böhmen und Mähren aus sowie 702.480 RM an Kapital und Zinsen aus dem Ostgebiet Oberschlesiens. Unter dem Strich jedoch kamen immer neue ungedeckte Versicherungs- und Anwartschaftsverhältnisse hinzu, die - denkt man nur an die ca. ein Mrd. RM Belastung aus der Übernahme der „Ostmark“ - mittel- und langfristig die Vermögensbilanz der RfA erheblich belastet hätten. Insofern war man mit dem verlorenen Krieg auch eine unkalkulierbare Belastung losgeworden.

302 Vgl. ebd., S. 21.

303 Vgl. dazu unter anderem den Bericht über den Stand der Vermögensübernahmen in Österreich, den sudetendeutschen Gebieten, in Ostoberschlesien und in Danzig vom 3.5.1940, in: BArch R 89/3457. 304 Vgl. Geschäftsbericht der RfA für 1941, S. 7, in: BArch R 89/3471.

305 Vgl. Bilanz im Geschäftsbericht der RfA für 1938 sowie Bilanz im Geschäftsbericht für 1941, in: BArch R 89/3470 bzw. R89/3471.

306 Vgl. Bilanz 1942, S. 11, in: Geschäftsbericht der RfA 1942, BArch R 89/3471. 